\title{
Dams Safety: Review of Satellite Remote Sensing Applications to Dams and Reservoirs
}

\author{
Nasrat Adamo, Nadhir Al-Ansari ${ }^{2}$, Sabah Hussain Ali $^{3}$, Jan Laue ${ }^{4}$ \\ and Sven Knutsson ${ }^{5}$
}

\begin{abstract}
Remote sensing is the collection and interpretation of information of an object, area or phenomenon by a recording device that is not in physical or intimate contact with the object or phenomenon under study. It generally refers to the use of satellite borne or airborne sensors to capture the spectral and spatial relations of objects and materials on Earth from the space. This is done by sensing and recording reflected or emitted electromagnetic radiation from the objects. A brief history of satellite remote sensing is given in this review but the bulk of it is devoted to the scientific satellites launched into orbit and their sensors tracking, and presenting changes in water resources fields. The used technologies and satellite systems for monitoring movements and changes include American GNSS, GPS, the Russian GLONASS, Europe's European Satellite Navigation System (GALILEO), China's COMPASS/BeiDou, the Indian (IRNSS); Japan's (QZSS) and many others. Details are presented on the present (LANDSAT), the Moderate Resolution Imaging Spectroradiometer (MODIS), as well as Synthetic Aperture Radar (SAR), and RADARSAT, JERS-1, and ERS, which are developed by various countries, especially the USA. These sensors have the refined capability of providing estimates of variables, which depending on the purpose and design of the sensor, can follow critical issues related to water management problems. This review presents examples of actual studies carried out including; building databases of small dams and lakes on regional scale, derivation of volume vs. elevation and surface area vs. elevation of hundreds of reservoirs around the world, various
\end{abstract}

\footnotetext{
${ }^{1}$ Consultant Dam Engineer, Sweden.

2 Lulea University of Technology, Lulea 971 87, Sweden.

3 Ass. Professor, Remote Sensing Center, University of Mosul, Iraq.

${ }^{4}$ Lulea University of Technology, Lulea 971 87, Sweden.

${ }^{5}$ Lulea University of Technology, Lulea 971 87, Sweden.
} 
bathymetric reservoir surveys, siltation of reservoirs and catchment areas erosion problems, monitoring of water quality changes, and above all monitoring dam deformation and stability problems of dams. The presented case studies cover the use of these different sensor together with the imagery used, their sources, methods of interpretation, validation and gives presentation of the end results. This review, which is only a very brief presentation of satellite remote sensing applications concludes that; in spite of the large volume of research done on this subject so far, which this review cites some of them, the expected future developments in satellite remote sensing technology coupled with advances in algorithms and models used in refining satellite imagery and validating the results will bring more accurate results and less laborious treatment work in addition to wider scope of applications.

Keywords: Remote sensing, satellites, sensors, electromagnetic radiation, GNSS, GPS, GLONASS, GALILEO, COMPASS/BeiDou, IRNSS, QZSS LANDSAT, MODIS, SAR, RADARSAT, JERS-1, ERS, bathymetric surveys, siltation of reservoirs, erosion, water quality, dam deformation.

\section{General}

Remote sensing is the collection and interpretation of information of an object or an area without being in physical contact with it. It involves the use of instruments or sensors to "capture" the spectral and spatial relations of targets observable at a distance from the space and analyzing and applying that information. The process involves the elements of energy source, radiation and the atmosphere, interaction with the target, recording energy by the sensors, transmission, reception, and processing, interpretation and analysis, finally the Application. So remote sensing provides a bird's eye view of much larger extent by looking down from above. The total area encompassed is considerably enlarged when looking downward from, say, a tall building or a mountain top. This increases even more from an airliner cruising above 10,000 meters. From a vertical or high oblique perspective, the obtained impression of the surface below is notably different than when observing the surroundings from a point on the surface [1]. In this information era, the trend is of remote sensing is to use new technologies for automation of monitoring important engineering undertakings or natural hazard such as dams, reservoir water level fluctuations and landslides [2]. This is especially important when it comes to accurately monitor absolute (3D) movements of a dam for example. In many cases, dam movement is measured by means of plumb lines, inclinometers or tiltmeters, and manual geodetic surveying techniques. Automation can be done here by using advanced instruments and means, and from that an absolute displacement can be estimated and recorded. There are even now many emerging technologies like robotized total stations, ground based radar, etc. which rely on very expensive and delicate equipment to be installed on site and subject to vandalism. The problem is even worse when it is required to monitoring slopes, abutments and landslides. The inaccessibility of some sites makes the task a huge challenge [3]. 
Satellite technologies, however, can provide tools to accurately monitor movements and changes without the need of expensive equipment on the ground. One example of such technology is the Global Navigation Satellite System (GNSS) which refers to a constellation of satellites providing signals from space that transmit positioning and timing data to GNSS receivers. The receivers then use this data to determine location and more detail information.

At present GNSS include many fully operational global systems; namely the United States' Global Positioning System (GPS) which became fully operational in 1993, and the Russian Federation's Global Navigation Satellite System (GLONASS) which was completed in 1995 and rejuvenated afterwards to be one of the most expensive projects in Russia's Space program budget in 2010 [4].

Other system went into orbit later on namely Europe's European Satellite Navigation System (GALILEO) which went alive in (2016), and China's (COMPASS/BeiDou), the North Star, which its last satellite was launched on June 23rd 2020, marking the completion of the deployment of China's own global navigation system. This satellite, the 55th in the family of BeiDou that means "Big Dipper" in Chinese, was successfully sent into the preset orbit by a Long March-3B carrier rocket, according to the launch center [5]. Then India's Regional Navigation Satellite System (IRNSS); which was completed in 2016 [6], and Japan's QuasiZenith Satellite System (QZSS) which had 18 satellites in operation by 2018 to be increased to 38 by 2024 [7].

Once all these global and regional systems become fully operational, the user will have access to positioning, navigation and timing signals from more than 100 satellites [8].

The second technology other than the GNSS which has been in wide use is the (Interferometric synthetic aperture radar: InSAR). This is a geodetic technique that can identify movements of the Earth's surface. Observations of surface movement made using InSAR can be used to detect, measure, and monitor crustal changes associated with geophysical processes such as tectonic activity, earthquakes, landslides and volcanic eruptions. When combined with ground-based geodetic monitoring, such as Global Navigation Satellite Systems, InSAR can identify surface. The technique can potentially measure millimeter-scale changes in deformation over spans of days to years. in particular monitoring of subsidence and structural stability [9]. Also, it's very important techniques for generating Digital Elevation Model (DEM) by using the Interferometric Phenomenon.

GNSS and InSAR are two different approaches that can provide tools to accurately monitor movements and changes without the need of expensive equipment on the ground, they complement each other to get a robust and complete solution. GNSS can provide fully automated motion monitoring in (3D) and real-time to a millimeter level accuracy for a discrete number of points by means of affordable GNSS receivers on the ground. InSAR on the contrary, provides infrequent, near vertical movements of a large number of points over a wide area also to millimeter-level accuracy without any equipment on the ground. Together, a comprehensive reservoir motion monitoring can be achieved. The radically two different approach 
provide robustness to the system to better comprehend the behavior of the damreservoir system [10].

Remote sensing has become now a major technological and scientific tool used to monitor planetary surfaces and atmospheres. In fact, from a dollar-based measuring stick, the expenditures on observing Earth and other planets has since the earliest days of the space program now exceeded $\$ 150$ billion. Much of this money has been directed towards practical applications, largely focused on environmental and natural resource management.

\section{Historical Development of Remote Sensing}

Remote sensing began in the 1840s as balloonists took pictures of the ground using the newly invented photo-cameras [11]. In the early 20th century remote sensing images were captured using kites and even by pigeons carrying small light weight cameras attached to these birds, and photos were automatically taken for military aerial reconnaissance using a timing mechanism. In 1906 professional photographer George Lawrence used a string of kites to raise a 49 pound camera 1000 feet in the air to capture the devastation of the earthquake in San Francisco. The steel kite line carried an electric current to remotely trigger the shutter. The famous photograph "San Francisco in Ruins" was taken 6 weeks after the earthquake and subsequent fires in San Francisco Figure 1 [12].

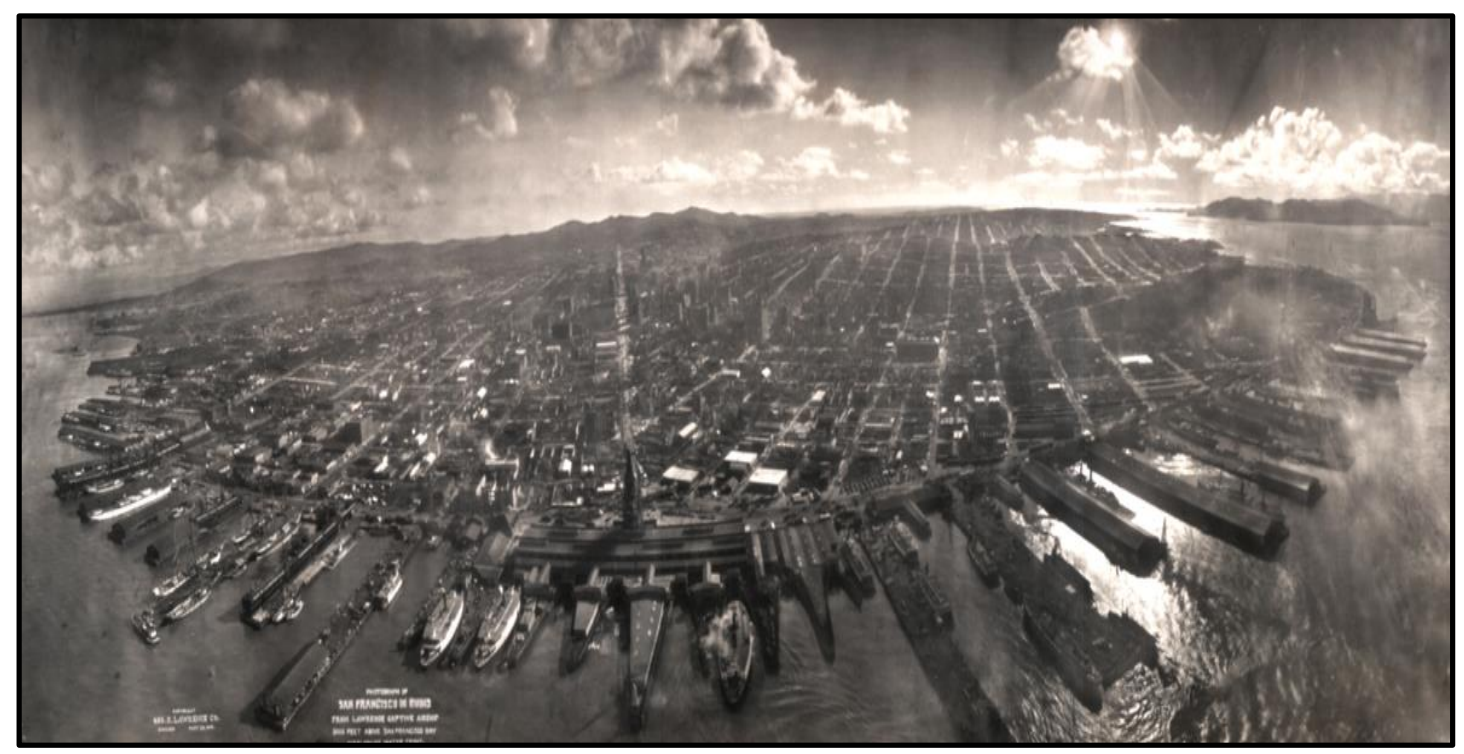

Figure 1: "San Francisco in Ruins" (by George Lawrence, 1906) [12].

Aerial photography became a valuable reconnaissance tool during the first world war and came fully into its own during the second world war [12, 13]. It was used for espionage in the (U2) flights program during the Cold War era, which was started in 1956 and came to an end on 1st May 1960 when a (U2) plane flown by Francis Gary Powers was shot down by (SAM) missile over Russia.

Use of aerial photography to produce maps in much faster and cheaper way 
compared to traditional ground surveys was used in the United States for farm programs beginning in the 1930s with the passing of the Agricultural Adjustment Act. The Agricultural Adjustment Administration (AAA) began its aerial photography program in 1937 and by 1941 the (AAA) has flown and acquired aerial photographs of more than $90 \%$ of the agricultural land in the US.

The development of satellite based remote sensing began with the (Space Race) by launching the first world satellite (Sputnik 1) in 1957 by the Soviet Union, followed by the United States in 1960 with the successful launch of (Explorer1). In 1972 (Landsat 1), the first earth resource satellite was launched by the US. The main goal of the (Landsat) program was to collect data from the Earth through remote sensing techniques. Landsat 1 was originally named (Earth Resources Technology Satellite 1). The Landsat program has continued for 45 years with (Landsat 8) launched in 2013 and with (Landsat 9) expected to be in orbit in mid-2021.

Since the launch of (Sputnik 1) thousands of satellites have been launched. There are great number of commercial and governments satellites in operation today, many of which are used for remote sensing applications. There are currently over 3,600 satellite orbiting the Earth, but only approximately 1,400 are operational. Of these satellites, there is well over 100 which are earth observing satellites that carry variety of different sensors to measure and capture data about the Earth. These satellites are often launched by governments to monitor Earth's resources, but private commercial companies are becoming increasingly active in launching earth observing satellites as well.

Seasat was the first satellite designed for remote sensing of the Earth's oceans with synthetic aperture radar (SAR) which was launched on 27th June 1978 [14].

On the 35th anniversary of (Seasat's) launch, the Alaska Satellite Facility (USA) released newly digitized Seasat synthetic aperture radar (SAR) imagery [15].

Until this release (Seasat SAR) data were archived on magnetic tapes, and images processed from the tapes were available only as optical images of film strips or scanned digital images. Neither the tapes nor the films allow the quantitative analysis possible with the new digital archives. With the great improvements in computer-based processing, especially now, the ability of personal computers to handle large amounts of remote sensing data has made satellite and manned platform observations accessible to universities, resources-responsible agencies, small environmental companies, and even individuals.

Application of remote sensing in the field of water resources has become nowadays one of the principle tools in following and solving problems of water quality, runoff and hydrological modeling, flood management, watershed management, drought management, irrigation command area management, snow cover and glaciers, groundwater studies $[16,17,18]$ in addition to solving problems of transboundary reservoir systems monitoring and dam safety monitoring [19]. The need to develop monitoring systems that can map changing land use, search for and protect natural resources, and track interactions among the biosphere, atmosphere, hydrosphere, and geosphere has become a paramount concern to managers, politicians, and the general citizenry in both developed and developing nations. 


\section{General Principles of Satellite Remote Sensing}

There two types of remote sensing imaging systems:

\section{i. Passive remote sensors}

Which gather radiation that is emitted or reflected by the object or surrounding areas. Reflected sunlight is the most common source of radiation measured by passive sensors and microwaves emissions is another one.

Examples of passive remote sensors include film photography, infrared chargecoupled devices, and radiometers that whereby the radiant energy is converted to bio-geophysical quantities such as temperature, precipitation, soil moisture, chlorophyll etc.

These sensors can be:

First: the passive microwave sensor (TMI) designed to provide quantitative rainfall information over a wide swath under the Tropical Rainfall Measuring Mission (TRMM) satellite by carefully measuring the minute amounts of microwave energy emitted by the Earth and its atmosphere. TMI is able to quantify the water vapor, the cloud water, and the rainfall intensity in the atmosphere. It is a relatively small instrument that consumes little power. This combined with the wide swath and the good quantitative information regarding rainfall make TMI the "workhorse" of the rain-measuring package on Tropical Rainfall Measuring Mission [20], and;

Second: the Moderate Resolution Imaging Spectroradiometer (MODIS) that was launched into orbit by NASA in 1999 on board the Terra satellite, and in 2002 on board the Aqua (EOS PM) satellite. They are designed to provide measurements in large-scale global dynamics including changes in Earth's cloud cover, radiation budget and processes occurring in the oceans, on land, and in the lower atmosphere, and they have been used in monitoring of large dams reservoirs storage.

\section{ii. Active remote sensors}

Active sensors create their own electromagnetic energy that is transmitted from the sensor towards the targets, interacts with the targets producing a backscatter of energy and is recorded by the remote sensor's receivers.

RADAR, LiDAR and LADAR are examples of active remote sensing where the time delay between emission and return is measured, establishing the location, speed and direction of an object [21]. In both LiDAR and LADAR, remote sensing is achieved by illuminating the target with laser light and measuring the reflection. Differences in laser return times and wavelengths can then be used to make digital (3-D) representations of the target [22]. LiDAR stands for Light Detection and Ranging and (LADAR)is abbreviated from; Laser Detection and Ranging. They are both acronyms that represent one type of remote sensing technology that can determine the distance between a sensor and an object. Coupled with the known location of the sensor, the range information can be used to produce a highly detailed 3-dimensional map of the object [23]. The Principles of passive microwave sensor and active remote sensors performances are illustrated in Figure 2. 


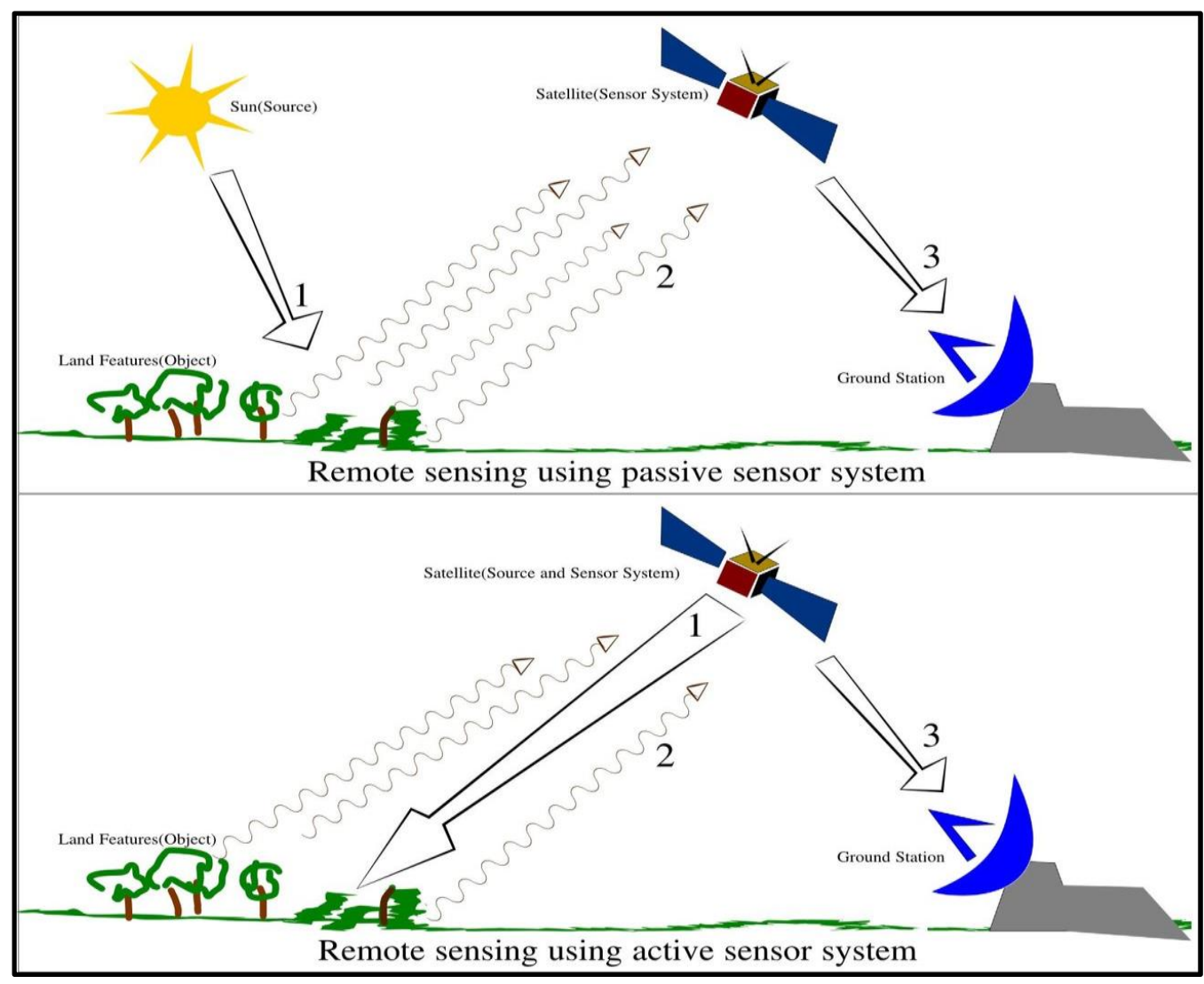

Figure 2: Passive and active sensors systems working principles [24].

In the passive remote sensing systems, the sensor itself is composed of several radiation detectors. Assembling a set of radiation detectors with different wavelength band sensitivity and adding the necessary hardware will result in a multispectral sensor. The recording of image generating data by multispectral sensors is often performed by multispectral scanning. A set of sequential scan lines will eventually build an image, Figure 3 [25].

The smallest element to be detected by a sensor is called the geometric resolution of the system. The detector will measure the average reflection in a selected wavelength band. The result will be recorded as an image element on the scan line called a pixel. the pixel size that is cited, e.g. $80 \mathrm{~m}$ pixel size means that the smallest image element records the average reflection from an area of 80 by $80 \mathrm{~m}$ i.e. 6400 $\mathrm{m}^{2}$. 


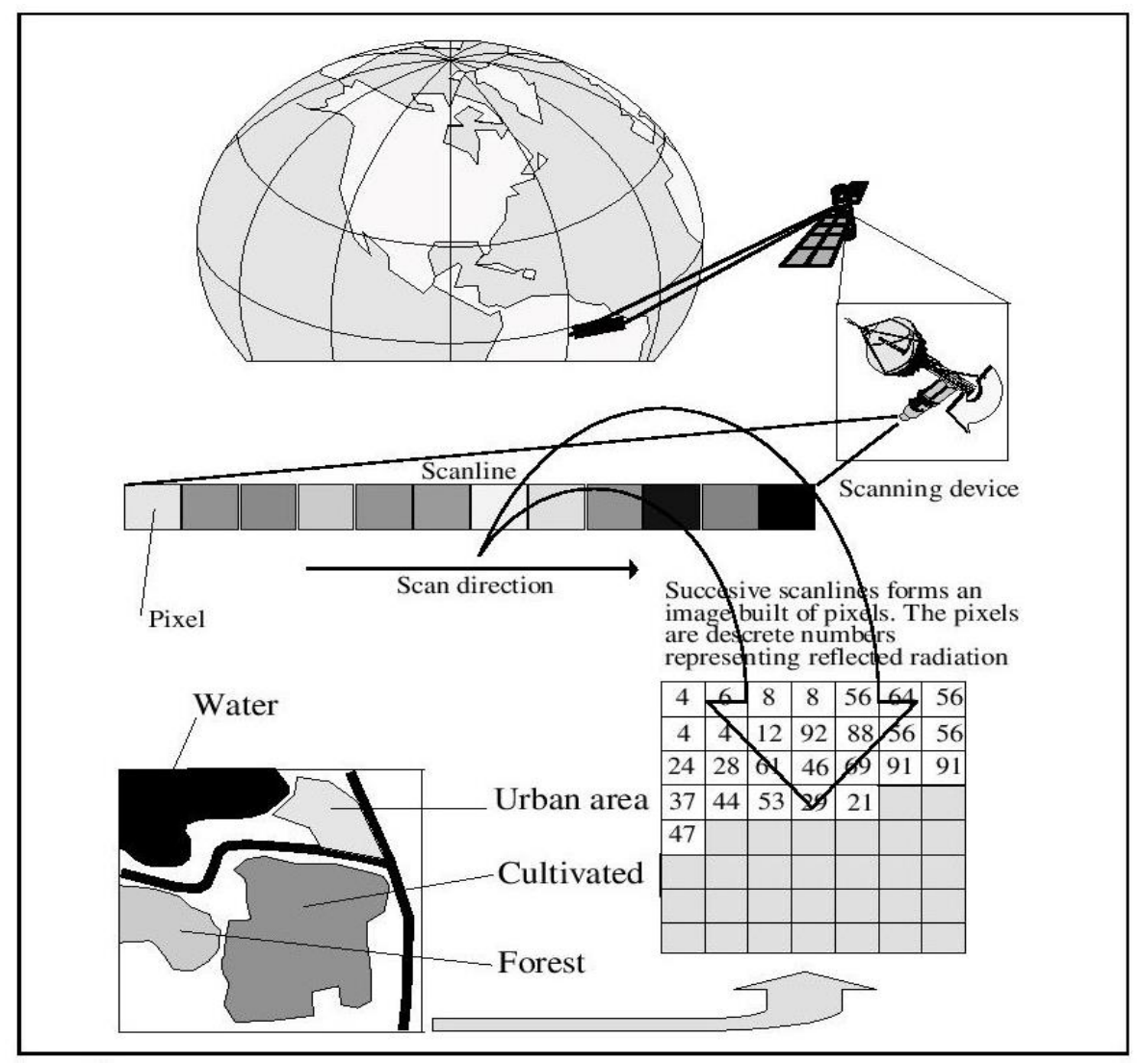

Figure 3: The chain of satellite data acquisition. The scanning device records data, pixel by pixel, along a scan line. Assembling the scan lines gives an image. The radiation is recorded in grey levels, most satellite sensors have an 8-bit resolution that permits 256 levels [25].

In cases of detecting, for example, a dry water course passing through an irrigated agriculture area. The reflectance from the river will differ very much from the surroundings since it lacks vegetation and has a bed of coarse sand and gravels with a high reflectance. The radiation detector will take an average reading from every pixel in the area. Pixels containing only irrigated fields will have a low reflection and appear dark on an image. Although the river is only $20 \mathrm{~m}$ wide it will significantly influence the average reading of the reflectance from all pixels it passes through. This will render these pixels brighter than the surroundings and on an image a series of pixels, following the river bed will get significantly different radiation readings, making the river appearing as a line on the image $[25,26,27]$. To summarize a satellite (sensor) image is built by pixels which are the smallest element in the image. A number of pixels are forming a line (scan line), recorded perpendicular to the flight direction of the sensor platform. When arranged properly using dedicated software the lines form an image. 
The basic information on satellite remote sensing given in the preceding pages are meant to guide the unspecialized reader in following the various applications in: First: fields of civil engineering projects in the stages of:

i. Reconnaissance.

ii. PreliminaryPlanning/Feasibility.

iii. Design.

iv. Construction.

v. Post construction/maintenance.

The potential role of remote sensing at each stage will vary from project to project, but the following sections indicate some of the possible uses of the techniques [28], and;

Second: water resources management where such applications have already been used successfully in observing flooding conditions and recording water level fluctuation in rivers and reservoirs, following reservoirs surface area variations, estimation of reservoirs storage and reservoirs siltation in addition to ascertain current dams and landslides stability conditions.

\section{Dams and Reservoir Site Selection using Satellite Remote Sensing}

Dams and reservoirs site selection may be done in various ways, but most of the traditional methods are costly and time consuming. Advances in remote space technologies, however, can be utilized to make optimum use of time and cost. Satellite Remote Sensing provides imaging technology for updating of available maps and information in real time frame as well as collecting data of land use and Landover. A well-selected site may give the optimum benefits with minimum problems related to its performance and its impacts on the environment. In many recent cases these methods have been supported by use of the Geographical Information System (GIS) which is computer based system that handles the attribute data as well as spatial data since geographical information is an important characteristic. Use of GIS in many such studies is considered as a decision support system regarding optimal site selection. Remote sensing methods may provide basic data required for the GIS to build geodatabase and make decisions by using the appropriate available software.

As a demonstration of using such methods it is worth referring to one case study describing the process of selecting potential dams/reservoirs for the water supply of Karachi in Pakistan which was published in 2010 [29].

The first step was to determine site selection criteria which were to be considered as constraints in this procedure. Identification and justification for each of them was given by: 
i. Sites should not be in the vicinity of densely populated areas due to safety considerations.

ii. Sites must have water accumulating topography to form reservoirs.

iii. General slope of the area shall be gentle and not exceeding $11^{\circ}$ to avoid slope failure for environmental considerations.

iv. Having enough water source (run off and rainfall) for satisfying the projected demand.

The required layers of data necessary for the (GIS) use were obtained by using combination of both traditional methods and by utilizing acquired remote sensing data. In this way it was possible to create and convert one information layer for each of the constraints data sets mentioned above by using (ArcGIS) software [30]. Information layers for constraints (i) to (iii) were produced from two satellite data sources; the first source was (SPOT-5), which is one of the earth observation satellites (Passive System) in the program developed by the French space agency in the 1970s in association with SSTC from Belgium and SNSB from Sweden [31]. The second source was Shuttle Radar Topographic Mission (SRTM) dated 2004. STRM)is a NASA mission initiated in 2000 to obtain elevation data for most parts of the world, and it is the current dataset of choice for digital elevation model (DEM) data since it has a fairly high resolution ( 1 arc-second, or around 30 meters), and it has near-global coverage (from $56^{\circ} \mathrm{S}$ to $60^{\circ} \mathrm{N}$ ), which is available in the public domain [32]. Finally, the rainfall data needed for (iv) and required for the study were obtained from available (1989-2000) local records. Summary of the criteria, the required data, and their sources is shown in Table 1.

Table 1: Site selection criteria, required data and their sources

\begin{tabular}{|c|c|c|}
\hline Criteria & Data & Source \\
\hline i. & Settlements & Satellite images (Spot 5) \\
\hline ii. & $\begin{array}{c}\text { Elevation/ } \\
\text { Topography }\end{array}$ & Satellite images (STRM) \\
\hline iii. & Rainfall & Precipitation records \\
\hline iv. & Drainage network & $\begin{array}{c}\text { Satellite images (STRM)/ } \\
\text { Satellite images (Spot 5) }\end{array}$ \\
\hline
\end{tabular}

Although this methodology makes the decision making process more objective, there is still an element of subjectivity which originates from the planner own experience and judgment. In this case selection of the more promising sites was done by allocation weights to each of the criteria and screening the result in a procedure described in the study. This procedure allows flexibility to be incorporated as varying degrees of importance are assigned to each criterion based 
on the planner's experience. The final decision was left to the relevant department which is the final decision maker. It is recognized that social, political and budgetary constraints could produce an alternative other than the best alternative obtained by the planner.

Our conclusion is that; the planning process of any development project of an engineering nature, such as dams, communication lines and live lines can be a complex process involving many disciples based on requirements dictated by natural elements, social rules and environmental factors. Space remote sensing can help as a tool to provide basic data of natural and environmental factors, which otherwise have to be obtained by costly and time consuming traditional methods. The great number of satellites and the numerous sensors onboard available today present good opportunities in planning, but decision making remains as an unchallenged human activity.

\section{Dams and Reservoirs Management Utilizing Satellite Remote Sensing Applications}

Space remote sensing has found its application in USA for many of the operational issues of dams and their reservoirs since the late 1980s. Initial work was done in 1987 over a small number of targets using data from SEASAT [33]. SEASAT was the first Earth-orbiting satellite that was managed by NASA for remote sensing of the Earth's oceans and had on board the first spaceborne Synthetic-Aperture Radar (SAR). This satellite was launched on 27 June 1978 but it stopped working on the10th of October 1978. Observation was followed after this by the extraction of decimal time series from TOPEX mission [34]. TOPEX/Poseidon was a joint satellite mission between NASA, the U.S. space agency, and CNES the French space agency, to map ocean surface topography; Launched on August 10th,1992.

Estimating water storage in large reservoirs and lakes is attributed to the advent of radar altimetry. The most commonly used spaceborne radar altimeters during the past period were; GEOSAT, Topex/Poseidon or T/P, ERS-1, ERS-2, GFO, ENVISAT, JASON-1 and JASON-2.These sensors are out of service now and are replaced by other more modern sensors such as LANDSAT, the MODIS, as well as SAR, and such as RADARSAT, JERS-1, and ERS. All these sensors have the refined capability of estimating water storage and storage variation in lakes and reservoirs, in addition to measurements of both surface water area and bathymetry. The primary advantage of LANDSAT is its high resolution of $30 \mathrm{~m}$ per pixel, but it has low repeat frequency and is susceptible to cloud cover contamination. For sensors with daily coverage, like MODIS, the frequency of observations is obviously an advantage, but the resolution is relatively coarse $250 \mathrm{~m}$ to $500 \mathrm{~m}$ per pixel.

As an example of studies on the use of such measurements for the derivation of the elevation- area variation time series one example is presented in the following text. It is taken from a comprehensive study which was carried out in 2012 on five of the largest reservoirs in the United States and 34 reservoirs in various parts of the world 
by utilizing available MODIS outputs [35]. Water elevations and surface areas data during any overlapping period(s) from (2000 to 2010) for each of these reservoirs were used to derive their elevation-area relationships. These elevation-area relationships were then used to estimate reservoir storage volume time series. In Figure 4 the water surface elevation and surface area relationship for Fort Peck Reservoir is presented as one of the outputs of this study.

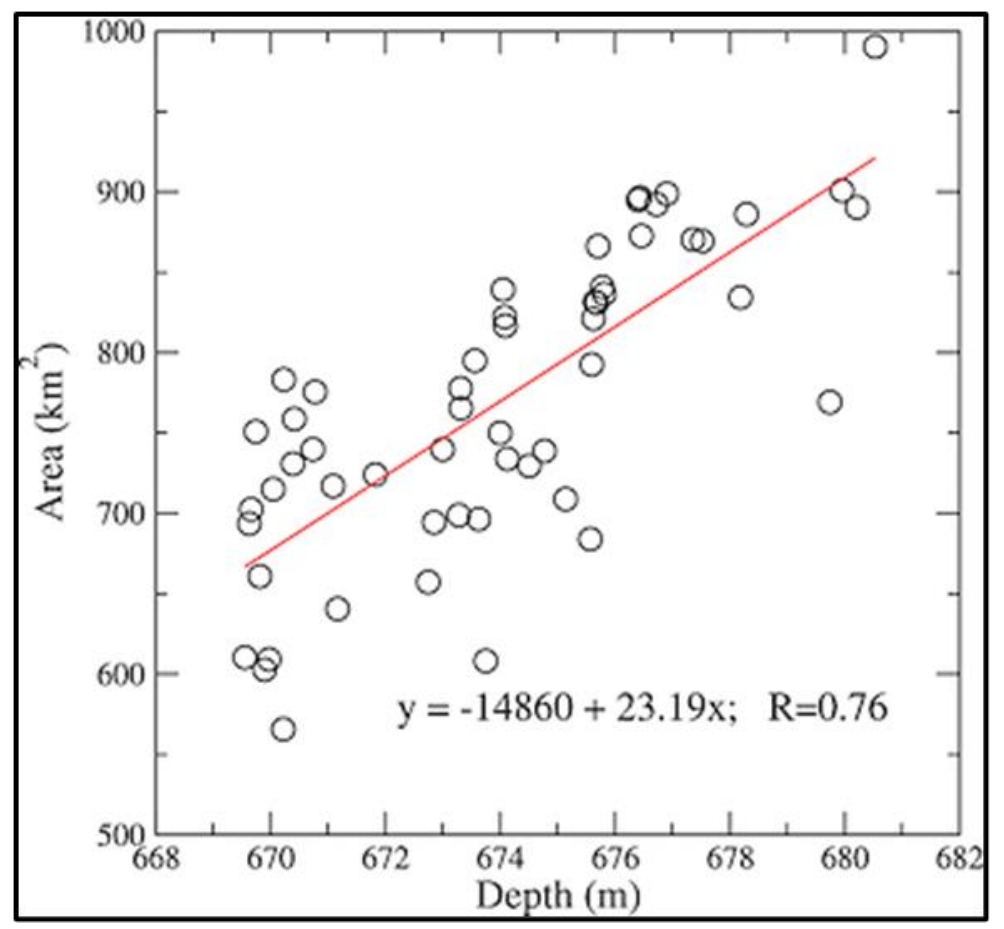

Figure 4: Water surface elevation and surface area relationship for Fort Peck Reservoir [35].

A linear regression was used to approximate the relationship between surface elevation (h) and surface area (A ) i.e.,

$$
A=f(h)
$$

For the period 1992- 2000, when MODIS data were unavailable, this relationship was applied to estimate the reservoir surface area from the water elevation historical data. Similarly, during periods when altimetry data were unavailable during the MODIS era, the water elevation was estimated as an inverse function of the surface area function $(\mathrm{h}=\mathrm{f}-1(\mathrm{~A}))$. 
The storage equation:

$$
\mathrm{Vo}=\mathrm{Vc}-(\mathrm{Ac}+\mathrm{Ao})(\mathrm{hc}-\mathrm{ho}) / 2
$$

was used to estimate reservoir storage,

where $\mathrm{Vc}, \mathrm{Ac}$, and $\mathrm{h} \mathrm{c}$ represent; storage, area, and water elevation at capacity, and Vo, Ao, and ho are the observed storage, area, and water elevation, respectively. The values at capacity ( $\mathrm{Vc}$ ) were taken mostly from the Global Reservoir and Dam (GRanD) database [36]. GRanD is based on multiple sources, including a variety of regional and national inventories and gazetteers, International Commission on Large Dam's World Register of Dams as well as a variety of publications, monographs, and maps.

By substituting the elevation-area relationship into above equation, the storage equation can be simplified into a single variable function, either as a function of water elevation from altimetry or as a function of surface area from MODIS. The value of MODIS data was provided in filling the gaps in the existing records to derive the complete elevation- area variation time series for all of these reservoirs for the period (1992 to 2010) which then could be used to estimate reservoirs storage volume time series for the same period. In Figure 5 the time series of reservoir storage volume estimated from remote sensing for Fort Peck Reservoir is presented as an example.

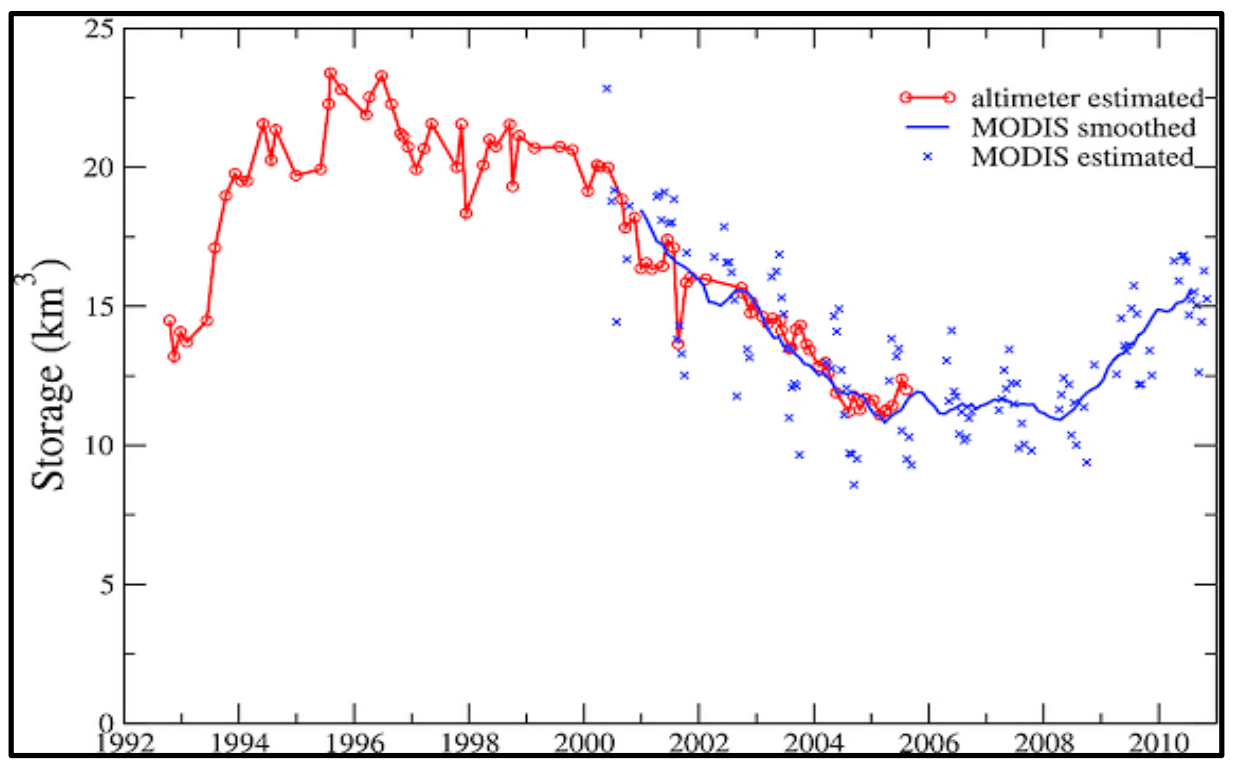

Figure 5: Time series of reservoir storage estimated from remote sensing for Fort Peck Reservoir [35]. 
The complete sets of the time series for water surface elevations, surface area, and storage volumes which are obtained from remote sensing for the five U.S reservoirs are given in Figure 6. This figure shows comparison of gauge observations for the reservoirs in black, altimetry-based estimates in red, and MODIS based estimates are in green.

In the same way, the elevation-surface area relationships for each of the 34 other world reservoirs were developed, and then they were used to estimate time series of reservoir storage volumes. The reservoir storage volume results are shown in Figure 7 and the elevation-area relationships are summarized in Table 2 . The total capacity of the 34 reservoirs is $1164 \mathrm{~km}^{3}$, which represents about $15 \%$ of global reservoir capacity. For 16 of these reservoirs, the estimated storage volume is available for 19 years (1992-2010) and the average record length for all reservoirs is 14.5 years. The correlation coefficient between the water elevation and surface area varies from 0.08 to 0.98 , with an average value of 0.5 . A high correlation usually indicates good quality for both data sets, while a low correlation can result from many conditions. These include errors from either the water elevation or surface area or both, and/or the possibility that within the range of variation the bathymetry is independent of area (i.e., vertical walls). For consistency within the time series for each reservoir, the MODIS estimated surface areas were used to maximize the record length, when altimetry water elevation was unavailable, but this is done only if the correlation coefficient between altimetry water elevation and MODIS surface area exceeded 0.5 .

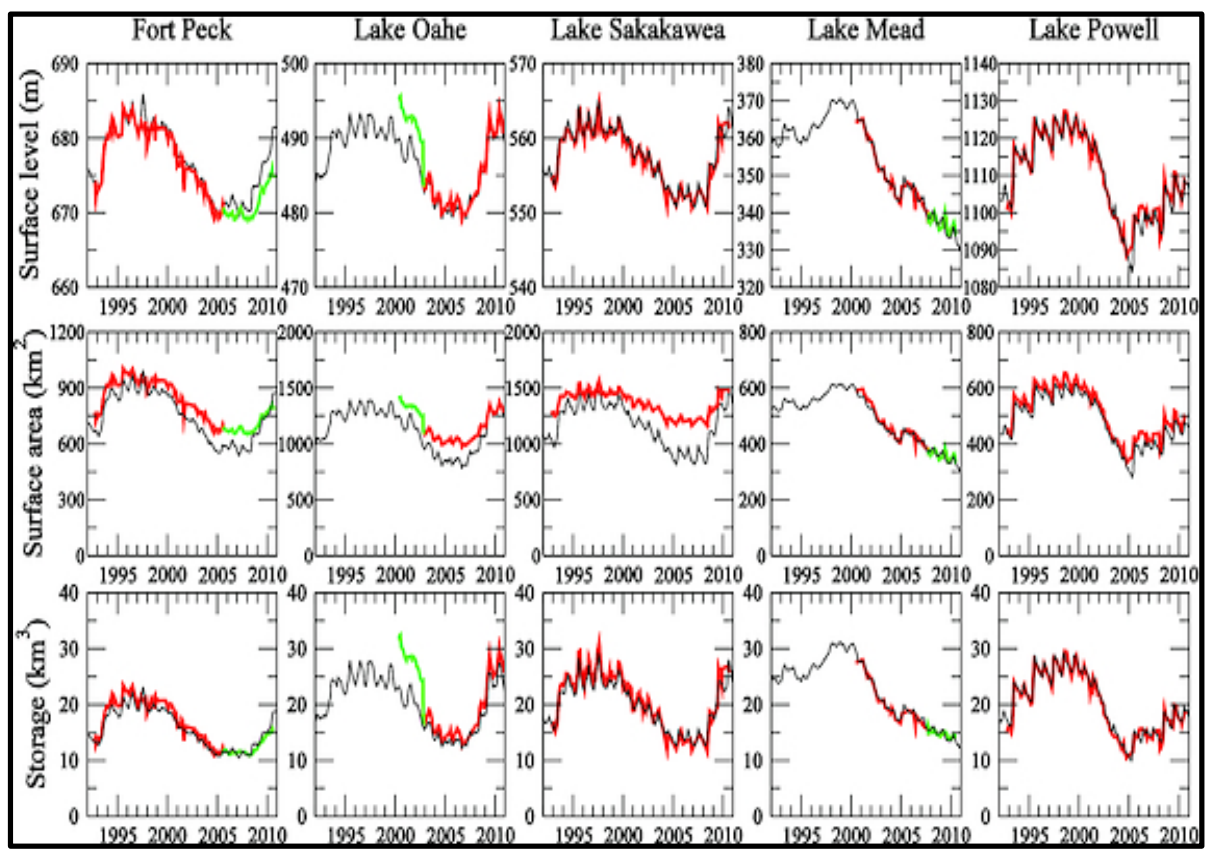

Figure 6: Comparison of gauge observations for five U.S. reservoirs; gauge observations in black, altimetry-based estimates in red, and MODIS based estimates are in (green) [35]. 
Three of the reservoirs given in this table are located in Iraq; Mosul Dam reservoir, Qadisiya Dam (Haditha) reservoir, and the Thartar Reservoir. Of these three reservoirs the Tharthar reservoir and the Qadisiya Dam, are selected for further comments, in addition to commenting on Lake Nasser on the Nile River (Egypt), and the Toktogul Dam reservoir (Kyrgyzstan), in addition to Guri Dam reservoir (Venezuela).

Lake Tharthar, the largest artificial lake in Iraq, is the first example. Its primary purposes are irrigation and flood control. During the study period, there were two severe droughts in the Fertile Crescent, one from 1998 to 2001 and the other from 2008 to 2010 . Both wheat and barley production dropped precipitously during these drought events. The remotely sensed reservoir storage for Lake Tharthar indicates that the lowest storage during these events was about 35\% of the peak value in 1993. Lake Qadisiyah (Haditha), a much smaller reservoir built for irrigation, flood control and power generation close to Lake Tharthar, was hit relatively harder by the droughts; reservoir storage was completely depleted by the end of 2009 for a short period. Knowledge of water availability in water-sparse regions like this is crucial for man-aging irrigation water use and for planning aid. 


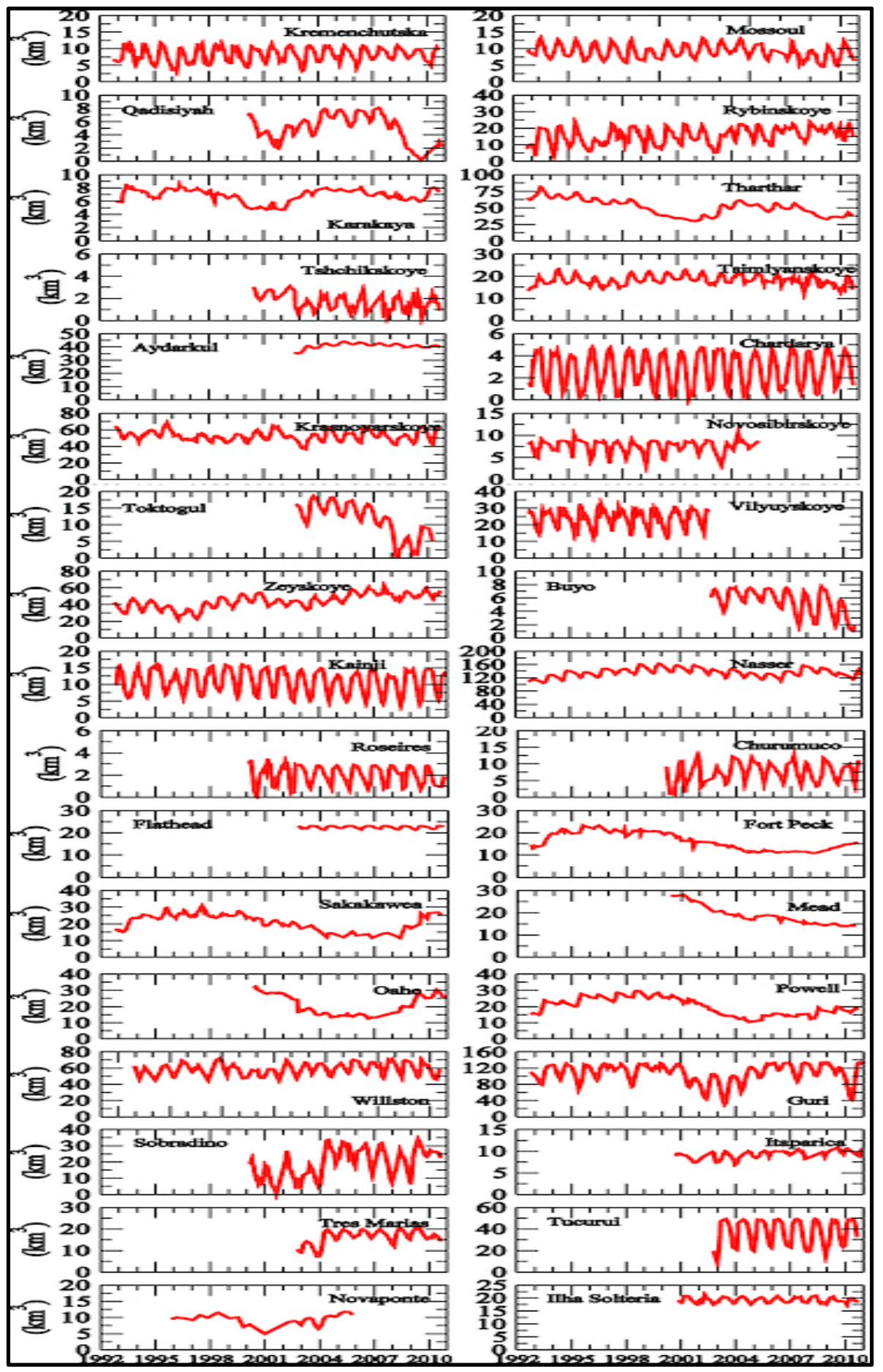

Figure 7: Global reservoir storage time series from remote sensing [35]. 
Table 2: Water Elevation-Area Relationships, Correlations, and Mean Absolute Errors [35].

\begin{tabular}{|c|c|c|c|c|c|c|}
\hline Reservoir & $\begin{array}{l}\text { Dam Location } \\
\text { (lat, lon) }\end{array}$ & $\begin{array}{c}\text { Capacity } \\
\left(\mathrm{km}^{3}\right)\end{array}$ & $\begin{array}{l}\text { Period of } \\
\text { Estimated } \\
\text { Storage }\end{array}$ & Level-Area Relationship & $\begin{array}{l}\text { Correlation } \\
\text { Coefficient }\end{array}$ & $\begin{array}{c}\text { Mean } \\
\text { Absolute } \\
\text { Error (\%) }\end{array}$ \\
\hline Kremenchutska & $49.08,33.25$ & 13.52 & $1992 \sim 2010$ & $y=-1536.9+45.972 x$ & 0.23 & 8 \\
\hline Mossoul & $36.63,42.82$ & 12.5 & $1992 \sim 2010$ & $y=-918.56+3.7919 x$ & 0.7 & 5 \\
\hline Qadisiyah & $34.21,42.36$ & 8.3 & $2000 \sim 2010$ & $y=-21246+499.78 x-3.97 x^{2}+0.0107 x^{3}$ & 0.98 & 2 \\
\hline Rybinskoye & $58.08,38.75$ & 25.4 & $1992 \sim 2010$ & $y=3226.3+13.198 x$ & 0.09 & 7 \\
\hline Karakaya & $38.23,39.14$ & 9.58 & $1992 \sim 2010$ & $y=-2944+4.6032 x$ & 0.78 & 2 \\
\hline Tharthar & $33.79,43.58$ & 85.59 & $1992 \sim 2010$ & $y=1444.6+19.447 x$ & 0.39 & 1 \\
\hline Tshchikskoye & $44.99,39.12$ & 3.1 & $2000 \sim 2010$ & $y=-89.297+13.882 x$ & 0.7 & 12 \\
\hline Tsimlyanskoye & $47.61,42.11$ & 23.7 & $1992 \sim 2010$ & $y=-3914.5+181.39 x$ & 0.42 & 8 \\
\hline Aydarkul & $40.95,66.5$ & 44.3 & $2002 \sim 2010$ & $y=-48738+210.28 x$ & 0.41 & 1 \\
\hline Chardarya & 41,68 & 6.7 & $1992 \sim 2010$ & $y=-8828.6+37.392 x$ & 0.96 & 5 \\
\hline Krasnoyarskoye & $55.5,92$ & 73.3 & $1992 \sim 2010$ & $y=-5.7725+8.171 x$ & 0.25 & 1 \\
\hline Novosibirskoye & $54.5,82$ & 9.08 & $1992 \sim 2004$ & $y=857.13+2.0431 x$ & 0.16 & 5 \\
\hline Toktogul & $41.78,72.83$ & 19.5 & $2002 \sim 2010$ & $y=151.03+0.1471 x$ & 0.14 & 2 \\
\hline Vilyuyskoye & 62.73111 .16 & 35.9 & $1992 \sim 2002$ & $y=-2121.1+19.197 x$ & 0.08 & 5 \\
\hline Zeyskoye & 54,128 & 68.4 & $1992 \sim 2010$ & $y=-1026.7+10.141 x$ & 0.38 & 2 \\
\hline Buyo & $6,-7$ & 8.3 & $2002 \sim 2010$ & $y=47.495+2.2899 x$ & 0.13 & 1 \\
\hline Kainji & $10.4,4.55$ & 15 & $1992 \sim 2010$ & $y=-4985.4+45.047 x$ & 0.97 & 10 \\
\hline Nasser & $23.97,32.88$ & 162 & $1992 \sim 2010$ & $y=-28160+185.02 x$ & 0.79 & 1 \\
\hline Roseires & $11.6,34.38$ & 3 & $2000 \sim 2010$ & $y=-3215.4+7.0832 x$ & 0.68 & 9 \\
\hline Churumuco & $18.265,-101.89$ & 12 & $2000 \sim 2010$ & $y=-624.09+6.9943 x$ & 0.68 & 5 \\
\hline Flathead & $47.67,-114.23$ & 23.2 & $2002 \sim 2010$ & $y=-1799+2.7029 x$ & 0.32 & 1 \\
\hline Fort Peck & $48,-106.42$ & 23.05 & $1992 \sim 2010$ & $y=-14860+23.19 x$ & 0.76 & 3 \\
\hline Sakakawea & $47.5,-101.42$ & 29.38 & $1992 \sim 2010$ & $y=-14439+28.339 x$ & 0.72 & 3 \\
\hline Mead & $36.01,-114.74$ & 31.92 & $2000 \sim 2010$ & $y=-2491+8.4546 x$ & 0.83 & 6 \\
\hline Oahe & $44.45,-100.39$ & 28.54 & $2000 \sim 2010$ & $y=-11798+26.661 x$ & 0.83 & 13 \\
\hline Powell & $36.94,-114.48$ & 30 & $1992 \sim 2010$ & $y=-8654+8.2567 x$ & 0.66 & 2 \\
\hline Williston & $56.01,-122.2$ & 74 & $1992 \sim 2010$ & $y=1108.4+0.9685 x$ & 0.11 & 3 \\
\hline Guri & $7.76,-63$ & 135 & $1992 \sim 2010$ & $y=-354.07+16.948 x$ & 0.4 & 2 \\
\hline Sobradino & $-10,-42$ & 34.1 & $2000 \sim 2010$ & $y=-48382+131.55 x$ & 0.81 & 4 \\
\hline Itaparica & $-9,-39$ & 10.8 & $2000 \sim 2010$ & $y=-11074+39.052 x$ & 0.8 & 1 \\
\hline Tres Marias & $-18,-45.5$ & 21 & $2002 \sim 2010$ & $y=357.44+0.7708 x$ & 0.19 & 2 \\
\hline Tucurui & $-3.88,-49.74$ & 49.54 & $2002 \sim 2010$ & $y=1645.7+7.299 x$ & 0.25 & 2 \\
\hline Novaponte & $-19.15,-47.33$ & 12.8 & $1995 \sim 2005$ & $y=73.749+0.19923 x$ & 0.08 & 1 \\
\hline Ilha solteira & $-20,-51$ & 21.2 & $2000 \sim 2010$ & $y=-18518+59.925 x$ & 0.59 & 5 \\
\hline
\end{tabular}


In central Asia, the time history of storage in Toktogul Reservoir was examined. It supplies water to Kyrgyzstan's single largest hydropower plant, and it also provides irrigation water downstream. During the 2007-2008 drought, the reservoir storage was completely depleted. Storage information for the Toktogul Reservoir is also crucial for water management in the Naryn/Syr Darya basin, which is a major international river system in Central Asia.

With a storage capacity of $157 \mathrm{~km}^{3}$, Lake Nasser in Africa is the third largest manmade reservoir in the world by volume. Its main use is for irrigation, with hydropower and flood control as secondary operation purposes. During the 1990s the water elevation and storage increased due to high precipitation in the Ethiopian Highlands. For the safety of the dam, water was spilled from Lake Nasser westward into the Sahara Desert, forming the Toshka Lakes (beginning in 1998). From 2003 to 2007, these discharges to the Toshka Lakes were stopped, and the new lake contracted. From knowledge of storage history for Lake Nasser it shows that the rebound of storage in 2008-2009 should have allowed more spillover to the Sahara, suggesting possible increases in irrigation diversions or releases to the Nile Delta. Guri Dam in South America is the world's third largest hydropower plant. It supplies $73 \%$ of Venezuela's electricity. Two major drought events (2001 to 2004 and 2009 to 2010) were the worst in the past 40 years in Venezuela, and the reservoir dropped to a low storage of $28 \%$ of its maximum in 2003. During the 2010 event, power rationing was implemented to close the electricity gap. The obtained reservoir time series shows that reservoir storage experienced a quick recovery from the last drought by the end of 2010 .

The interest for securing reliable water resources in many semiarid regions of the world has increased sharply during last decades to meet the increasing population demand for food. This has led to expanding irrigated agriculture from small water sources and required the use of small reservoirs for the hitherto neglected such resources. The increasing number of small size dams and their wide distribution over large swaths of rural countryside has made their monitoring much more difficult. To overcome the lack of baseline data, some studies have classified the extent of small reservoirs surface areas of such reservoirs from Landsat ETM which utilize the Enhanced Thermal Mapper sensor (ETM) born by Landsat 7 (1999) [37].

One study published in 2009 explained the use of (ENVISAT-ASAR) to monitor three small dams close to the village of Tana Natinga in upper east region of Ghana, West Africa, where water supply from these three small dams was critical for the population of three villages to satisfy irrigation demand, livestock watering and household use [38]. The area was semiarid with an annual average precipitation of not more than $986 \mathrm{~mm}$ and the three reservoirs had shallow depths. The study used 22 (ENVISAT-ASAR) images acquired bimonthly from June to August 2006 to ensure observing seasonal variation, the changing vegetation context, and the large variability of backscatter from water surfaces i.e., through wind-induced water surface roughness. The ENVISAT or "Environmental Satellite" is a large inactive Earth-observing satellite which is still in orbit, operated by the European Space Agency (ESA) [39, 40], and ASAR is the advanced Synthetic Aperture Radar sensor 
[41]. The overall conclusion of this research has shown that regional to basin scale inventories of small inland water bodies are readily possible with ENVISAT-ASAR images. In combination with regional area-volume equations, basin-wide reservoir storage volumes can be estimated, and the impact of further development can be assessed and monitored.

Moreover, in a research carried out in 2005 [42], the inventory of small farm reservoirs in Insiza District that forms part of Mzingwane catchment (Zimbabwe) [43] was obtained through remote sensing by acquisition of images from (LANDSAT 5, bands 5, 4 and 2). Using Red- Green- Blue channel, water bodies were depicted in colors ranging from blue to almost black and reservoirs were uniquely identified. This procedure was applied for all reservoirs studied in this research work. The objectives of the study were:

i. To identify small reservoirs in terms of their numbers and spatial distribution in the study area from satellite images.

ii. To develop a methodology to estimate small reservoir capacities as a function of their remotely sensed surface areas in the basin.

The estimated number of small farm reservoirs when this study was conducted in (2005) was 1000 in Insiza District as depicted from satellite image and they were quite evenly distributed in the entire catchment as displayed in Figure 8.

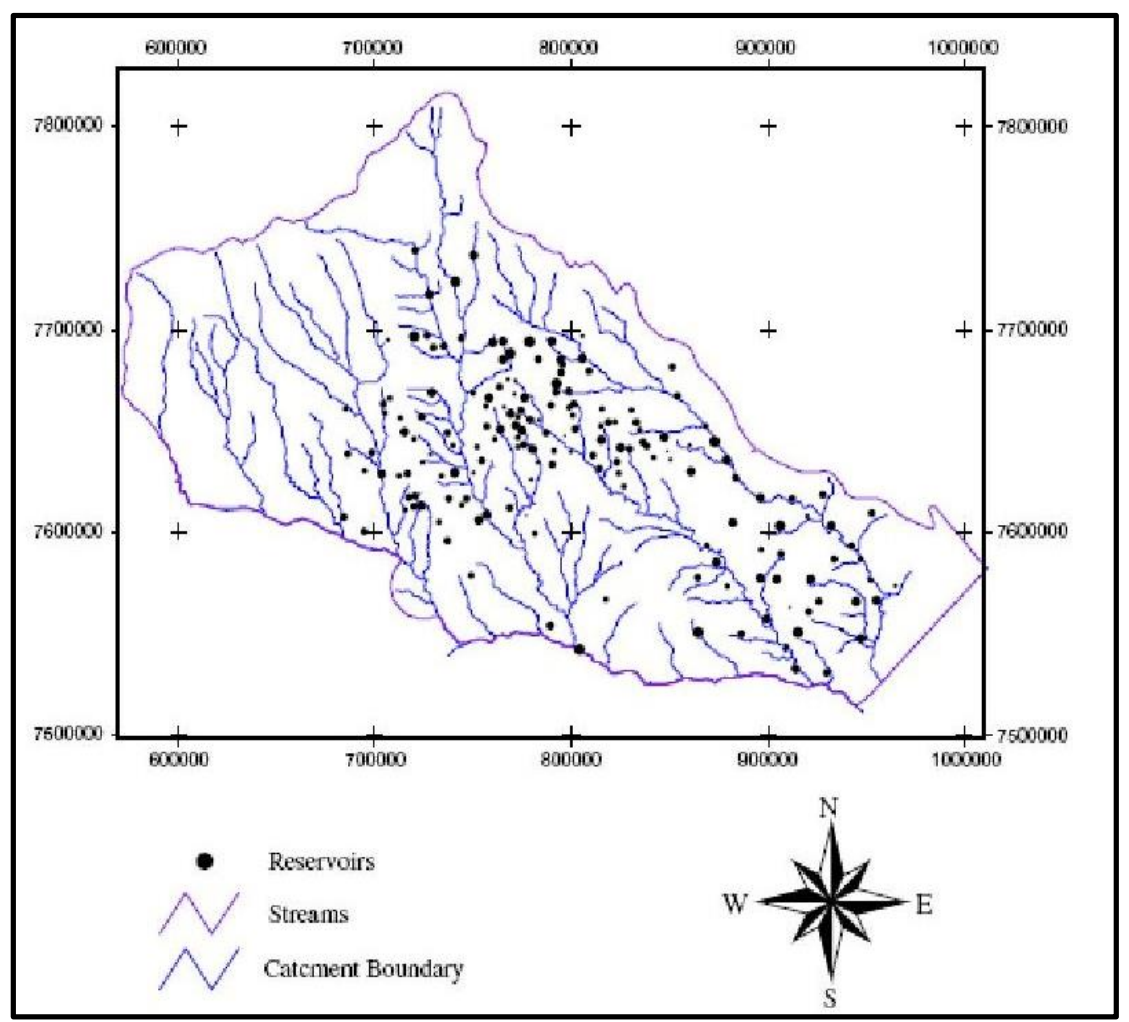

Figure 8: Spatial distribution of small reservoirs in the Mzingwane catchment [42]. 
This number included small reservoirs in both communal lands and resettlement areas, which means an update baseline data of reservoirs was obtained by use of remote sensing. The method of using satellite information to estimate the number of small reservoirs and keep an update of small reservoir database proved to be useful. The difference in the number of small reservoirs' records obtained from other sources in later years maybe due to construction of small farm dams in these years by some farmers without prior approval from the water authorities.

Having established the spatial distribution of small reservoirs in the study area in question, field study on 12 selected reservoirs from this inventory was carried out. The depths of water accompanied with their coordinates were measured; from which area and capacity relationships were calculated for each reservoir using geographical information system (Arc View 3.2 GIS) package with Spatial Analyst, plus Surface Areas and Ratios from elevation Grid extension [44] were used to automate surface area calculations and to provide surface area statistics. The use of (Arc View 3.2 GIS) software was actually validated in 2003 [45].

The conclusions were; the applicability of the method over other catchments may have to be looked at in future as well as the need to carry out a hydrological modelling to investigate the impacts of small reservoirs in water resources in other basin. In general, and with the capacities of these small reservoirs known, planners and water managers will quickly make decisions on how to utilize and manage the available water given the various competing uses. Moreover, a water manager will in case of flooding be able to predict the likelihood of floods and hence putting in place remedial actions to ensure the community is not at risk [46].

Estimation of small reservoir storage capacities with remote sensing in the Brazilian Savannah Region was also conducted and results were published in 2011. This work was carried out for the purpose of efficient water management and sound planning of 147 small reservoirs which can store $19 \times 10^{6} \mathrm{~m}^{3}$ of water at full capacity located in the Preto River Basin which was hindered by inadequate knowledge of the number, storage capacity and spatial distribution of reservoirs in the basin.

To address this lack of data, a simple method to estimate reservoir storage volumes based on remotely sensed reservoir surface area measured with (LANDSAT) was developed. The method was validated by choosing a subset of reservoirs in this basin for which surface areas, shapes and depths were determined with groundbased survey measurements. The agreement between measured and the remotely sensed reservoir volumes was satisfactory indicating that remotely-sensed images can be used for improved management of water in the Brazilian Savannah. The inventory and classification of reservoirs was conducted by means of remote sensing using three Landsat ETM images taken in 2005. Investigation of the selected reservoirs in the chosen subset consisted of visiting the site, collecting information from farmers with questions focused on reservoir characteristics such as existence of technical information (area, depth, maps, etc.), maintenance, age, purpose, etc. The initial database consisted of 252 small reservoirs, but only those with surface areas between 1 and 50 ha were considered. Estimation of water depths was done using a plummet from a boat and GPS coordinates determined at many 
locations inside these reservoir. In order to assure good quality data and whether more readings should be takes, the depth and GPS data were downloaded to a laptop and analyzed before leaving the site.

Satellite measurements of 75 reservoir surface areas were well correlated with field measured areas. Deviations in surface area measurements between the two methods were the result of both the coarse image spatial resolution of $30 \mathrm{~m}$ and the presence of herbaceous water plant cover in the shallow tail parts of the reservoirs. Surfer Golden Software was used to calculate the surveyed reservoir volumes by creating a 3D-Model for each reservoir, and the volume-area relationships were determined by a linear regression of the log of both the maximum surface area and storage capacity [47].

The general relationship between measured reservoir volumes and their remotely sensed surface areas showed good agreement. The $\mathrm{R}^{2}=83 \%$ gives, in some extent, confidence in its use, especially for reservoirs with no other available information. Combining this relationship with periodic satellite-based reservoir area measurements will allow hydrologists and planners to have a clear picture of water resource system in the Preto River Basin, especially in ungauged subbasins. At full capacity, the water that the Preto River Basin's 147 small reservoirs can capture is likely small, but these act as a set of well-distributed and easily accessible water source systems that have multiple uses, reducing the population's vulnerability and improving their livelihoods. The applicability of the derived relationships to other catchments should be examined in future [48].

In 1994 a comprehensive study on the applications of remote sensing methods summed up the application of remote sensing methods required in the field of hydrology, of which many have their use in the investigations of potential dam sites, creating inventories of small dams on regional scale, obtaining volume-area relationships of dams, floods studies and so on. The study indicated the need for more research before operational applications can be made in other areas. The areas requiring additional emphasis that were indicated in this 1994 study were: Land Cover, Sediment Loads and Erosion, Snow Water Equivalent (Complex Terrain), Soil Moisture, Groundwater, Physiography, Albedo, Evapotranspiration, Areal Inputs to Models, Streamflow, Infiltration, Chemical Pollution. The study concluded that rapid advances in this field were expected in the following several years, especially if adequate effort is devoted by technique developers to technology transfer of the remote sensing methods [49]. This prediction proved its foresight as may be seen from another publication in 2018 which includes details of advances made in the following years in the technology of remote sensing and the versatility of the topics researched [50]. 


\section{Remote Sensing Application in Bathymetry Studies}

Accurate determination of water depth is important both for the purposes of monitoring underwater topography and movement of deposited sediments, and for producing nautical charts in support of navigation. Moreover, bathymetry has proven its value in studies on hydrological and biochemical processes in water bodies such as lakes and reservoirs, in addition to presenting an aid to constructing weather forecast models where temporal variation of surface area and reservoirs depths are taken into consideration. Bathymetry has been traditionally done by vessel based echo sounding and also by airborne remote sensing by (Lidar) by illuminating the target with laser light and measuring the reflection with a sensor which can produce accurate depth measurements. These methods, however, can in situations be costly, inefficient, and inapplicable to very near shore shallow waters and limited by the survey width. By comparison, satellite remote sensing methods offer more flexible, efficient and cost-effective means of mapping bathymetry over broad areas.

This remote sensing bathymetry generally falls into two broad categories [51]:

i. non-imaging

ii. imaging methods

The first category; is based on the use of (Lidar) sensors, that measure distances by illuminating the target with laser light and measuring the reflection. Differences in laser return times and wavelengths can then be used to make digital 3D representations of the target and the method has terrestrial, airborne, and mobile applications [52]. It is able to produce accurate bathymetric information over clear waters at a depth up to $70 \mathrm{~m}$. However, this method is limited by the coarse bathymetric sampling interval and high cost.

The second category; this method can be implemented either analytically or empirically, or by a combination of both. Analytical or semi-analytical implementation is based on the manner of light transmission in water. It requires inputs of a number of parameters related to the properties of the atmosphere, water column, and bottom material. Thus, it is rather complex and difficult to use.

Both implementations of this category can produce fine-detailed bathymetric maps over extensive turbid coastal and inland lake waters quickly, even though concurrent depth samples are essential. The detectable depth is usually limited to $20 \mathrm{~m}$. The accuracy of the retrieved bathymetry varies with water depth, with the accuracy substantially lower at a depth beyond $12 \mathrm{~m}$ and it is influenced by such factors as water turbidity and bottom materials, as well as image properties.

With the introduction of new sensors, new data collection technology and the explosion of digital datasets, there has come the ability to develop accurate geospatial products. DEMs and bathymetric navigation surfaces are generated from combining high-resolution and spatially dense, raw digital data with proper vertical reference datum surfaces and are capable of supporting a variety of applications pertinent to the coastal manager. By using VDatum software [53] bathymetric and 
topographic data can be transformed into common vertical datum such as shoreline, or Mean High Water; a seamless DEM can then be created. Data integration allows bathymetric-topographic or bathy-topo (DEMs) to be produced upon which various scenarios can be overlaid, such as sea-level rise, storm surge, tsunami and other inundation scenarios [54]. It is worth mentioning that the airborne (Lidar) has been used to map the bathymetry of thousands of small shallow lakes over the Alaska Slope [55].

Advancements made in recent years and the growth of spaceborne altimetry have shown, however, promise for deriving reservoir bathymetry. An example published in 2018 explained such use which was applied to derive $3 \mathrm{D}$ bathymetry of the lower portion of Lake Mead by combining the time series radar altimetry and Landsat data sources, which included the hydrological data and maps based on Shuttle Elevation data at multiple scales, and on Envisat and Altika radar altimeters, and Landsatbased water extents. Lake Mead, created by Hoover Dam on Colorado River, which is located in Nevada, USA, was used as the study case due to the large ground-based data availability, including bathymetric measurements used for evaluations. It is also the largest reservoir in the U.S, with a maximum water capacity of $32.2 \mathrm{~km}^{3}$. The focus of the study was the lower portion of the lake, i.e., the Boulder Basin. Figure 9 shows a location map of the study area which has a maximum water capacity of $10.5 \mathrm{~km}^{3}$. The objectives of the study were to evaluate different techniques that rebuild reservoir bathymetry by combining multi-satellite imagery of surface water elevation and extent.

DEMs were processed in two distinct ways in order to determine 3D reservoir bathymetry.

They were defined as:

(a) linear extrapolation and

(b) linear interpolation. 


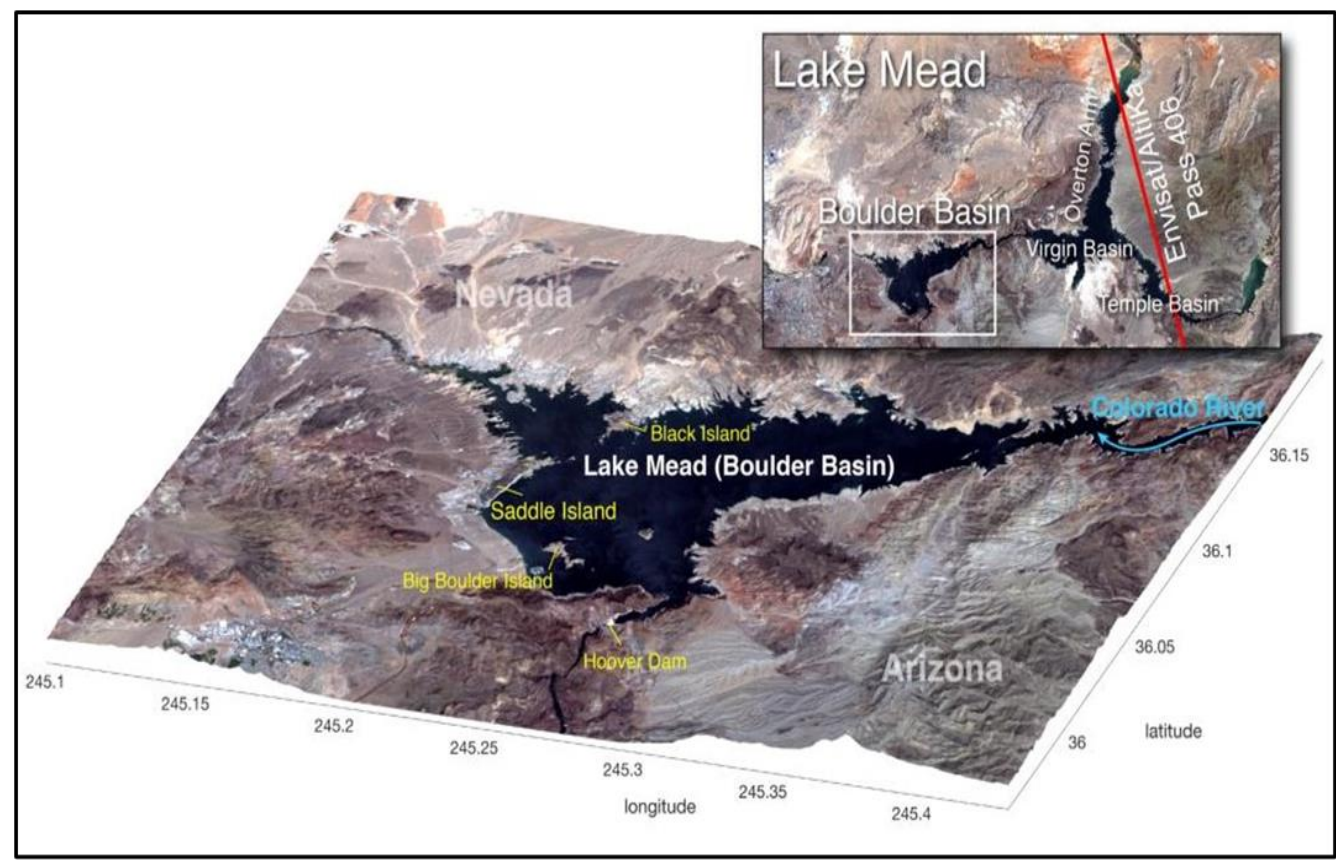

Figure 9: Geographical information of Lake Mead in the USA and Boulder Basin. The figure is derived from Landsat-8 OLI image taken on August 14, 2017 [56].

The first one linearly extrapolates the land slope, defining the bottom as the intersection of all extrapolated lines. The second linearly interpolates the uppermost and lowermost pixels of the reservoir's main river, repeating the process for all other tributaries.

A visible bathymetry, resulting from the combination of radar altimetry and water extent masks, could be coupled with the DEM improving the accuracy of techniques (a) and (b). Envisat and Altika based altimetric time series was combined to a Landsat based water extent database over the 2002-2016 period in order to generate the visible bathymetry, and topography was derived from the (3-arcsec HydroSHEDS DEM (i.e. 900m). Fourteen 3D bathymetries derived from the combination of these techniques and datasets, plus the inclusion of upstream and downstream riverbed elevations, were evaluated over Lake Mead. Accuracy was measured using ground observations, which showed that metrics improve as a function of added data requirement and processing. Best bathymetry estimates were obtained when the visible bathymetry linear extrapolation technique and riverbed elevation were combined. Water storage variability was also evaluated and showed that best results were derived from the aforementioned combination.

In this type of studies two limitations, however, were recognized in the evaluation. They were:

i. Limited number of the evaluation techniques to generate 3D bathymetry.

ii. Limited number of evaluation sites. 
Applying and combining additional extrapolation and interpolation techniques (i.e. polynomial, logarithmic, exponential, among others) to a wider range of reservoirs can result in a more refined evaluation, and metrics could be related to hydrogeological features (e.g. shape, depth, etc.) in order to determine the most appropriate techniques to be used. Unfortunately, access to ground-based bathymetric observations is still limited, restricting a broader evaluation [56]. To overcome the limitation of availability of elevation observations from radar altimetry another study was published in 2019 which was made with the objective to explore the potential of generating high resolution reservoir bathymetry at a global scale using data collected by the Multiple Beam Experimental Lidar (MABLE) on board NASA, Ice, Cloud, and land Elevation ICESat-2, which is the 2nd-generation of this series [57]. The study covered again the Bolder Basin forming the western part of Lake Mead shown in Figure 10, also indicated in Figure 9 above.

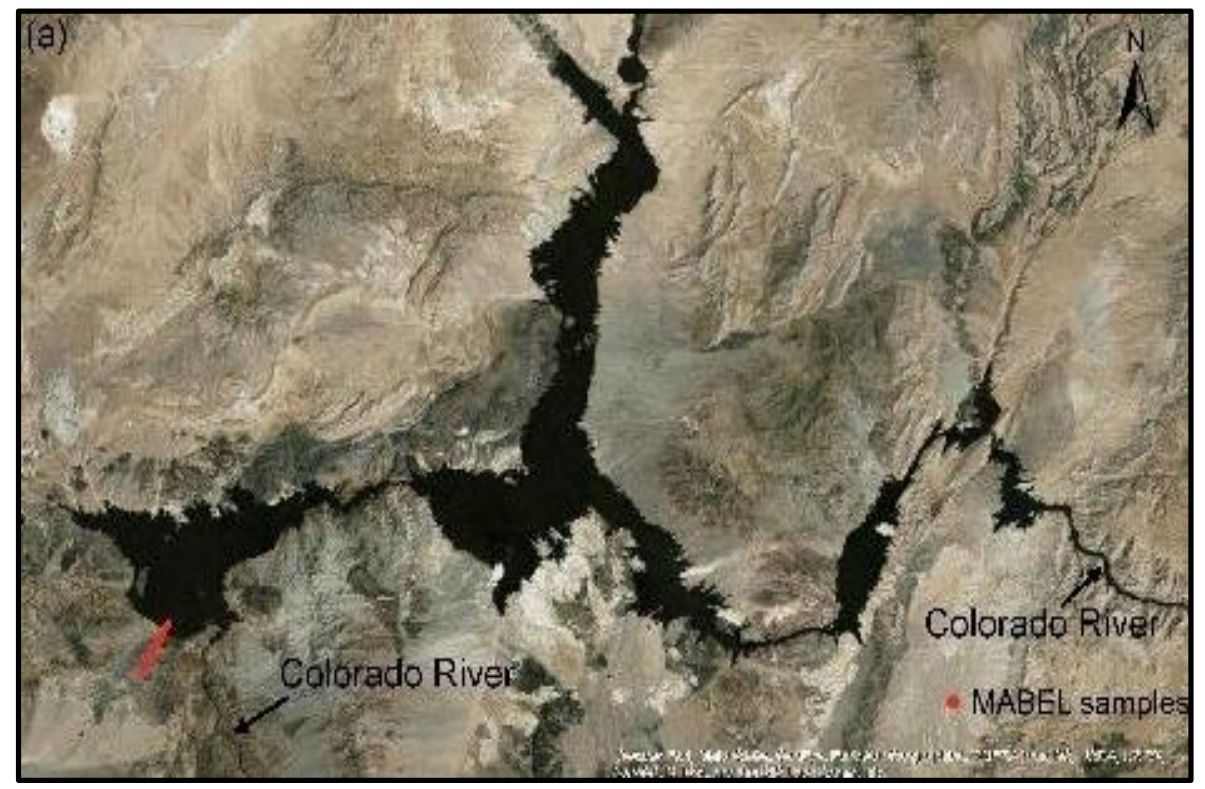

Figure 10: Location map [58].

MABEL elevation data were collected on February 24, 2012, with reported clear sky and relatively low turbidity where the collected data was over approximately $2 \mathrm{~m}$ footprint along its track. The data was then merged with the Shuttle Radar Topographic Mission (SRTM DEM) to get the final telemetry. Leak Mead (Lidar) survey data collected by the United State Bureau of Reclamation (USBR) in 2009 were used to validate part of the bathymetry product which was generated using MABEL data. The methodology can be illustrated by the flow chart in Figure 11. 


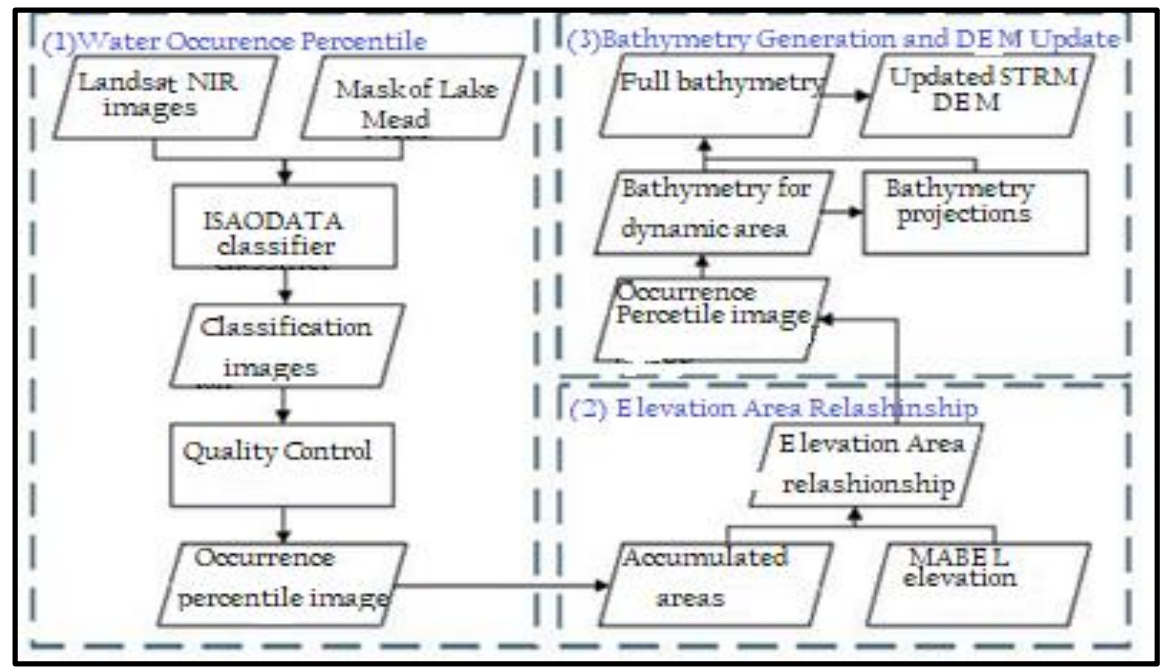

Figure 11. Flowchart of the bathymetry generation algorithm.

It consists of three parts (contained in the three blue boxes): 1) The water occurrence percentile image was generated from the Landsat classifications, which essentially provided the bathymetry contours; 2) The Elevation-Area relationship was established by combining the area from occurrence percentile image with MABEL elevation values. This was then used to identify and assign elevation values to the contours, and 3) The ElevationArea relationship was applied to the bathymetry for the dynamic lake area. Which was used to project the bathymetry of the dynamic lake for the central area to obtain the full lake bathymetry. Then the full lake bathymetry was overlapped with the SRTM DEM data to replace the constant value [58].

Figure 12a shows the full bathymetry of Lake Mead, including the remotely sensed part (330.62-369.65 m) and the projected part (263.00-330.62 m). Although the performance of the projected bathymetry varies with region, it has an overall good pattern. Close-up views of the two regions were selected to show the details. In the subset area shown in Figure 12b, the contours based on the projected bathymetry agree well with those from the sedimentation survey data. However, in the subdomain depicted by Figure 12c, the projected results largely missed those from the survey; which was caused by the assumption made that the slope remains constant. The resultant full bathymetry was then embedded onto the SRTM DEM data. The comparison between the bathymetry and SRTM DEM is shown in Figure 13. It was evident that the elevation of Lake Mead from DEM is constant (372 m) over the entire reservoir. In order to be accurate, the researchers first applied the reservoir area from the DEM $\left(587.50 \mathrm{~km}^{2}\right)$ to the (MABEL)-based elevation-area relationship to estimate its corresponding elevation $(367.82 \mathrm{~m})$. A systematic bias of $4.18 \mathrm{~m}$ was found between this elevation value and that according to the SRTM DEM. A bias correction of $4.18 \mathrm{~m}$ was then applied to the bathymetry such that it 
could be seamlessly combined with the DEM. Thus, the part of the DEM with a constant value of $372 \mathrm{~m}$ was replaced by the part of the bathymetry results representing $372 \mathrm{~m}$ and below after the systematic bias correction. Moreover, contour maps with different horizontal intervals (e.g., 5, 10, and $20 \mathrm{~m}$ ) were drawn from the bathymetry, which can help to delineate the profile. An example of the contour map at a 20-m interval is shown in Figure 13.

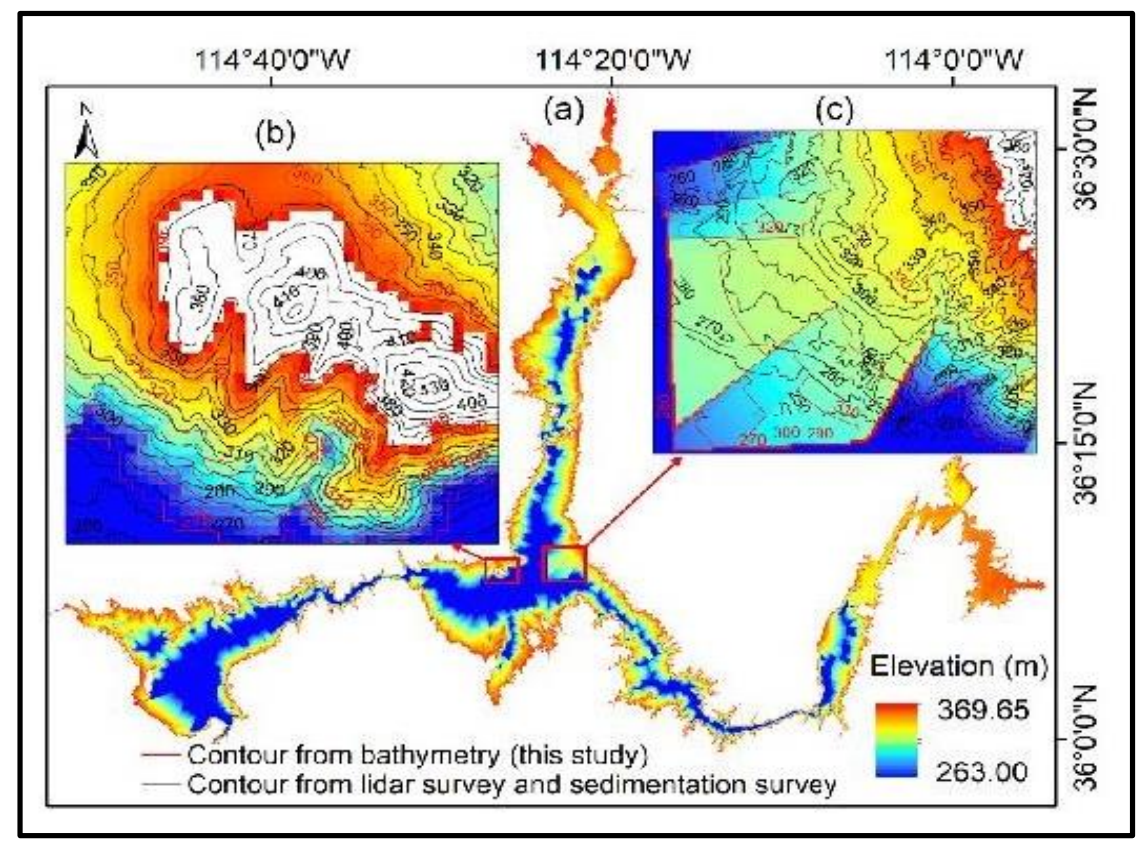

Figure 12: (a) Full bathymetry of Lake Mead, including the remotely sensed bathymetry (3330.62-369.65m) and the projected bathymetry (263.00330.62m); (b), (c) close-up views of the two regions with (b) satisfactory and (c) unsatisfactory performances are selected to show the details. Note that the contour data from both sources have an elevation interval of $10 \mathrm{~m}$. The contour data are not shown in (a) because they are relatively dense and would not be useful to the reader [58].

Validation of the remotely sensed bathymetry products showed an overall good agreement when comparing it with available USBR Lidar data and sedimentation data sets. Comparing the statistical bathymetry results obtained from this study with those obtained from the (Lidar) survey within each percentile band (at a $10 \%$ interval), there was a clear overestimation in the $1 \%-30 \%$ range and an underestimation in the $80 \%-100 \%$ range. However, the derived bathymetry in overall agrees very well with the (Lidar) survey data. The overall survey data show a larger variation within each band, which can be attributed to both the higher resolution and the measurement error of the raw data, but it was unclear why the survey elevations in the $90 \%-100 \%$ band are higher than those in the $80 \%-90 \%$ band. 


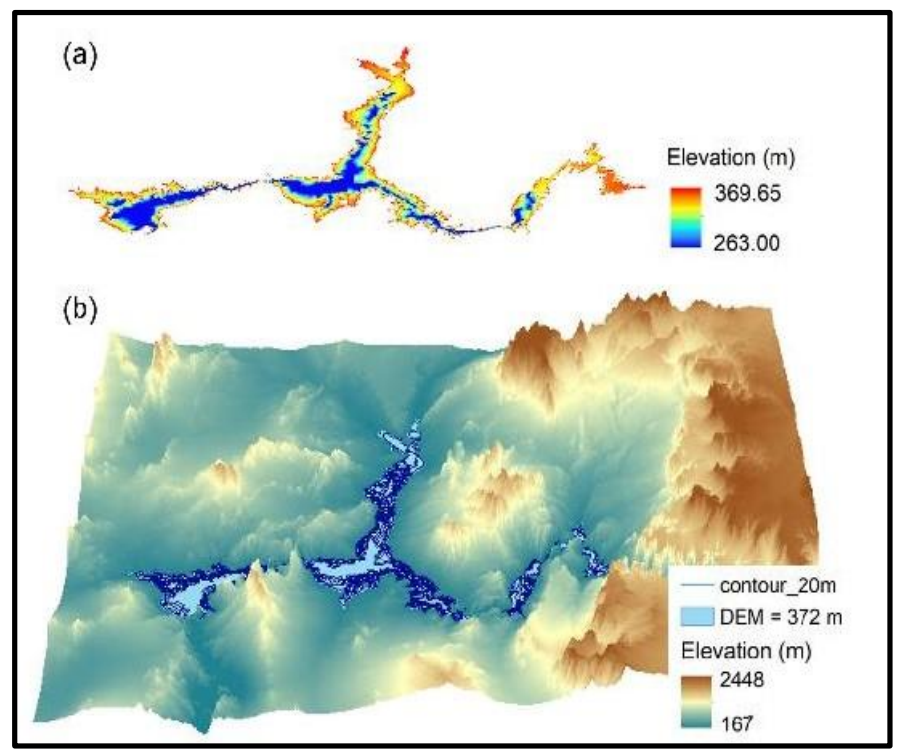

Figure 13: (a) Full bathymetry and (b) STRM DEM data over Lake Mead. The contour map (with a $20 \mathrm{~m}$ interval) is derived from bathymetry information and DEM elevation is constant $(372 \mathrm{~m})$ over the entire lake[58].

In summary, it was demonstrated that the $532 \mathrm{~nm}$ (MABEL) elevations and imagery data sets can be combined to generate high-resolution 3D reservoir bathymetry results for the dynamic area over the last three decades. The bathymetry for the central reservoir area can be projected by extrapolation and then integrated with the remotely sensed results to obtain the full bathymetry. The highlight is; that a $30 \mathrm{~m}$ resolution and high-quality bathymetry profile representing the complete range of the dynamic reservoir area over more than 30 years (i.e., 58\% of Lake Mead's capacity) was produced exclusively from remote sensing data. The next conclusion was that until the time of this research work, there had been no cost-effective approach to derive reservoir bathymetry on a global scale.

Similar method was used to derive area-elevation relationships for reservoirs on global scale and a 30m resolution bathymetry data set was generated for 347 global reservoirs, representing a total volume of $3,123 \mathrm{~km}^{3}(50 \%$ of the global reservoir capacity). This was documented in a recent study published in 2020 study [59].

First, Area- Elevation (A-E) relationships for the identified reservoirs were derived by combining altimetry data from multiple satellites with Landsat imagery data. Next, the resulting (A-E) relationships were applied to the Surface Water Occurrence (SWO) data from the Joint Research Center (JRC) Global Surface Water (GSW) dataset [60] to obtain bathymetry values for the dynamic areas of the reservoirs. Lastly, an extrapolation method was adopted to help achieve the full bathymetry dataset. 
The remotely sensed bathymetry results were primarily validated as follows:

i. Against Area-Elevation (A-E) and Elevation-Volume (E-V) relationships derived from the in situ elevations and volumes for 16 reservoirs, with root-mean-square error (RMSE) values of elevation from $0.06 \mathrm{~m}$ to $1.99 \mathrm{~m}$, and normalized RMSE values of storage from $0.56 \%$ to $4.40 \%$, and

ii. They were also validated against survey bathymetric maps for four reservoirs, with $\mathrm{R}^{2}$ values from 0.82 to 0.99 and RMSE values from $0.13 \mathrm{~m}$ to $2.31 \mathrm{~m}$.

The projected portions have relatively large errors and uncertainties (compared to the remotely sensed portions) because the extrapolated elevations cannot fully capture the underwater topography. Overall, this approach performs better for reservoirs with a large dynamic area fractions. It can also be applied to small reservoirs (e.g., reservoirs with surface areas of a few square kilometers or less), where (ICESat) observations are available, and to large natural lakes. With the contribution of (ICESat-2), this dataset has the potential to be expanded to thousands of reservoirs and lakes in the future [59].

It is noted that large volume of research work was performed during the last decade on various bathymetry applications utilizing satellite techniques and innovations in monitoring water bodies; ranging from oceans to lakes and reservoirs of various sizes. To cite very few examples, one may mention some of them such as; Complete Remote Sensing Approach to Monitor Reservoirs Volume (2011) [61]; Bathymetric Mapping Using Landsat8 Scattered Imagery (2015) [62]; Lake Nubia Bathymetry Detection by Satellite Remote Sensing 2018 [63]. A New Digital Lake Bathymetry Model Using the Step-Wise Water Recession Method to Generate 3D Lake Bathymetric Maps Based on DEMs (2019) [64].

\section{Reservoir Siltation and Catchments Erosion Observed by Satellite Remote Sensing}

Evaluation of sediments volume and its spatial distribution in any reservoir is an important factor in water management of river basins especially those on which dams and reservoirs are constructed. Sediments accumulation does not only affect the useful life of the reservoir and causes reduction of its storage, and hence water availability, whether for irrigation or/and power generation, but it will also affect its operation schedule, in addition to its impact in many cases on water quality. Increased sediment concentration can create turbid waters with a smaller euphotic zone which may have negative impacts on fish and bird species and causing abrasion of fish gills, thus increasing potential for diseases or mortality. Turbidity can also cause visual impairment for predatory fish, affecting their feeding habits. Conducting studies on sedimentation accumulation in any reservoir and its spatial distribution can be performed by conventional and remote sensing techniques. The conventional techniques of quantification of sediment deposition in a reservoir such as hydrographic surveys and the inflow-outflow methods, are cumbersome, 
costly and time consuming, while on the other hand the alternative possible technique, which is the digital image processing of remotely sensed data is; easy, less costly and subjective of minimum human errors, and can be used for routine assessment of sedimentation in reservoirs. Remote sensing techniques use the fact, that the water spread area of reservoir at various elevations keeps on decreasing with the passage of time and recurrence of floods which bring fresh quantities of such sediments. Remote sensing satellite provides information regarding the water spread area of the reservoir at a particular elevation on the date of pass of the satellite which helps to estimate sedimentation in a reservoir over a period of time. The broad spectral range of available satellite remote sensing devices can provide synoptic, repetitive, and timely information regarding the sedimentation in a reservoir. Reduction, if any, in the water spread area for a particular elevation indicates deposition of sediments at that elevation [64].

Moreover, considering the fact that sediments carried to, and deposited in any reservoir originate from the drainage basin in which the reservoir is located, it follows that understanding of the factors leading to this; such as slope, soil type, land use within the drainage basin is important. The study of the factors contributing to the erosion process can help in taking preventive measures on such drainage basin. These actions may range between improving land use methods, stopping deforestation and enhancing vegetative cover, cultivating on terraces, and constructing silt check structures and control of gulling.

Studies based on remote sensing of the whole watershed area have been carried out in some cases to establishing the factors contributing to erosion and rating them in order to have the full view and the dimensions of the problem. An example of such a study is cited from the case of the Ramganga reservoir (India) and the contribution of its drainage basin to the problem [65].

The Ramganga dam is $128 \mathrm{~m}$ earth fill dam that was constructed on the Ramganga River, a tributary of the Ganga River during 1961-1974 and it has a live storage capacity of 2,190 million cubic metres. It generates hydroelectric power and facilitates irrigation. The catchment area of Ramganga basin is approximately $32,493 \mathrm{~km}^{2}$ [66]. The study was performed using historical records of water level elevations from 1988-2001 and satellite data from LISS- III sensor [67] of the Indian Remote Sensing (IRS-1C) satellite launched on 28 December 1995 [68]. The study area was covered in Path 97, Row 50 of the satellite orbit, and the remote sensing data for the following dates were considered; 28 September 2000, 15 November 2009, 9 December 2000, 19 February 2001, 8 April 2001, and 2 May 2001. For the preparation of drainage area and contour map, Survey of Indian topographical maps $53-\mathrm{K} / 9,10,11,13,14$, and 15, 53O/1 and 2 at scale of 1: 50,000 were used.

The Methodology that was followed in the study was carried out into two steps:

i. Watershed prioritization.

ii. Study of the reservoir siltation itself. 
Watershed prioritization is the process of ranking different micro watersheds of the main watershed according to the order in which they have to be taken up for development.

Holistic integrated planning involving remote sensing, and it was found that (GIS) to be effective in planning on watershed approach $[69,70]$.

In the above mentioned study, the drainage network and contours of the study area were converted into digital formats based on topographical maps (1:50,000 scale) obtained from the Survey of India as mentioned, and for drainage networking and development of a digital elevation model (DEM), the GIS software (ILWIS) "abbreviated from; Integrated Land and Water Information System"- was used. (ILWIS) has the capabilities to integrate image processing, tabular databases, and conventional GIS characteristics [71].

The reservoir catchment was divided into nine sub-basins based on the drainage network. The two parameters considered were: (i) the greenness index, to study the effect of vegetation; and (ii) the brightness index, to study the effect of soil and slope. The function "interpolation from iso-lines in (ILIWS)" was applied to each rasterized contour map to generate the DEM. Using the DEM, the slope for each sub-basin was estimated. For computation of other parameters, such as the greenness and soil brightness indices, tasseled cap transformation [72] in the ERDAS IMAGINE software was then applied [73].

For the quantification of the volume of sediments deposited in the reservoir, the basic information extracted from the satellite data are the reservoir surface areas at different water surface elevations. With the deposition of sediment in submerged areas of the reservoir, the area enclosed by an individual contour, at any elevation, decreases. Greater deposition of sediment causes greater decreases in the contour area. Using the synoptic satellite data and image interpretation techniques, the surface area of the reservoir at the instant of satellite overpass is determined. The decremental change in reservoir capacity between two consecutive levels is computed using the prismoidal formula. The overall reduction in capacity between the lowest and the highest observed water levels can be obtained by adding the decremental capacity at various levels. It is important to note that the amount of sediment deposited below the lowest observed level cannot be determined using remote sensing data. It is only possible to calculate the sedimentation rate within the particular zone of the reservoir. Hence, the volume of the reservoir below the lowest observed level is assumed to be the same before and after sedimentation. The study concluded that the average sedimentation rate in the Ramganga dam reservoir assessed using remote sensing for the period $1988-2000$ was $\left(4.28 \times 10^{6} \mathrm{~m}^{3}\right.$ per year). This was in reasonable agreement with the average sedimentation rate calculated from recurrent bathymetric surveys of $\left(4.80 \times 10^{6} \mathrm{~m}^{3}\right.$ per year $)$. As such, the study confirmed that using remote sensing techniques represents an economical as well as a practical alternative to the much more expensive and tedious conventional bathymetric surveys. As result of siltation, the reservoir appears to be losing, on average of $0.15 \%$ of its initial capacity every year; which is within the normal range of loss in similar environments. The watershed prioritization process 
carried out as a first step has helped to identify where land management actions were needed most, and the priorities of the most vulnerable sub-watersheds.

In following studies of reservoir sedimentation, many more assessments were performed of various dams in many other watersheds in India. The results of these studies were summarized and published in 2011 [74].The results of 23 reservoirs studies were presented including new study on Ramganga dam reservoir. The storage capacity of these reservoirs ranged between $195 \times 10^{6}$ to $10,287 \times 10^{6} \mathrm{~m}^{3}$.The sedimentation rates and capacity loss rates were listed in this new study including the new evaluation of Ramganga dam reservoir sedimentation. The study used water levels data and results of sedimentation surveys from 1974- 2001 historic in addition to the data from IRS ID, LISS-III sensors. The results of Ramganga dam reservoir revealed a sedimentation rate of $4.23 \times 10^{6} \mathrm{~m}^{3}$ per year and capacity loss rate of $0.163 \%$ per year; both figures show very close results to those obtained in 2005 which confirm the adequacy of the method and technique used [74].

On the spatially distributed assessment of various sedimentation problems on watershed scale, remote sensing was also used as a powerful tool to assist with other available techniques. In this matter the study on the upper River Citarum Basin in West Java, Indonesia may be mentioned. This study concentrated on the sediment yield and shallow landslide potential area in the upper Citarum River basin which contributed to the silting up of the Saguling dam reservoir located at the outlet of this watershed. The total area of the upper basin is the $2,310 \mathrm{~km}^{2}$ lying between altitudes of 600 and 3,000 m, and comprising 16 main sub-basins. Geographically, the area is located between $107^{\circ} 26^{\prime} \mathrm{E}-107^{\circ} 95^{\prime} \mathrm{E}$ and $6^{\circ} 73^{\prime} \mathrm{S}-7^{\circ} 25^{\prime} \mathrm{S}$. The average gradient derived using a $90 \mathrm{~m}$ resolution DEM ranged from $0.01^{\circ}$ in the central area to $31.15^{\circ}$ in the northern and southern parts, Figure 14 [75].

This basin was recognized as an area with some of the most persistently active landslides in Indonesia. The floods that trigger the landslides occur almost every year and cause extensive damage. The hydrologic response of the basin has been characterized by land degradation resulting from ; floods, debris flows and others landslide types which were very frequent during the rainy season. The soils derived from volcanic tuff are highly erodible and prone to landslides. Hill slope erosion is also a serious problem in this upper area where hillsides are steep. Shallow landsliding, as a form of mass wasting, and surface soil erosion, are the main source of the basin sediment yield. Therefore, there was an urgent need to devise control measures. Within sediment risk and disaster reduction programs, effective control of sediment mobilization requires implementation of Best Management Practices (BMPs) in the critical sediment source areas of the basin.

Numerous studies have indicated that, for many basins, a few critical locations are responsible for a high proportion of the downstream sediment load. Therefore, it is better to implement control and management measures in the most critical internal locations, as identified at the sub-basin scale, which makes it essential to prioritize individual subbasins. Such prioritization involves ranking of the different critical sub-basins of a main basin according to the order in which they should be targeted for the implementation of structural or non-structural control measures. This 
procedure was already mentioned in relation to the case of Ramganga study case.

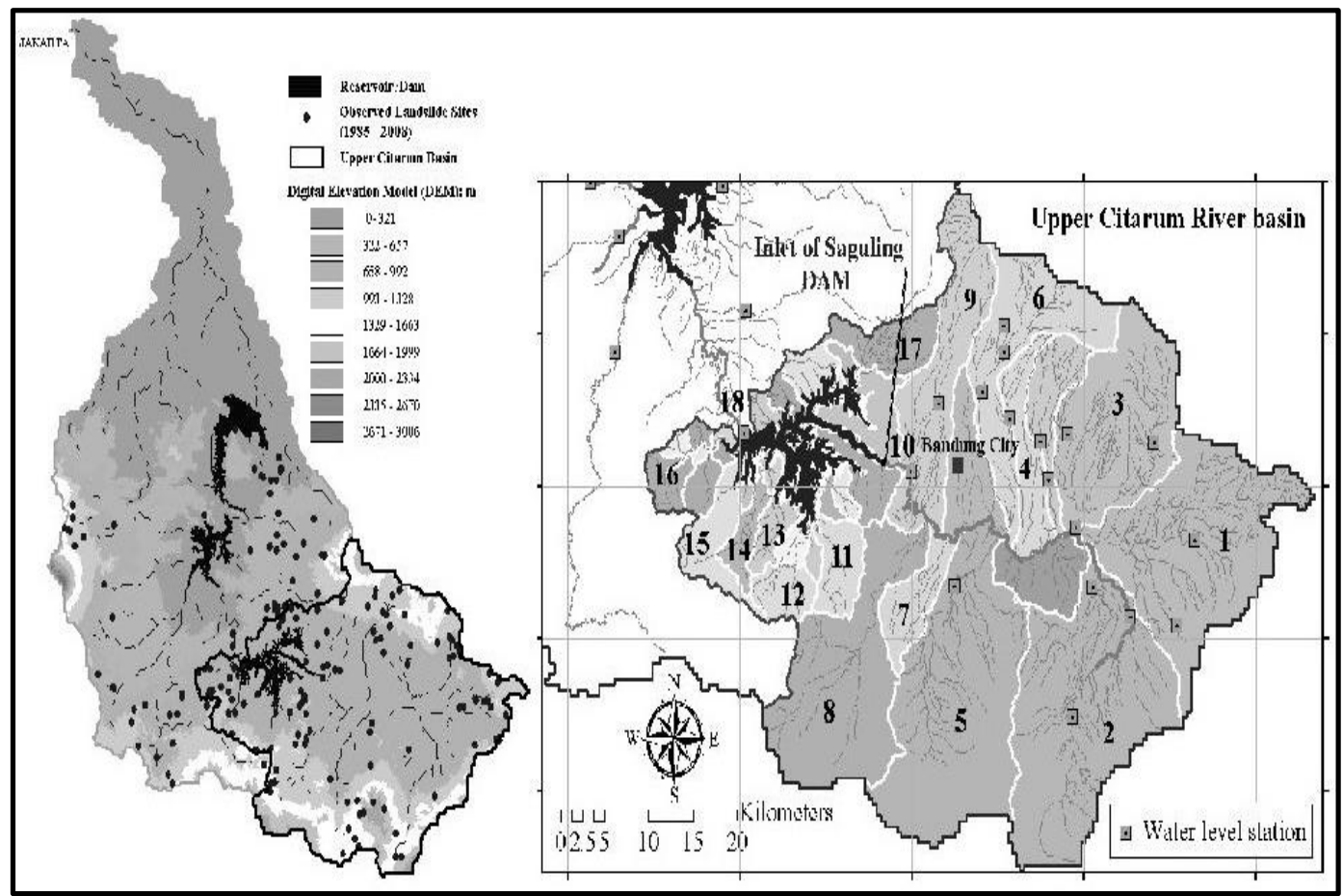

Figure 14: (a) Location of the upper Citarum River basin and the DEM for the whole basin. The filled circles indicate the locations of landslides as recorded by the Geological Agency of Indonesia. (b) Sub-basins boundaries (shown by numbers) and location of water level stations.

The nature of vegetation on the land surface influences both the hydrologic conditions and slope stability. In this study land use information was derived from (LANDSAT7/ETM $\pm 30 \mathrm{~m}$ resolution) satellite images verified by field investigation [76]. A 12-type land-use classification was applied for years 2002 and 2005. Below $800 \mathrm{~m}$, the land use is mainly paddy fields and as settlement areas. At intermediate altitudes and on the steep slopes the land use is mainly farmland (cultivation of annual or tree crops), orchards (perennial trees), forests, grass, and shrubs. Urbanized areas are also found on the steep slopes, although these are relatively small and are concentrated in several small areas which are highly susceptibility to land sliding.

An integrated hydrological-geotechnical model for this assessment was used and it consisted of hill slope hydrology, soil erosion, slope failure, and sediment transport algorithm. Although this model was not named specifically in the study report but we may guess that it could have been the known model called (CRESLIDE)Coupled Routing and Excess Storage and Slope-Infiltration-Distributed Equilibrium- or similar. Evaluation of the hydrological model performance was carried out through calibration and validation of the hydrological response, using 
long-term simulations. Adjustment of the final parameters was undertaken by performing Monte-Carlo-type simulations on the basis of best model performance. The years 2004 and 2005 were selected as the calibration and validation periods. Sediment discharge data from the Nanjung Station was used to calibrate and validate the simulated streamflow discharges. The rainfall records at 17 daily rainfall stations, distributed in and around the basin, were utilized to account for the distribution of rainfall. However, only one recording (hourly) rain gauge was available, and daily rainfall data were disaggregated to hourly values using an approach derived from analysis of the various temporal rainfall patterns of heavy rainfall events at the automatic rain gauge located at the BMG Station. The total number of rainstorm events of different duration during the period 1986-2004 was analyzed. It was found that heavy 4-hour rainfalls represented the highest density of rainfall events. The average temporal distribution pattern of heavy 4-hour rainfalls was used as a simple model for generating hourly rainfall series from a daily rainfall. Then the hourly rainfall values were spatially interpolated. The spatial rainfall distribution in the basin was estimated using the Thiessen polygon method. The interpolated and disaggregated data standardized to a GIS format served as the input for space- and time-varying hydrological model.

The DEM was derived from HydroSHEDS products. HydroSHEDS is a mapping product that provides hydrographic information for regional and global-scale applications in a consistent format. It offers a suite of geo-referenced data sets (vector and raster) at various scales, including river networks, watershed boundaries, drainage directions, and flow accumulations. HydroSHEDS is based on highresolution elevation data obtained during a Space Shuttle flight for NASA's Shuttle Radar Topography Mission (SRTM) [77]. The conclusion of this study was that such physically based distributed hydrological-geotechnical model could accurately simulate streamflow discharges, soil erosion, sediment yield and the spatial pattern of documented historical landslides. All of this will lead to the overall understanding of the erosion-sedimentation pattern and help in adopting the most suited land management procedures.

In countries which depend to large extent on hydropower generation, it is crucial to adopt management tools to reduce sediment inflow to reservoirs of power generating dams for the elongation of the useful operational life. In Brazil for example this is most important; for, although hydroelectricity may represent nearly $25 \%$ of the world's electric power generation, this rate increased to $97 \%$ during the 1990s in this country. In Brazil, the option for a hydroelectric matrix was strongly influenced by the presence of large fluvial systems, such as the Amazon River (north), Paraná River (southeast) and São Francisco River (northeast). The Paraná basin has the largest hydroelectric potential in operation in South America and there are more than 150 large reservoirs for power generation in the Paraná River and its main tributaries. It follows that the monitoring of sedimentation in hydropower dams has to be considered as a priority and innovative solutions must be evaluated to improve the management of existing reservoirs. 
In this case it was most important to use more efficient and cheaper solution to monitor and evaluate sediment trap efficiencies of these reservoirs than assessing load balance at different point along the river system for computing mid to shortterm variations in sediment yield or, repeated bathymetric surveys to calculate the sediment volumes stored at the lakes bottom. Both solutions are extremely time consuming and costly and the protocols used are inhomogeneous. From these considerations and after in-depth studies it was found that optical remote sensing could be efficiently used for such assessments, and a study on the evaluation of using optical remote sensing in this field was published in 2019 [78] which is summarized here.

The optical monitoring of water color or the spectral behavior of water is based on the fact that water color is linked to the presence of optically active components within the water column, and three main components alter the optical properties of water in the visible and infrared wavelength ranges. Significant knowledge had been accumulated on the optical properties of oceanic and continental waters through experimental measurements, modeling approaches and remote sensing methods. Numerous studies have indicated that the red and infrared wavelengths are appropriate for retrieving of the suspended particulate matter (SPM) concentrations. Moreover, It was demonstrated that the optical properties of the main Amazonian rivers were stable enough to support SPM monitoring using satellite data; thus, a unique retrieval algorithm may be used regardless of the river and hydrological period considered within a large catchment.

The use of satellite data for water quality monitoring over open water bodies may be hampered by the spatial, temporal and spectral resolution of the images, which can limit the retrieval capacity of the sensor. Therefore, selecting the correct spaceborne platform is critical and depends on the application. In the case of hydrosedimentary studies, fine temporal resolution monitoring is mandatory because the sediment fluxes vary considerably over time. Thus, spaceborne platforms offering fine revisiting frequency together with fine radiometric calibration and sufficient spectral resolution should be prioritized. Moderate resolution imaging spectroradiometer (MODIS) sensors, have been considered as most appropriate for monitoring (SPM) concentrations in large rivers, such as the Amazon basin. In particular, MODIS is capable of monitoring surface SPM over more than 10 years at different river gauges ( $1 \mathrm{~km}$ wide or larger) and at intermediate to high levels of SPM concentration (10 to $1,000 \mathrm{mg}$ per liter).

The objective of the mentioned study was to evaluate the use of (MODIS) remote sensing data for the synoptic monitoring of sedimentation in a series of hydroelectric dams in southern Brazil. It was aimed to demonstrate that satellite data, through the monitoring of spatial and seasonal turbidity variation in reservoirs, provide consistent estimates of sedimentation in reservoirs. To this end, a 13-year time series of satellite data was processed to calculate turbidity at different points over six different reservoirs on the Paranapanema River, a tributary of Parana River in south east of Brazil, shown in Figure 15.

A reflectance retrieval model was calibrated and validated using two independent 
field turbidity data sets acquired in the catchment. The remote sensing derived turbidity time series retrieved were analyzed as a function of reservoirs' operational characteristics and flow conditions. In particular, the study compared the satellitederived turbidity decrease with the prediction of a sediment trap efficiency model. A methodology based on remote sensing for indirect assessment of sedimentation processes in reservoirs was then proposed.

In this study, moderate resolution imaging spectroradiometer MODIS satellite images were used to quantify the sedimentation processes in the cascade of the six hydropower dams mentioned along a 700-km transect in the Paranapanema River, Figure 15. Turbidity field measurement acquired over 10 years were used to calibrate a turbidity retrieval algorithm based on MODIS surface reflectance products.

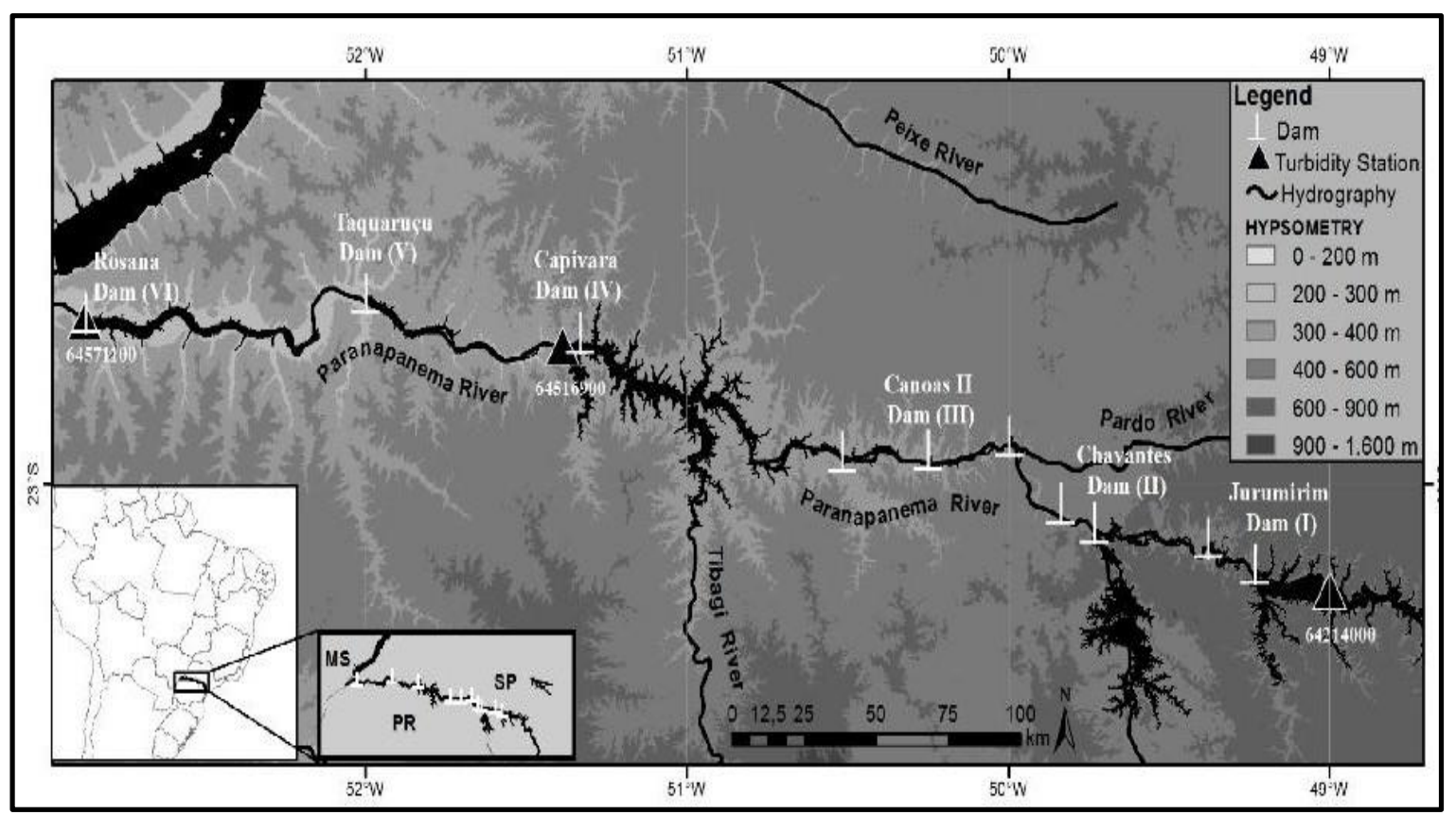

Figure 15: Map of the Paranapanema River catchment showing the location of the hydropower dams (white bars) and turbidity sampling stations (black triangles). The six reservoirs studied are numbered from upstream to downstream (I to VI)[78].

An independent field dataset was used to validate the remote sensing estimates showing fine accuracy (Root Mean Square Error (RMSE) of 9.5 NTU, $r=0.75$, $\mathrm{N}=138$ ). By processing 13 years of MODIS images since 2000, it was shown that satellite data can provide robust turbidity monitoring over the entire transect and can identify extreme sediment discharge events occurring on daily to annual scales. The decrease in the water turbidity as a function of distance within each reservoir, that was related to sedimentation processes was retrieved. The remote sensing- 
retrieved turbidity decrease within the reservoirs ranged from 2 to $62 \%$ making possible to infer the reservoir type and operation (storage versus run-of-river reservoirs).

The reduction in turbidity assessed from space presented a good relationship with conventional sediment trapping efficiency calculations, demonstrating the potential use of this technology for monitoring the intensity of sedimentation processes within reservoirs and at large scale. The study, therefore, fulfilled its objectives and provided more confidence in using remote sensing to assess and monitor sedimentation problems in reservoirs, moreover, it showed the suitability of MODIS for such use.

It is interesting to know that about $0.5 \%$ to $1 \%$ of the total volume of $6,800 \mathrm{~km}^{3}$ of water stored in reservoirs around the world is lost annually as a result of sedimentation. As a result, global per capita reservoir storage has rapidly decreased since its peak at about 1980. Current storage is equivalent to levels that existed nearly 60 years ago. Loss of reservoir storage reduces flexibility in generation and affects the reliability of water supply. Without storage, hydropower facilities are entirely dependent on seasonal flows. These flows might not occur when energy is needed, eliminating one of the key benefits that hydropower provides over other renewables. Sediments discharged from an upstream dam in a cascade system can increase tailwater levels, reducing power generation. This would impact the generation potential of all plants in the cascade and increase the possibility of powerhouse flooding [79].

Many more studies, using remote sensing, have been performed on worldwide scale concerning sediment assessments of individual reservoirs without referring this to erosion in the catchment, such as the Ujjani Dam reservoir study (2017) [80]. This reservoir is located on the Bhima River, a tributary of the Krishna River in Maharashtra state in India. The dam is a combined Earthfill- Masonry Gravity Dam which is the terminal dam on the river and is the largest in the valley. It intercepts a catchment area of $14,858 \mathrm{~km}^{2}$ which includes a free catchment of $9,766 \mathrm{~km}^{2}$.The construction of the dam project including the canal system on both banks was started in 1969 and completed in June 1980. The reservoir created by the dam had a water spread area of $357 \mathrm{~km}^{2}$ at the High Flood Level (HFL) and $336.5 \mathrm{~km}^{2}$ at Full Reservoir Operation Level causing submergence of land and houses in 82 villages. The reservoir stretches upstream of the dam to a length of $134 \mathrm{~km}$, and the maximum width of the reservoir is $8 \mathrm{~km}$. In the mentioned study, (LANDSAT-7) satellite data (resolution $30 \mathrm{~m}$ ) was obtained for the four cloud free dates of water year 20012002 from USGS website i.e. www.usgs.gov.

Digital analysis was performed for identifying the water pixels and for determining the water spread areas. In order for the determination of capacity of the reservoir, reduced levels or water levels were acquired for above four dates from Bhima Irrigation Division, Solapur Maharashtra.

Water Spread areas were found for the four dates from LANDSAT-7 satellite runs for 27 Oct 2001, 15 Jan 2002, 4 March 2002, 8 June 2002. These were respectively $207.06,189.69,178.7,137.71 \mathrm{~km}^{2}$. The original total design capacity of the 
reservoir at RL 493.36 was found from the design documentation to be 717.182 million cubic meters, and the reservoir capacity obtained by using Remote Sensing at RL 493.36 in year 2001-2002 was found out to be 509.36 million cubic meters which indicated and annual capacity loss 9.89 million cubic meters during the period of 21 years from 1980 to 2002.

This was judged to be a very high rate of sedimentation which caused concern, so the study called for taking corrective measures in the catchment area to reduce input of silt in the reservoir. One remark on this study is its failure to mention the specification of the sensor on Landsat 7, which was in fact the Enhanced Thematic Mapper Plus (ETM+). Landsat 7 itself was launched on 15 April 1999 and it was designed to last for five years. It had the capacity to collect and transmit up to 532 images per day. It was in a polar, sun-synchronous orbit, meaning it scanned across the entire Earth's surface. With an altitude of $705 \mathrm{~km}$, it took 232 orbits, or 16 days to cove the whole surface of the Earth [81]. More of such studies were carried out in recent years on the use of remote sensing on the assessment of sedimentation of dams reservoirs. Mentioning only two of them as examples we can refer the readers to the study case of Murrumsilli dam reservoir sedimentation (2017) [82], and the Patratu Dam reservoir study (2016)[83].

\section{Water Quality Monitoring by Satellite Remote Sensing}

Water quality is the general term used to describe the physical, chemical, thermal and biological characteristics of water e.g., temperature, chlorophyll content, turbidity, clarity, Total Suspended Solids (TSS), nutrients, Colored Dissolved Organic Matter (CDOM), dissolved oxygen, pH, Biological Oxygen Demand (BOD), Chemical Oxygen Demand (COD), total organic carbon, and bacteria content. Conventional methods for monitoring water quality parameters by taking in-situ measurement and conducting laboratory analysis are very elaborate, and time consuming. These methods are generally less capable of providing temporal and spatial coverage necessary for the accurate assessment in large water bodies. On the contrary, remote sensing is an effective tool for synoptic monitoring of ecosystem health. Even a few images are useful as aids in the design or improvement of point sampling programs, often through highlighting the best locations and timing for sampling [84].

Application of the remote sensing techniques, due to their capability to provide better spatial and temporal sampling frequencies are gaining importance in the water quality assessment [85]. Figure 16 shows the chlorophyll concentration in the offcoast of California using observation from the SeaWiFS and MODIS sensors. SeaWiFS stand for "Sea-Viewing Wide Field-of-View Sensor" which was a satellite-borne sensor designed to collect global ocean biological data that was active from September 1997 to December 2010, its primary mission was to quantify chlorophyll produced by marine phytoplankton [86]. 


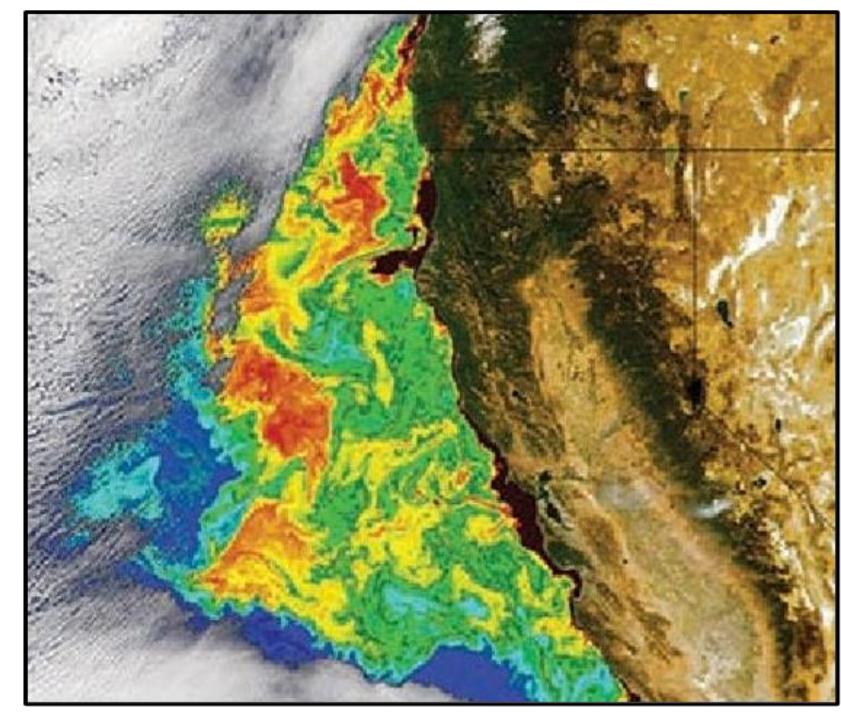

\section{Figure 16: Chlorophyll concentration in the off-coast of California estimated using the SeaWiFS and MODIS sensors. Bright reds indicate high concentrations and blues indicate low concentrations sources [85].}

In remote sensing, water quality parameters are estimated by measuring changes in the optical properties of water caused by the presence of the contaminants. Therefore, optical remote sensing has been commonly used for estimating the water quality parameters. Water quality parameters that have been successfully extracted using remote sensing techniques include chlorophyll content, turbidity, secchi depth, total suspended solids, colored dissolved organic matter and tripton. In addition, thermal remote sensing methods have been widely used to estimate the water surface temperature in lakes and estuaries. In remote sensing, optimum wavelength to be used for measuring the water quality parameters depends on the substance that is measured. Based on several in-situ analyses, the visible and near-infrared radiation portions of the EMR spectrum with wavelengths ranging from 0.7 to 0.8 $\mu \mathrm{m}$ were found to be the most useful bands for monitoring suspended sediments in water. Optical properties of water measured using remote sensing techniques are then converted into the water quality indices by using empirical relationships, radiative transfer functions or physical models.

The USBR has been aware of remote sensing applications for very long time, being responsible for managing, developing, and protecting water resources and having particular interest in understanding water characteristics of inland water bodies such as lakes and reservoir. The Bureau has published many reports on the subject including (Remote Sensing Technology: Guidelines and Applications within the Bureau of Reclamation) [87]. This publication explains its use of (Landsat) images for solving water management problems. In the chapter on "Water Studies" it states that the use (Landsat) series could and had been used for studies of some of the properties of water bodies. For illustration purposes, portions of a scene from 2 July 
1989, near the Wind River Range in Wyoming, was presented as shown in Figure 17 [87]. At the time, Landsat in orbit was Landsat 5 [88], and it carried same instruments as Landsat 4 did, including the Thematic Mapper and Multi-Spectral Scanner (TM) [89]. The bands were not surface calibrated but served as proxies for the properties. There were several lakes on the southwestern side of the mountain range presented for study that received meltwater from the snow-capped mountains. TM band 6 gave the surface temperature of the scene; dark was cold and bright was warm. Figure 17 had been colorized over the narrow temperature range of the lakes such that each digital number had a different color, with blue being coldest, red being warmer, then magenta and purple being warmest. The land areas were warmer than the water. In Figure 17 the snow pack was in the upper right and was much darker but with colored edges, indicating that the colored temperatures were close to the melting value. As for the lakes, each lake had a different pattern. The two at higher elevations were cold (light blue). Two have significant temperature patterns within the lake. Notice also that the irrigated agricultural fields in the lower left were cooler (darker) than the barren land.

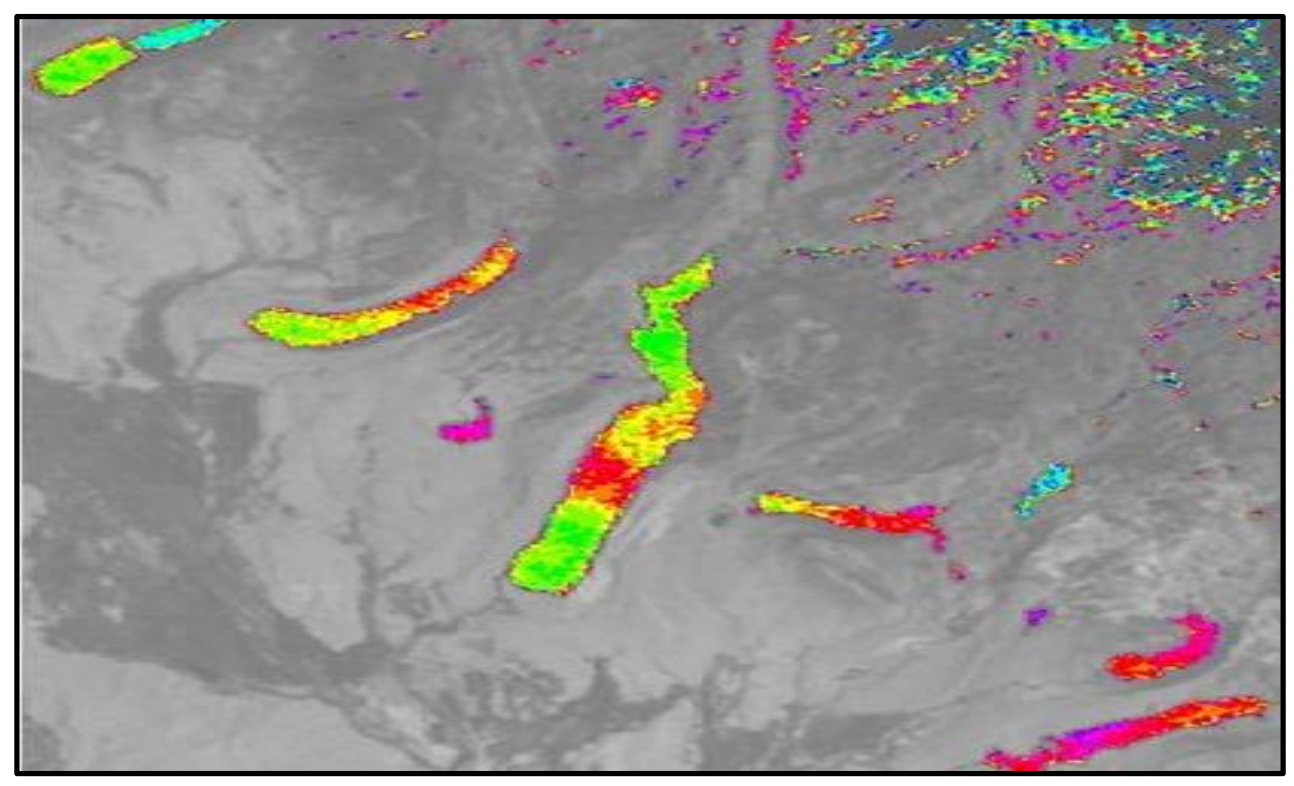

Figure 17: Colorized according to surface temperature [87].

Another area, to the northeast of the Wind River Range, WY, Figure 18 was also selected for further study. The main feature is Ocean Lake, surrounded by an agricultural area with water distribution canals. The natural color version in Figure 18 showed a lightly blue colored lake, suggesting fine sediments from a glacial source in the mountains. This scene was used as a base map for the next views, in which water bodies were colorized to show other water properties. 


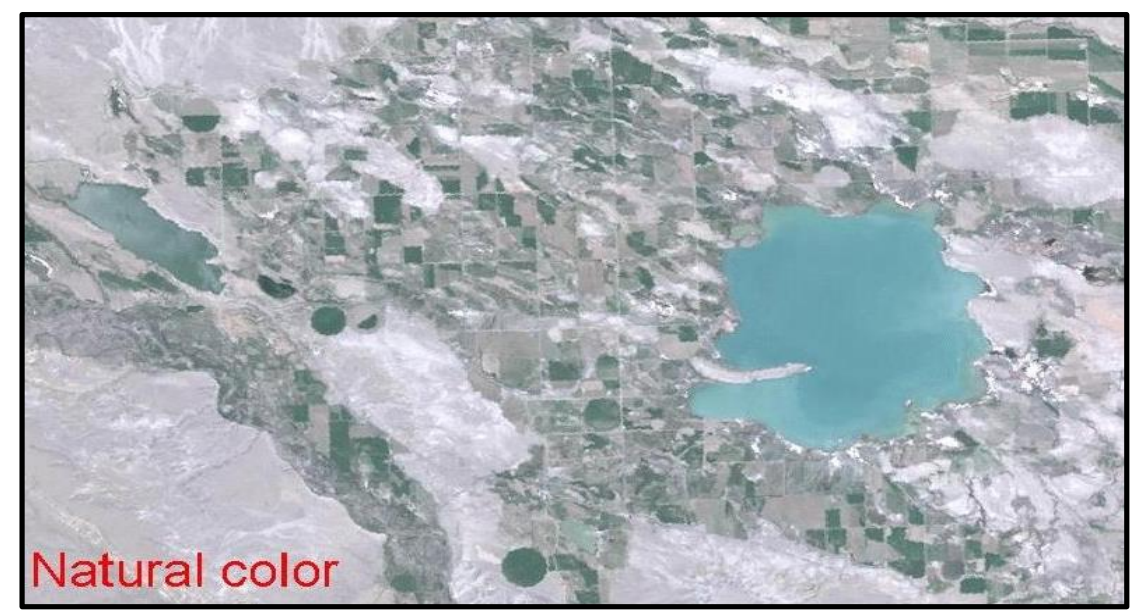

Figure 18: A natural color version of the Ocean Lak, WY [87].

The uncalibrated temperature patterns (TM band 6) showed little variation across the lakes in Figure 19. The western lake was the coldest. The two largest lakes showed warmer (greenish) shorelines, probably because the shallow water let the satellite see to the bottom sediments which are easily warmed by the sun. Along the upper left was a canal with very warm (red) water. The river in the lower left was cooler (green).

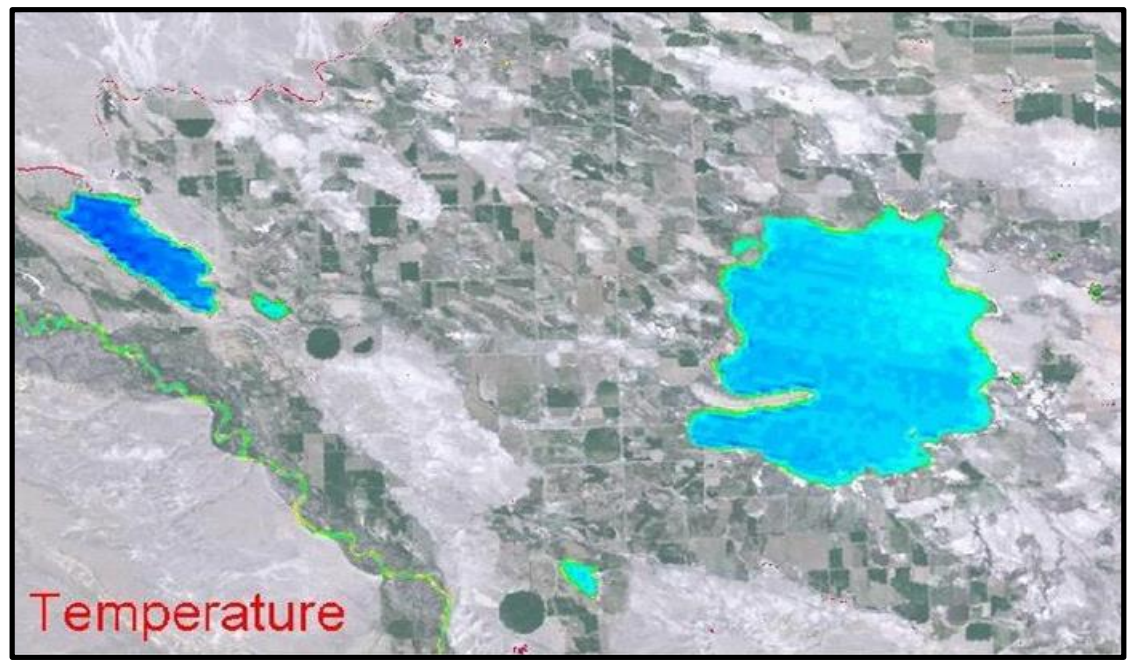

Figure 19: The Ocean Lake scene with water colorized by temperature [87].

Band 1 (blue) was chosen as a proxy for turbidity. The Larger Ocean Lake shows strong patterns as in Figure 20, with red indicating the greatest mud content. There was a small pond at the left that had the cleanest (blue) water. The upper left canal was muddy (reds and oranges) and the lowest river is intermediate (greens). A proper calibration would require field observations of secchi depths; i.e. the depth to which a white disk can be seen in the water. 


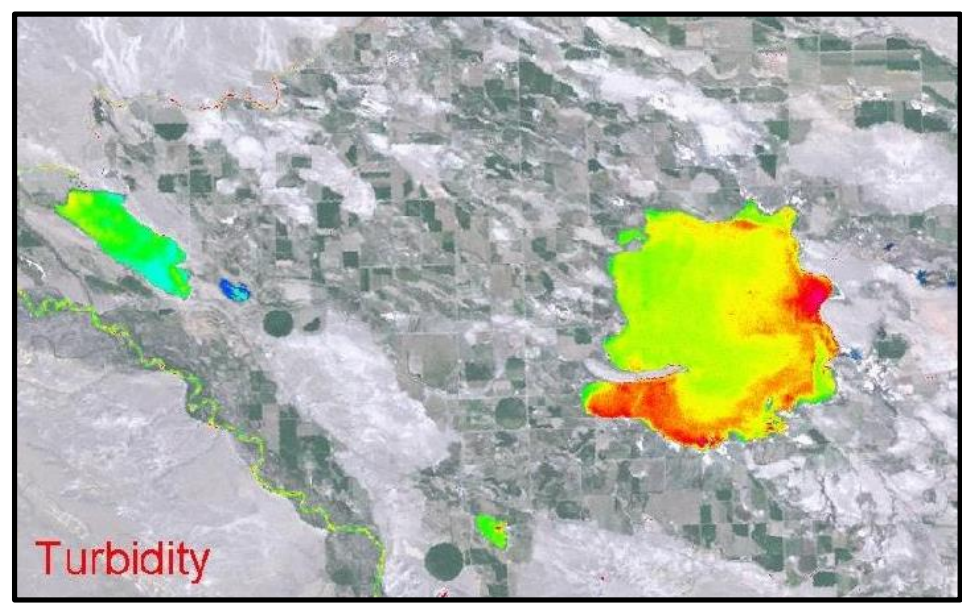

Figure 20: The Ocean Lake scene with water colorized by turbidity [87].

Bands 4 (near-IR) and 3 (red) were combined as a normalized difference vegetative index. This index is greatest for growing vegetation. Though darkened by the water, it serves in Figure 21 as a proxy for chlorophyll content. Reds (small western pond, lower left river) indicate the greater amounts of growth while greens indicate lesser amounts. A proper calibration for chlorophyll makes a regression analysis among the TM bands.

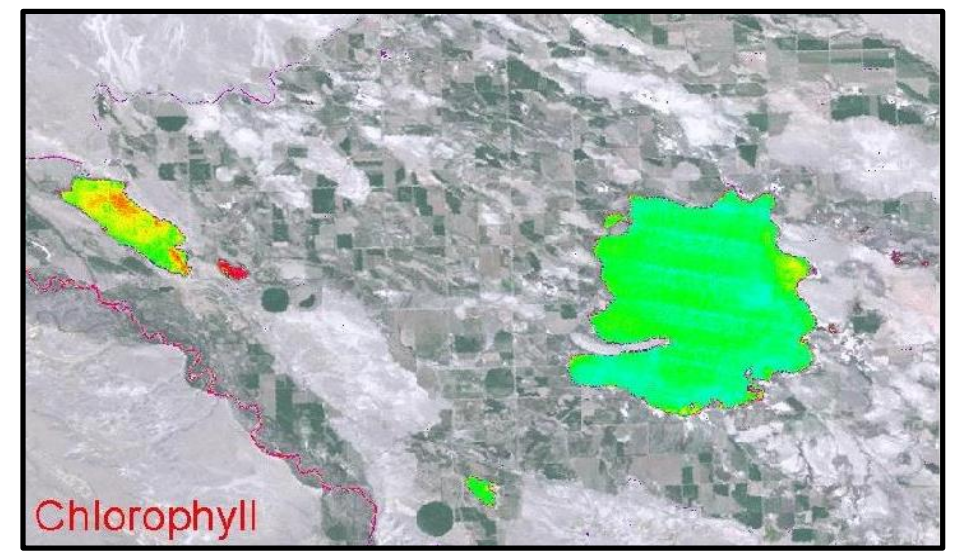

Figure 21: The Ocean Lake scene with water colonized by chlorophyll content [87].

All six reflective TM bands (not band 6) can be combined in a "tasseled cap" analysis to create three mathematically orthogonal bands labeled: Brightness, Greenness, and Wetness. For the Ocean Lake scene in Figure 22 these products are displayed as R, G, and B, respectively. Only a few fields showed a wetness signal. Growing vegetation had variable greenness. Barren areas had the strongest brightness. 


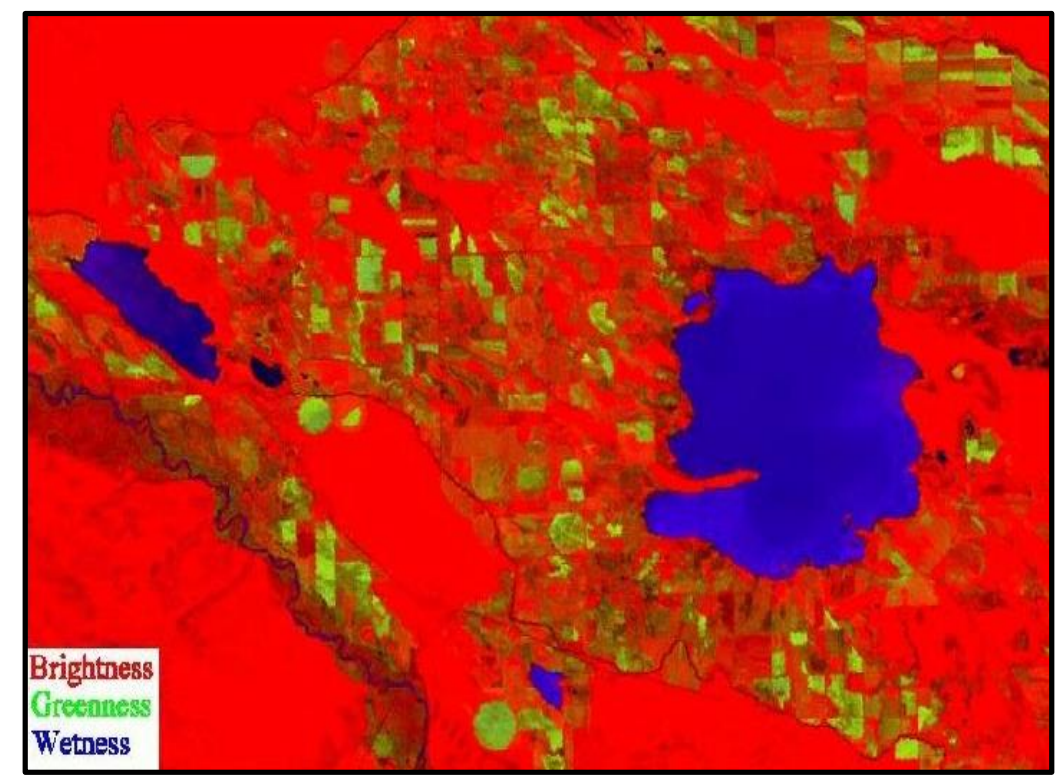

\section{Figure 22: The Ocean Lake scene with false color rendition of brightness, greenness, and wetness [87].}

The preceding information serve only as an introduction to the techniques in water quality observations by spaceborne remote sensing as used by USBR in 2005. But since then there has been great developments in these applications coupled by remarkable progress in space technology.

One review of the research trends in the use of remote sensing that was published in January 2020 explores the progression of inland water quality remote sensing from methodological development to scientific applications; this was based on the examination of 236 key research papers. The results highlight an initial 30 year period where the majority of publications focused on model development and validation, followed by a spike in publications beginning in the early-2000s applying remote sensing models to analyze spatiotemporal trends, drivers, and impacts of changing water quality on ecosystems and human populations. Recent and emerging resources, including improved data availability and enhanced processing platforms, are enabling researchers now to address challenging science questions and model spatiotemporally explicit patterns in water quality.

Examination of the literature shows that the past 10-15 years have brought about a focal shift within the field, where researchers are using improved computing resources, datasets, and operational remote sensing algorithms to better understand complex inland water systems. Future satellite missions promise to continue these improvements by providing observational continuity with spatial/spectral resolutions ideal for inland waters [90].

One of the remote sensing applications, which has been used for long time and has become popular in recent years, is the observation of water quality in water bodies where eutrophication has been one of the most common problems facing the health 
of lakes and reservoirs. Eutrophication is rapidly increasing due to excessive discharge of nutrient-rich effluents originating from industry and agriculture in basin areas which is primarily causing the production of Chlorophyll-a. This is a specific form of chlorophyll used in oxygenic photosynthesis which absorbs most energy from wavelengths of violet-blue and orange-red light. It also reflects greenyellow light, and as such contributes to the observed green color of most plants [91]. Remote sensing models estimate chlorophyll concentrations by correlating spectral reflectance and reservoir chlorophyll. Different algal populations have different spectral signatures and thus different correlation models; an issue addressed typically by developing and applying models using the same satellite image. The population differences can be exploited by developing seasonal models which can be applied to other images from that season. Algal succession and the assumption that the phytoplankton population is relatively constant over a season are relied upon. In this context, a specific study, authored by Hansen and others, published in 2019 shows how this was applied by dividing the growth season into three parts as substitutes for population measurements. In previous works the same authors had developed seasonal models for Deer Creek and Jordanelle dams reservoirs in Utah (USA) by using Landsat-5 and Landsat-7 reflectance measurements, but in the present study the previous work was generalized by demonstrating regional application using models developed with a more extensive dataset. The authors show how this approach can be used to develop a long-term record of water quality in several reservoirs from available historic (Landsat) data. They used data from the two reservoirs to develop seasonal models, then applied these models to similar regional reservoirs without sufficient field data for model development. Because the seasonal models can be applied to other satellite collections that occurred in the same season, this approach supports chlorophyll estimates to define long-term seasonal trends, provides frequent updates on reservoir conditions, supports comparison among reservoirs, and may be used for short-term forecasting [92].

The sampling locations for Deer Creek and Jordanelle reservoirs (green dots) used for the study are shown in Figure 23. Landsat image from 14 July 2014 shows the five study reservoirs in Utah; this is presented in Figure 24. Deer Creek Reservoir is located on the Provo River and supplies potable water for much of the Salt Lake City valley. The reservoir has a surface area of 1200 ha. with a capacity of about 240 million $\mathrm{m}^{3}$ and a maximum depth of $42 \mathrm{~m}$ near the dam. Deer Creek Reservoir was identified as highly eutrophic in the 1970s and 1980s and continues to exhibit high phosphorus and low dissolved oxygen levels during the summer. Jordanelle Reservoir is a large reservoir with surface area of about 1335 ha. and feeds into Deer Creek Reservoir. It has a capacity of approximately 445 million $\mathrm{m}^{3}$ and a maximum depth of $89 \mathrm{~m}$. The dam was completed and the reservoir completely filled in 1994 . The other three reservoirs to which the results of the study were extended were:

i. East Canyon Reservoir; a 276 ha reservoir located behind the Wasatch Mountains. It has a capacity of approximately 63 million $\mathrm{m}^{3}$ and a maximum depth of $60 \mathrm{~m}$. The surrounding watershed is relatively dry compared to the other watersheds in the area. One of the main concerns 
for this reservoir is the rapid urbanization and development in the contributing watershed.

ii. Rockport Reservoir; a 481 ha impoundment on the Weber River, with a capacity of 93.4 million $\mathrm{m}^{3}$ and a maximum depth of $45 \mathrm{~m}$. Although the historical water quality of this reservoir has been good, conditions have exceeded standards for phosphorus and dissolved oxygen, issues that are closely related to algal biomass.

iii. Echo Reservoir; also, on the Weber River, located north of Rockport Reservoir. It is comparable to Rockport in size at 564 ha, 91.1 million $\mathrm{m}^{3}$ in capacity, and a maximum depth of $33.5 \mathrm{~m}$, (Figure 24).

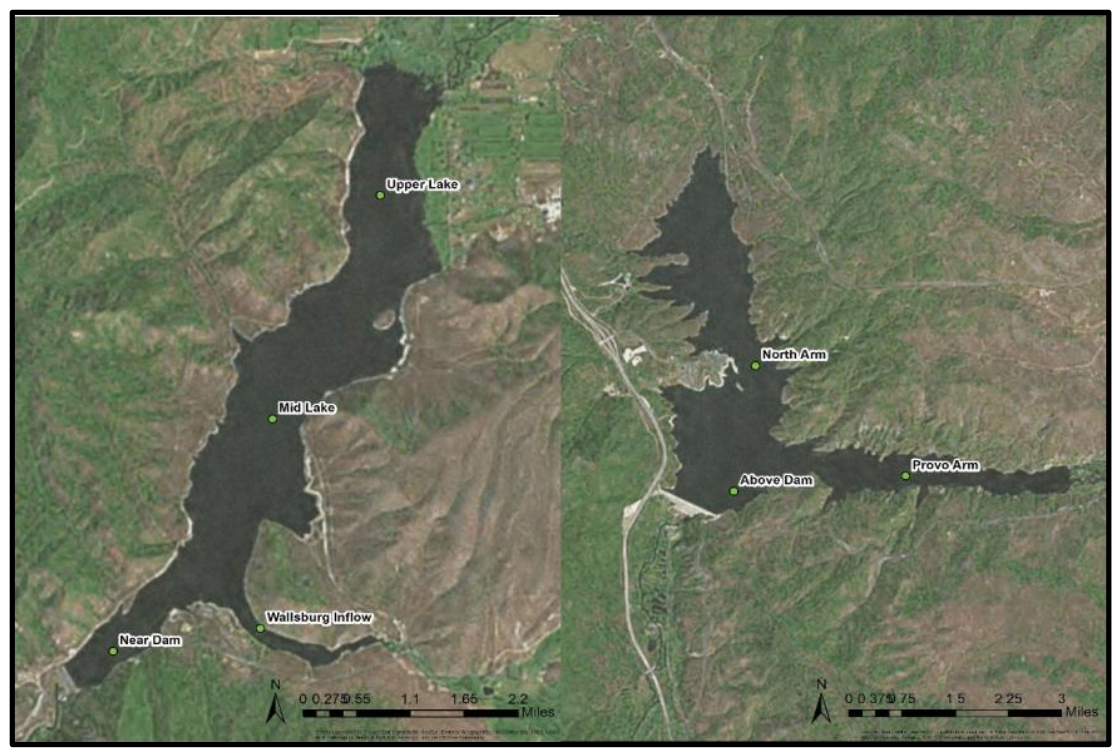

Figure 23: Sampling locations (green dots) for Deer Creek and Jordanelle Reservoirs [92]. 


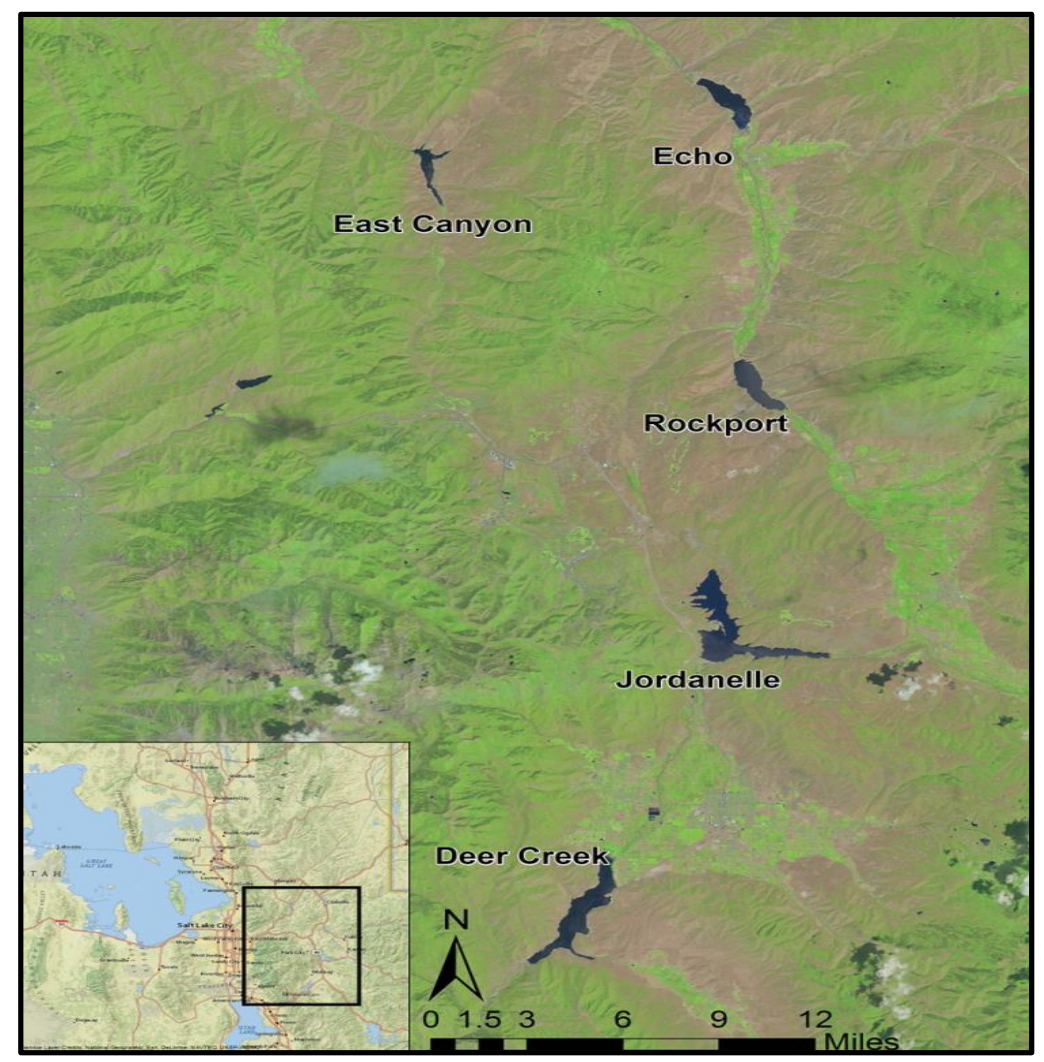

Figure 24: Landsat image from 14 July 2014 showing the 5 study reservoirs in Utah [92].

The methodology used in the analysis was to follow a stepwise procedure by first collecting the archived data for the first two dams for the years from 1984-2012 for Deer Creek reservoir, and from 1993-2012 for Jordanelle reservoir. These data had been collected by Landsat 5-TM mapper for the year 1984- 1999 and Landsat 7ETM + for the years 1999-2012. The seasons were split into three periods, each one according to the relative similar phytoplankton communities present in the reservoirs. Phytoplankton is defined as a flora of freely floating, often minute organisms that drift with water currents. These periods were April- May, June- July, August- September. Following this, the Landsat images were radiometrically calibrated and atmospherically corrected by selecting a group of 9 pixels centered on each field sample location and computing a mean filtered average reflectance for bands 1-5 and 7. This procedure was meant to remove noise. Models development for each of the two reservoirs for the three periods was done using multiple least square approach in which a model form is selected from a least square fit to determine model coefficients, and for that a combination of Landsat bands 1, 2, 3 and 4 were used. For Models application, the ENVI, v4.7-(Exelis Visual Information Solutions, Boulder, $\mathrm{CO}$ was used as the base software platform for applying the models to historical images. The validation of the procedure was done by using the models obtained for each of the three periods for Deer Creek and 
applying them to corresponding period in another season and comparing the results with field measurements. The results showed good agreements between models of the same periods of different seasons, but when an all-season model was developed for this reservoir, this model showed poor agreement with field measurements for early and mid-season data, and the fit was better for the late season data, although still not as close as the season specific model.

These results confirmed the suitability of the obtained Periods Models, but not the All-Season Model to application on all other reservoirs with the possibilities of forecasting conditions from just referring them to satellites images that would be taken in future dates.

For the five reservoirs used in this case study, it was observed that each of them demonstrated unique behavior, both historically and within the growing season. Managers can use this knowledge to identify which reservoirs require additional monitoring or mitigation efforts. Because the Landsat data provide full spatial coverage, they may better identify which areas of a reservoir should be targeted for field sampling.

Generally, while estimated concentrations using this approach may not be precise, changes in concentration over time and spatial distributions are relatively accurate, implying that even reservoirs without field data can be monitored as long as the optical characteristics of the reservoirs are similar.

In similar study performed in 2019, it was established that monitoring water quality of small water bodies can be done using High-Resolution Remote sensing data. The study was conducted on the Bora-bey dam reservoir in Turkey [93].

Water quality in this relatively small dam was assessed using high-resolution satellite data from RapidEye and in situ measurements collected a few days apart. RapidEye-AG was a German geospatial information provider focused on assisting in management decision-making through services based on their own Earth observation imagery. The company operated a five-satellite constellation producing 5 -meter resolution imagery. Today, RapidEye refers to the constellation of 5 earth observation satellites owned and operated by Planet Labs [94].

The satellite carries a five-band multispectral optical imager with a ground sampling distance of $5 \mathrm{~m}$ at its nadir and a swath width of $80 \mathrm{~km}$. Several different algorithms were evaluated in the study using Pearson Correlation Coefficients for electrical conductivity (EC), total dissolved salts (TDS), water transparency, water turbidity, depth, suspended particular matter (SPM), and chlorophyll-a. The results indicated strong correlation between the investigated parameters and (RapidEye) reflectance, especially in the red and red-edge portion with highest correlation between red-edge band and water turbidity $\left(R^{2}=0.92\right)$. Two of the investigated indices showed good correlation in almost all of the water quality parameters with correlation higher than 0.80 . The findings of this study emphasized the use of both high-resolution remote sensing imagery and red-edge portion of the electromagnetic spectrum for monitoring several water quality parameters in small water area.

It may be concluded that available procedures coupled with available previous and future satellite images can present wide applications on monitoring reservoirs, 
inlands lakes, and open seas water quality issues. In reservoirs and lakes problems like turbidity, salinity, eutrophication, contamination with tailings and sewerage can be investigated by following variations in Water Quality indices. For open seas, the same can be done in addition to such things as following oil spills impacts, changes in coral reefs and fish habitats and all sorts of changes in the hydro ecosystems. This can be done by using proper satellite images and developing the procedures and models applicable to the intended use. The future will certainly bring new satellites technological innovations. Looking just a little ahead launching Landsat 9 in mid2021 will open new horizons in this field. Landsat 9, like Landsat 8, will have a higher imaging capacity than past Landsat satellites, allowing more valuable data to be added to the Landsat's global land archive [95].

\section{Assessment of Reservoir Evaporation Losses by Remote Sensing}

Evaporation from open water surfaces is a major element and continuous process in the global hydrological cycle. With respect to reservoirs, quantities of water lost to evaporation have to be accounted for in the water management of each reservoir as an unredeemed loss. On a world scale these losses are estimated to be more than the combined consumption from industrial and domestic water uses. For example, the evaporation from agricultural irrigation reservoirs in a semiarid basin in Spain is equivalent to $27 \%$ of the total domestic water use in this basin [96]. It is estimated that half of water stored in Australia's reservoirs is lost due to evaporation [97]. Accurate estimation of evaporation losses are, therefore, very important to the evaluation of available water resources of a given basin, region or even individual reservoirs. No continental consistent and locally practical evaporation dataset have been produced so far that can be used in the policy making process at a regional scale. To precisely quantify the evaporation losses from a given reservoir, water surface area and evaporation rate data are needed. However, both high quality reservoir surface area and evaporation rate data can be difficult to gather [98]. Regarding evaporation rate, a variety of methods are available, ranging from localscale approaches such as the use of eddy covariance tower and scintillometer to regional-scale energy balance methods that are based on water surface temperature $[99,100,101]$.

Nevertheless, the use of evaporation pans remains the most popular method for water resource managers despite its sensitivity to local weather and landscape conditions.

Regarding reservoir area, which is a controlling factor, the reservoir area-elevation curve is a widely-accepted approach to estimate the fluctuation of reservoir area. However, reservoir curves could be unavailable if the reservoir is in a data-sparse region, or questionable if long-term sedimentation has changed the original elevation-area relationship. The error in reservoir area estimates is largely neglected in analyzing the uncertainties of reservoir evaporation.

Research in the Satellite Sensing applications to the estimation of evaporation losses 
is still in its early beginnings. Researchers in recent years have become interested in the use of remote sensing products as a direct mean in the assessment of evaporation losses from lakes and reservoirs, but much is still needed to be done before generalizing their use. One group explored the wide use of the satellitederived MODIS dataset in studies on evapotranspiration, but this study does not cover rivers, lakes, reservoirs, and wetlands [102].The study was designed to describe evapotranspiration from vegetated land surfaces and its input includes Leaf Area Index, which is not applicable for water bodies.

Another study, however, demonstrated the possible use of MODIS as a good tool for evaporation losses assessment [103]. The study obtained the seasonal variation in evaporation for the five major lakes in the Savannah River Basin (in South Carolina, USA). These were; Lakes Jocassee, Keowee, Hartwell, Russell, and Thurmond. The Savannah River Basin (SRB) originates in the Blue Ridge Mountains of Georgia, North Carolina, and South Carolina. The basin has a total drainage area of $27,400 \mathrm{~km}^{2}$, of which $11,900 \mathrm{~km}^{2}$ are in South Carolina, 15,100 $\mathrm{km}^{2}$ are in Georgia, and $453 \mathrm{~km}^{2}$ are in North Carolina. The basin serves as a major water source for more than 1.5 million people within Georgia, South Carolina, and North Carolina as well as possessing a total power generating capacity of approximately 10,661 MW for residential and commercial use. A significant part of the upper Savannah River is controlled by the United States Army Corps of Engineers which operates three multipurpose reservoirs: Lakes Hartwell, Russell, and Thurmond. Duke Energy Company has constructed three additional reservoirs above Lake Hartwell as part of its Keowee-Toxaway project: these are Bad Creek Reservoir (a small pumped storage reservoir located above Lake Jocassee), Lake Jocassee, and Lake Keowee. Full pool elevations of Bad Creek, Jocassee, Keowee, Hartwell, Russell, and Thurmond are 704, 338, 244, 201, 145, and 101 (m.a.s.l), respectively. Geometric data for these five reservoirs are presented in Table 3. A map of the basin and its main reservoirs is presented in Figure 25. The volume of Bad Creek Reservoir and a few other small lakes are negligible, compared to the remaining five lakes in the (SRB), and only those five lakes are considered in the study.

Table 3: Geometric information on the five major lakes in the Savannah River Basin [103].

\begin{tabular}{|c|c|c|c|c|c|}
\hline Lake & $\begin{array}{c}\text { Surface } \\
\text { area }\left(\mathbf{k m}^{\mathbf{2}}\right) \\
(\mathbf{a}, \mathbf{c})\end{array}$ & $\begin{array}{c}\text { Mean depth } \\
(\mathbf{m}) \mathbf{( b )}\end{array}$ & $\begin{array}{c}\text { Max } \\
\mathbf{d e p t h}(\mathbf{m}) \\
(\mathbf{b})\end{array}$ & $\begin{array}{c}\text { Shoreline length } \\
(\mathbf{k m})(\mathbf{c})\end{array}$ & $\begin{array}{c}\text { Volume } \\
\left(\mathbf{M m}^{\mathbf{3}}\right) \mathbf{( a , \mathbf { c } )}\end{array}$ \\
\hline Jocassee & 30.6 & 48.1 & 99.4 & 121.0 & 1489 \\
\hline Keowee & 75.0 & 16.0 & 90.5 & 482.8 & 1072 \\
\hline Hartwell & 226.6 & 14.0 & 53.6 & 1548.2 & 3132 \\
\hline Russell & 107.8 & 12.1 & 44.8 & 869.0 & 1262 \\
\hline Thurmond & 283.3 & 11.3 & 43.3 & 1931.2 & 3072 \\
\hline
\end{tabular}

a) Calculated at full pool elevation, b) Data supplied by South Carolina Department of Health and Environmental Control (SCDHEC), c) Data supplied by USACE. 


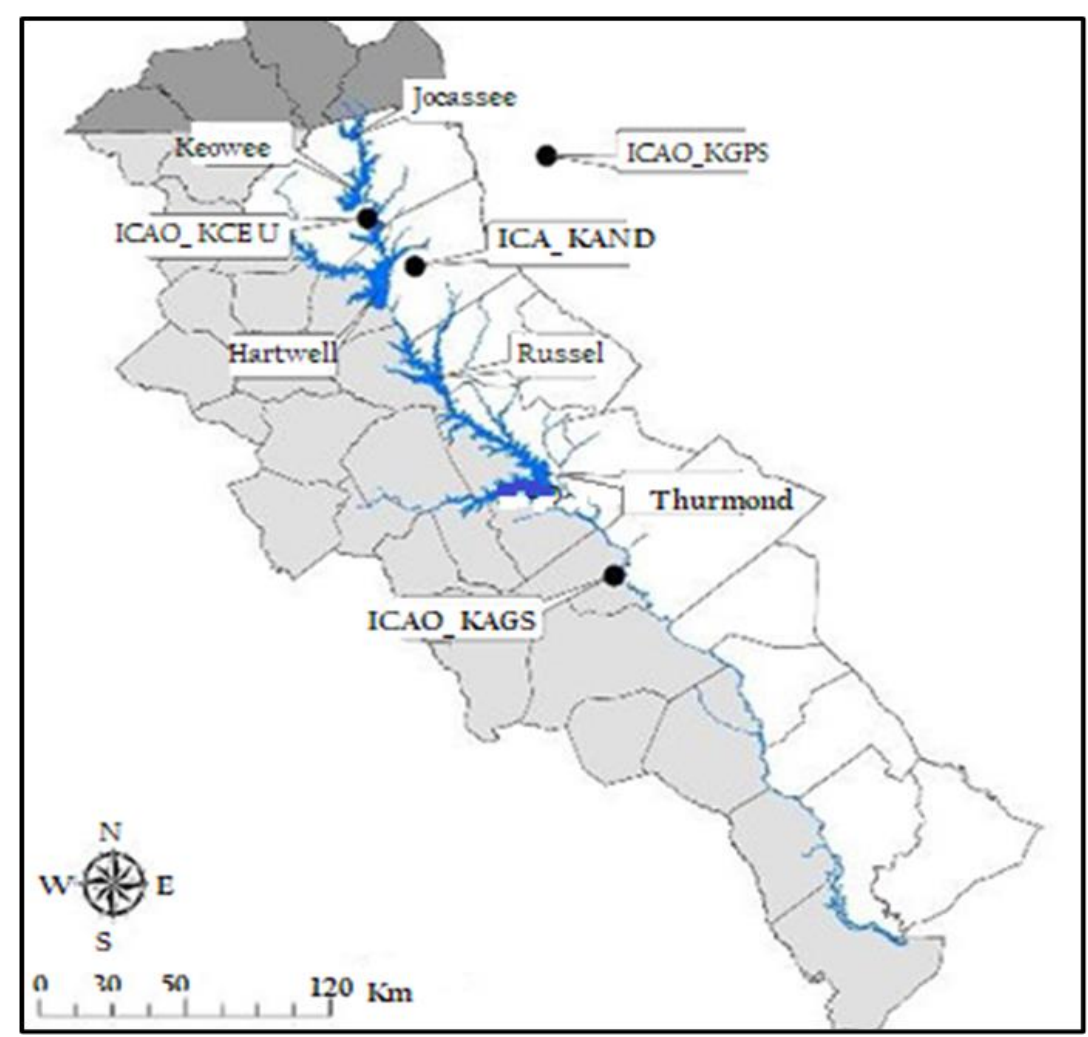

Figure 25: Map of the Savannah River Basin, including major lakes, and nearby regional airport weather Stations (ICAO). North Carolina, South Carolina, and Georgia counties are represented as dark, gray, white and light gray, respectively [103].

The study used data from two sources:

1. Satellite (MODIS) data for obtaining spatially resolved lake surface temperature (Ts) were gathered from MOD11 A1 and MYD11 A1. The Land Surface Temperature (LST) products were generated from MODIS Thermal bands 31 (11 $\mu \mathrm{m})$ and $32(12 \mu \mathrm{m})$. The LST MODIS data was pre-processed to account for atmospheric and surface emissivity effects. Also, a cloud mask was incorporated for inland water estimates, providing a surface temperature measurement when there is a $66 \%$ or greater confidence of clear-sky conditions.

LST were obtained in the form of daily MODIS land surface temperatures, as LST level 3, 1-km nominal resolution data for Terra (MOD11A1, version 5) and Aqua (MYD11A1, version 5). Water Surface Temperature (Ts) data was obtained by combining measurements from the MODIS sensor on NASA's Terra and Aqua satellites [104]. These data were available from the NASA Earth Observing System Data and Information System (EOSDIS) from July 2002 to December 2012.

The LST product is able to provide water surface temperature. Also, the LST from the Aqua and Terra platforms can be intercompared without correction. 
Landsat 7-ETM imagery was used to develop a shoreline mask, which was used to exclude any MODIS LST pixels-containing land. The number of land-free pixels were $6,1,12,3$, and 19 for lakes Jocassee, Keowee, Hartwell, Russell, and Thurmond, respectively. On-site measurements of Ts were not available for the lakes studied, and so validation of the MODIS data used herein was not possible for the lakes studied. However, validation studies of MODIS (Ts) measurements of lake surfaces had been performed by several other authors, which shows the Root Mean Square (RMS) and bias errors between the MODIS measurement and in situ measurement for the lake studied were not significant, suggesting the reliability of this approach.

2. National Weather Service meteorological stations (NWS) supplied the land temperatures measurements $(\mathrm{Ta})$, wind speed $(\overline{\mathrm{u}})$, eddy flux $(\varnothing)$ and relative humidity. These NWS stations were belonging to nearby regional airport weather stations (ICAO) shown in the map of Figure 25. These data were used to obtain a mass transfer coefficient $(\mathrm{hm})$ whereby the evaporation rate $(\mathrm{E})$ can be quantified from the respective equation.

i. The methodology of the study was to compute in two approaches; i- the evaporation rates obtained from Mass Transfer Methods based on (MODIS) obtained data.

ii. ii- to compare the results with those results of evaporation loss rates calculated from Pan Evaporation measurements.

In the first approach the "Harmonic Analysis of Time Series (HANTS)" [104] algorithm was used to get the time series of (hm) from the Temperature Time series. These in their turn were obtained by applying three general Mass Transfer Methods namely; the turbulent boundary layer (TBL) Method, the general aerodynamic (AERO) Method, and the heat transfer (HT) Methods. The Temperature Time Series themselves were based on Ts values from the spatially averaged LST data, and the corresponding hourly $\mathrm{Ta}, \varnothing$, and $\overline{\mathrm{u}}$ measurements from the meteorological station closest to each of the respective lake. The evaporation rates $(\mathrm{hm})$ obtained by the TBL, AERO, and HT methods and HANTS were computed by scaling the hourly net evaporative flux by the water density calculated at Ts so that all methods report evaporation in units of length per unit time. Finally, the four hourly evaporation. In the second approach, several sets of Pan Evaporation measurements were available throughout the Savannah River Basin. However, Pan data from the (Class A) pan located in Clemson, SC was the only available data set with measurements dating back to the development of the Free Water Surface (EWS) grids (1956-1970), as well as covering the period of record for this study. As a result, these daily Pan evaporation data measured in Clemson, South Carolina were used. These were obtained from National Oceanic and Atmospheric Administration (NOAA)'s National Climatic Data Center (NCDC). Based on this, a monthly pan coefficient was developed for each of the lakes within the basin through the use of the Free Water Surface (FWS) evaporation estimates from NOAA's digitized evaporation 
maps and the Pan measurements obtained from the Clemson (Class A) pan.

As stated before the goal of the study was to investigate the seasonal variation in lake evaporation in the SRB using two different methods for measuring evaporation, namely; the three Mass Transfer Methods based on MODIS data and the Pan measurements Method. These methods were used to calculate four monthly averaged evaporation totals for each lake. The data clearly showed a significantly different seasonal behavior between the Pan data and the mass transfer methods. For all five lakes, the Pan data showed a peak in early to midsummer, while the mass transfer methods showed a range of seasonal behaviors, none having a peak in the summer. Most of the lakes showed two peaks in evaporation, one in the spring and one in the fall. The exception was Hartwell, which exhibited a single peak in the fall.

The derived Yearly Lake Evaporation corresponding to MODIS period of record for each mass transfer approach and for Pan evaporation results are shown for each of the five lakes in Figure 26. Water resources managers in the United States seeking to use the approach presented herein, but wanting to have results that provide similar yearly average totals to historical pan measurements, should use the historical MODIS and the Automated climatological observing network in the United States (ASOS) data to establish which mass transfer method best matches their Pan data. For the SRB, this would be either the TBL)or HT methods. Given the absence of absolute ground truth and the known issues with pan measurements, such a comparison should not be taken to indicate which mass transfer method is the best in an absolute sense.

Future research would enable further development of this method. For example, the application of the method described to a more instrumented lake could be used to investigate the impact of using remote sensing data on the resulting evaporation measurements. Measuring the meteorological conditions on the lake shore or lake surface could be used to quantify the potential error associated with using remote weather station data. Likewise, local measurement of lake surface temperature could be used to assess the quality of the MODIS data. These measurements could also be used to validate the use of the HANTS algorithm for filling in missing MODIS data. Comparison with on-lake measurements of evaporation using, for example, an eddy co-variance probe or scintillometer would also better parameterize the remotely sensed evaporation measurements against more direct local measurements. In fact, given the availability of historical data going back to June 2002, this approach could be compared with previously published evaporation studies. 


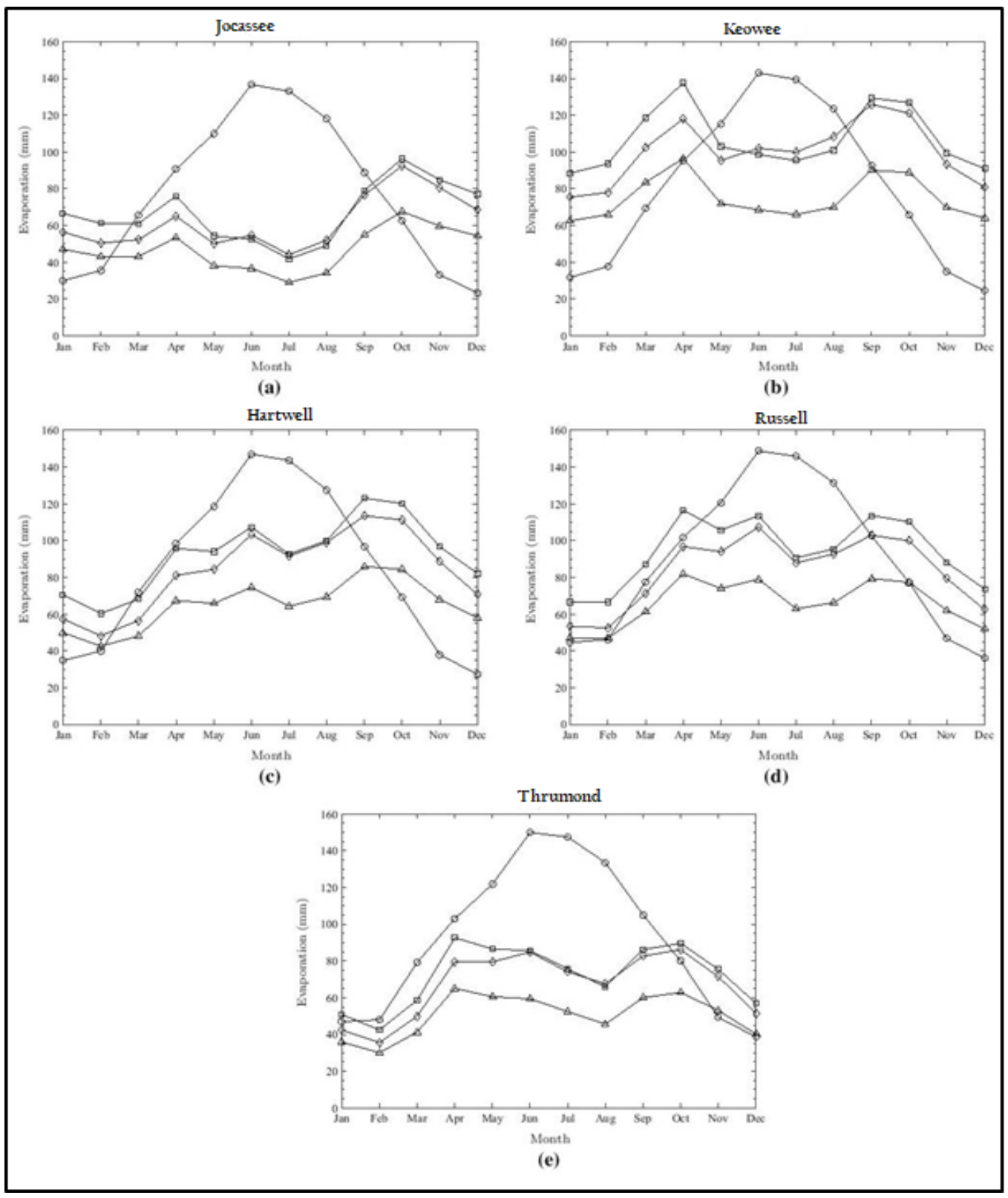

Figure 26: Yearly lake evaporation corresponding to MODIS period of record for TBL (square), AERO (triangle), HT (diamond) and Pan (circle): (a) Jocassee; (b) Keowee; (c) Hartwell; (d) Russell; and (e)Thurmond [103].

The researches claim that since this approach requires only an existing satellite resource with global coverage and existing (NWS) stations, this method can potentially be ported to any lake where there is a nearby meteorology station. Hence, this method could be used by both water resource managers and limnologists alike with the possibility of extending this approach beyond a single basin to encompass an entire geographical region or continent. 
Another study on remote sensing method for estimating regional reservoir area and evaporative loss was published in 2017 [105]. The researches propose a remote sensing framework to estimate reservoir evaporative loss at the regional scale. This framework uses a multispectral water index to extract reservoir area from Landsat imagery and estimate monthly evaporation volume based on pan-derived evaporative rates. The optimal index threshold is determined based on local observations and extended to unobserved locations and periods. Built on the cloud computing capacity of the Google Earth Engine (GEE), this framework can efficiently analyze satellite images at large spatiotemporal scales, where such analysis is infeasible with a single computer. The study involved 200 major reservoirs in Texas, captured in 17,811 Landsat images over a 32-year period Figure 27.

The results show that these reservoirs contribute to an annual evaporative loss of 8.0 billion cubic meters, equivalent to $20 \%$ of their total active storage or $53 \%$ of total annual water use in Texas. At five coastal basins, reservoir evaporative losses exceed the minimum freshwater inflows required to sustain ecosystem health and fishery productivity of the receiving estuaries. Reservoir evaporative loss can be significant enough to counterbalance the positive effects of impounding water and to offset the contribution of water conservation and reuse practices. Our results also reveal the spatially variable performance of the multispectral water index and indicate the limitation of using scene-level cloud cover to screen satellite images. The selected reservoirs are all visible on Landsat imagery with cloud cover below $10 \%$. Their total conservation capacity is 40.9 billion $\mathrm{m}^{3}$ and accounts for $79 \%$ of Texas's total capacity. Monthly evaporation and precipitation rates of reservoirs are obtained from the Texas Water Development Board (TWDB) in one-degree latitude by one-degree longitude quadrangles, Figure 28.The dataset is based on daily precipitation rates measured at 2,400 precipitation stations and daily evaporation rates at 76 pan evaporation stations across Texas (TWDB, 2016). The daily gross pan evaporation rates are first summed into monthly pan evaporation rates at each evaporation station. Then Thiessen polygons are developed based on the locations of all evaporation stations. The quadrangular pan evaporation rate is calculated as the sum of pan evaporation rates of all stations weighted by the areas of their Thiessen polygons in the quadrangle. It is further converted into a quadrangular reservoir evaporation rate by multiplying by pan-to-lake coefficients, which are developed by the National Weather Service at the monthly level and are specific for each quadrangle. The quadrangular precipitation dataset is produced in a similar way except that there is no need for pan-to-lake precipitation coefficients. 


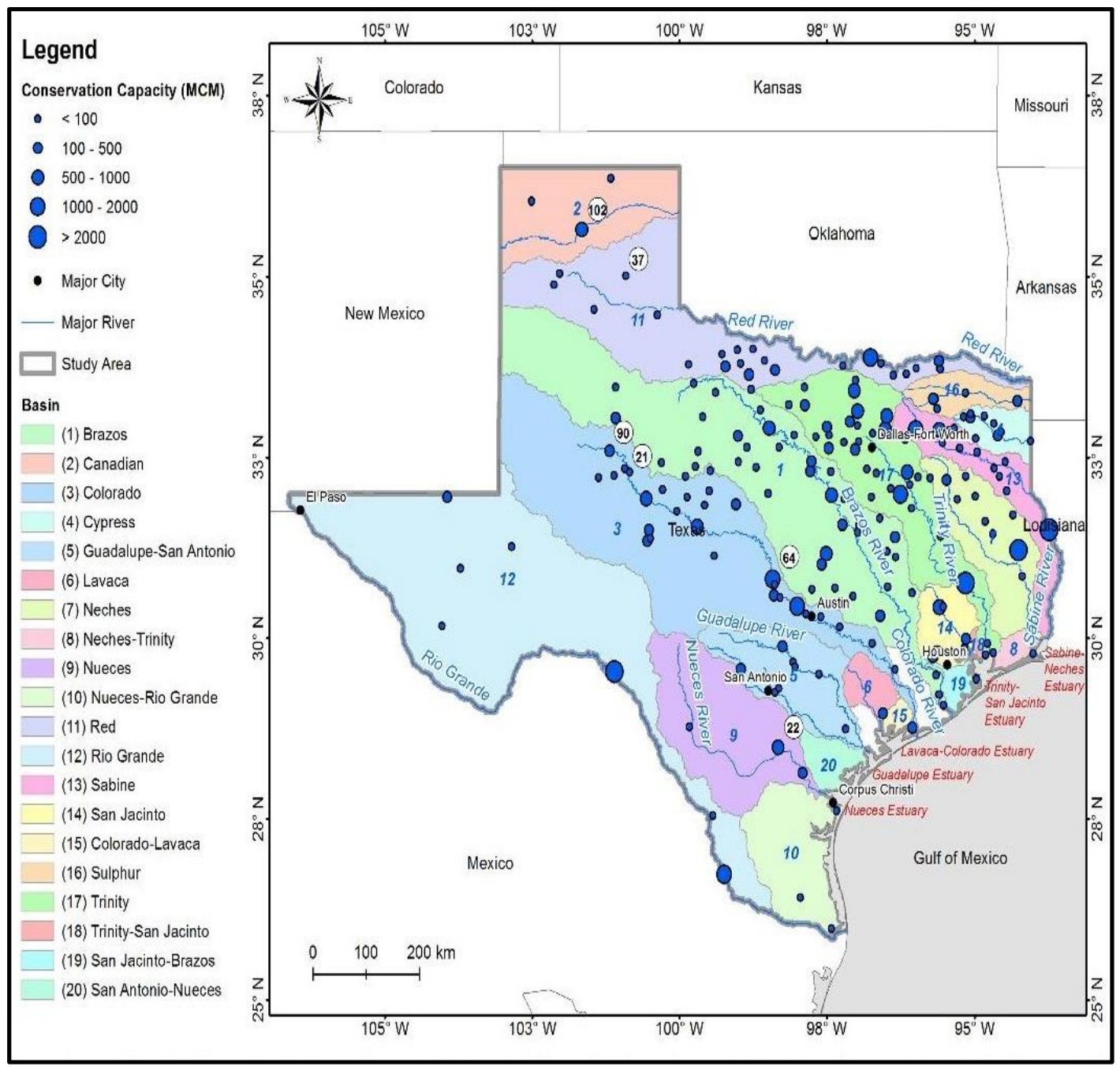

Figure 27: Study area, blue circles show 200 reservoirs in 20 basins in Texas. The size of the circles indicate the capacity and the active storage volume of the reservoirs [105]. 


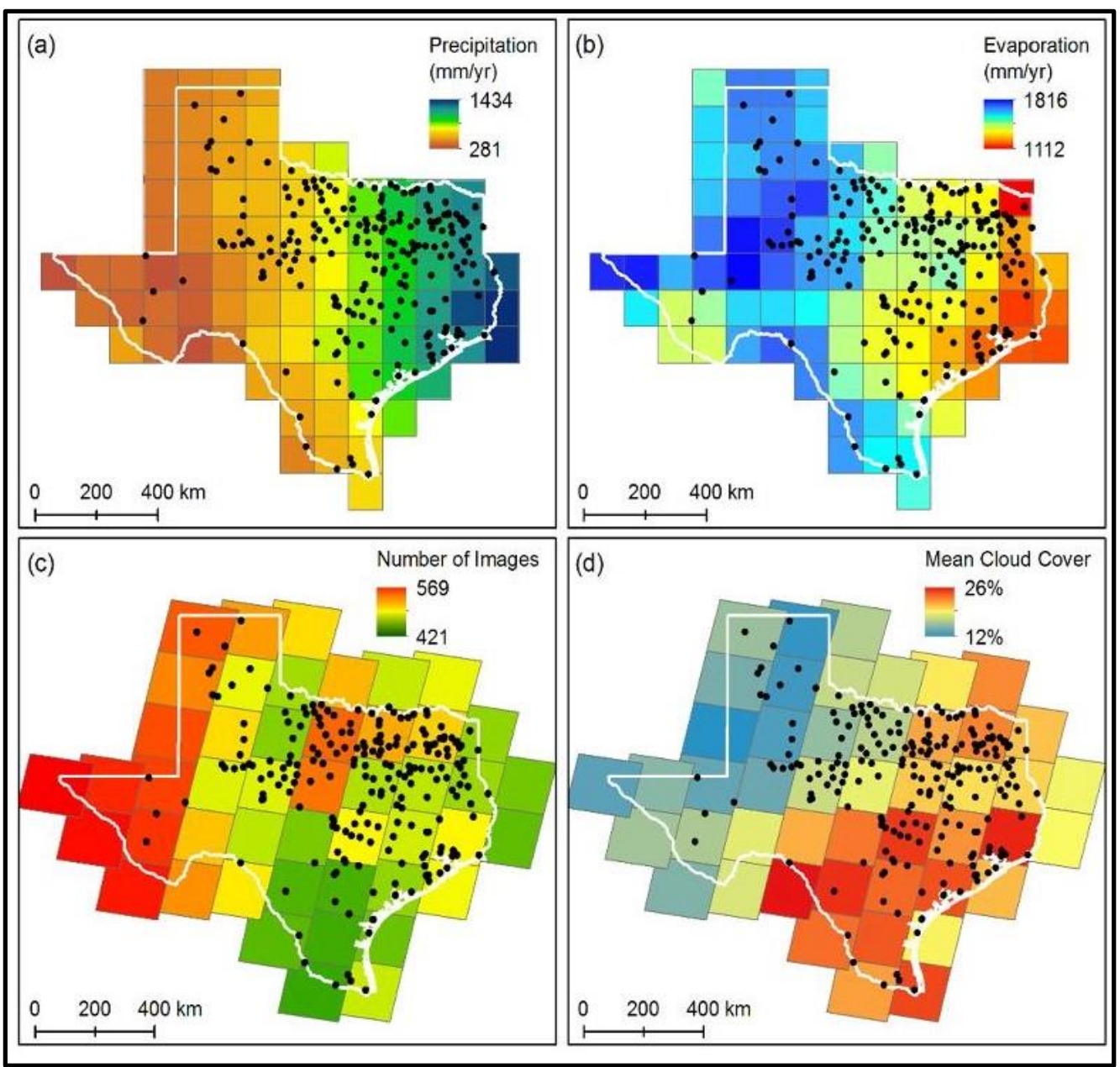

Figure 28: Ground observation data and satellite imagery of the study area: (a) quadrangle precipitation rate, (b) quadrangle evaporation rate in (c) and (d) indicate Landsat WrS-2 scenes [105].

Satellite data used in this study are surface reflectance derived from Landsat 5 and Landsat 8 imagery. Landsat 5 TM images have six 30-m visible bands and a $120-\mathrm{m}$ thermal band. Landsat 8 OLI images have eight 30-m bands, two 100-m thermal bands and a 15-m panchromatic band. The study used a total of 17,811 Landsat images across 47 (WRS-2) scenes of the Worldwide Reference System (WRS) [106] including 15,748 (Landsat 5 TM) images from 1984 to 2011, and 2,063 (Landsat 8 OLI) images from 2013 to 2015. The gap in data in 2012 was filled by using the surface reflectance data produced by the U.S. Geological Survey (USGS) using the Landsat Ecosystem Disturbance Adaptive Processing System (LEDAPS) and accessed through Google Earth Engine (GEE).

Without going into the cumbersome details of the study, the methodology follows the flow charts shown in Figure 29, and for details on the modified normalized difference water index (MNDWI) the reader is referred to [107]. 
The study presented estimates for six reservoirs monthly areas variation (1984-2012) and including Landsat images, (MNDWI), and water pixels. Average monthly evaporation and net evaporation for 20 basins were extracted and presented in graphical and tabular forms. Comparison of satellite derived reservoir evaporative loss to observed reservoir storage change per month for (1984-2015) at eight reservoirs were also given.

This study demonstrated the advantage of a Google Earth Engine (GEE)-based water resources assessment formwork that can process geospatial big data to assess regional reservoir evaporative loss. This study also confirmed (MDNWI) as an effective spectral index for water identification and revealed the spatial heterogeneity of (MNDWI) thresholds at the regional scale. It is important to note that this method is not developed to estimate evaporation in an area where all reservoirs are totally ungauged. However, this method is capable of generating a satellite-based direct quantification of reservoir area dynamics, completing or extending the current area estimates, expanding the estimates to ungauged reservoirs that are close to gauged reservoirs.

The amount of evaporative loss reflects the combined effects of various engineering, geological and meteorological factors. Understanding the spatiotemporal patterns of reservoir evaporation provides important information for designing effective evaporation suppression measures, evaluating water infrastructure performance and improving regional water resilience.

Results of this study indicate that the magnitude of water loss through evaporation is comparable to water use of major economic sectors and ecosystem water requirements. It can be significant enough to counterbalance the positive effects of impounding water and offset the contribution of water conservation and reuse practices. Neglecting the critical impact of reservoir evaporation could result in serious overestimation of water availability and therefore underestimation of the required storage capacity to support the desired water release.

All these findings emphasize the need for more studies on basin or regional scale, and even on individual large reservoirs, to obtain more refined assessments and predictions of these losses. While available literature in this field can also help in forming the basis of such future work; few of such studies can be cited from references such as [108, 109, 110, 111]. 


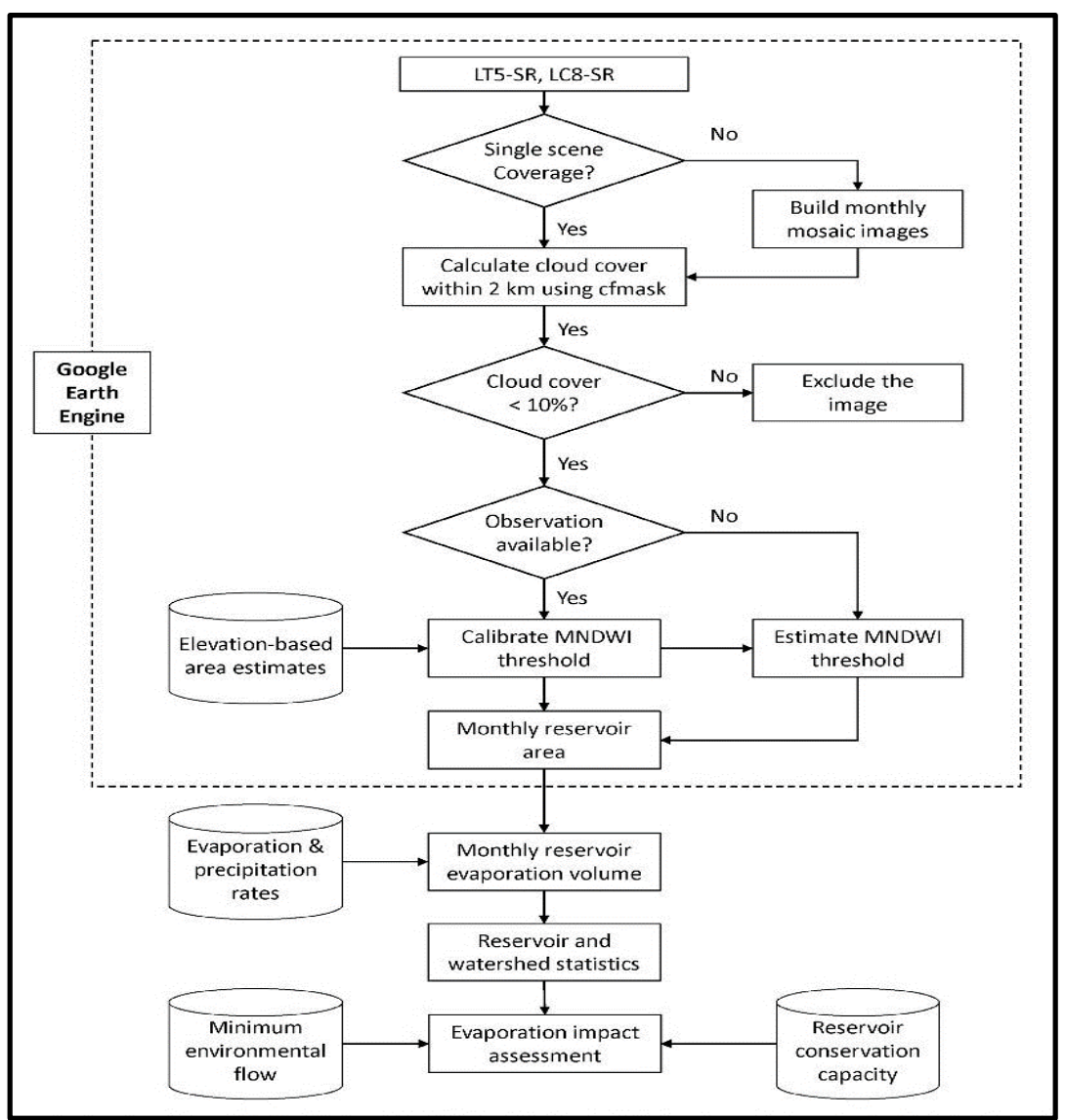

Figure 29: Research framework. The abbreviations LTS-Sr and MNDWI stand for Landsat 5 TM surface reflectance, Landsat 8 OLI surface reflectance and modified normalized difference water index, respectively [107].

\section{Monitoring Dam Deformation by Remote Sensing}

Remote sensing applications have been used not only in following up and evaluating the issues discussed in the previous paragraphs, but, they have been extended to all other related fields, such as climate change impacts on water resources, droughts, floods, and irrigation. One of the important applications has been monitoring the health of dams and water control structures in addition to landslides.

Great advances have been made in the field of remote sensing since the launch of the first satellite by the Soviet Union on the 4th of October 1957. Since then tremendous progress has been made by USA, Russia, EU, China, India in addition to many other countries gradually entering into the space age club. The contribution of USA in this field, however, remains the largest through its Landsat and other scientific space programs and the development of a great variety of sensors capable of tracing minute changes on earth surface. Dams and reservoirs have received their fair share of attention through the application of these technologies in monitoring 
their stability and structural integrity. In recent years, some of these new technologies have been applied to dam deformation measurement, offering unprecedented opportunities to safety management and structural analysis. Among these; Areal Deformation Measurement (ADM) techniques from Terrestrial Laser Scanning and Ground Based (InSAR) and spaceborne (InSAR) sensors which provide the chance to extend the observed region to a large portion of a structure, instead of merely measuring a set of a few control points, in addition to GNSS techniques.

Exploitation of satellite-based (InSAR) included the use of variety of; American, Canadian, Japanese, Italian, German, EU satellites dating from 1980s, to the recent European Space agency (ESA) satellites; (Sentinel-1A) and (Sentinel-1B). Together, they have provided (InSAR) coverage on a global scale and on a 6-day repeat cycle [112].

GNSS techniques have reached a consolidated maturity for dam deformation monitoring, either for the periodical measurement of networks, or for the implementation into continuously operating systems. Research in the field of data processing is still ongoing, especially for the robust solution of geodetic networks. Eventually, the development of sensor networks and methodologies for data integration has offered the opportunity to analyze different observations in a spatial and temporal content [113].

Monitoring of dams safety issues has always taken a great deal of the dam owners and Engineers attention due to the high risk they present to societies, if neglected. Instrumentation of large dams has been an issue in this kind of high risk civil infrastructures for a long time. The complexity of dams calls for the use of various devices, each of them focusing on a different area of the structure; on structural and non-structural elements, and on different processes such as structural deformations, water infiltration, corrosion, weathering, etc. Since decades, optical instruments and contact deformation sensors have been widely applied to this purpose. These sensors can provide precise observations but limited to a relatively small number of points and with variable time acquisition rate; from quasi-continuous observations up to periodical repetition of observation campaigns at monthly or yearly rate.

The development of new ground based instruments, sensing techniques, and algorithms has opened a new era in the field of terrestrial deformation monitoring and related applications. Robotic total stations with reflector-less range measurement and increasingly also image assistance terrestrial laser scanners [114], and digital photogrammetry allow the acquisition of dense point clouds within a short time, thus yielding detailed snapshot representations of surfaces and a basis for measuring deformations over wide areas. In addition, Ground Based Interferometric Radar (GRIR) can be used to derive differential deformation with very high resolution, in particular with respect to persistent scatters [115].

GBIR, limitation, however, is its suitability for monitoring small areas from a single building to a slope at short term sampling time up to a few of minutes, as sketched in Figure 30. But the strength of GBIR is its complementarily with spaceborne SAR, Figure 31, the latter is a powerful and effective remote sensing technique for 
surveying large areas (many $\mathrm{km}^{2}$ ) at long term (return time in the order of several weeks or months).

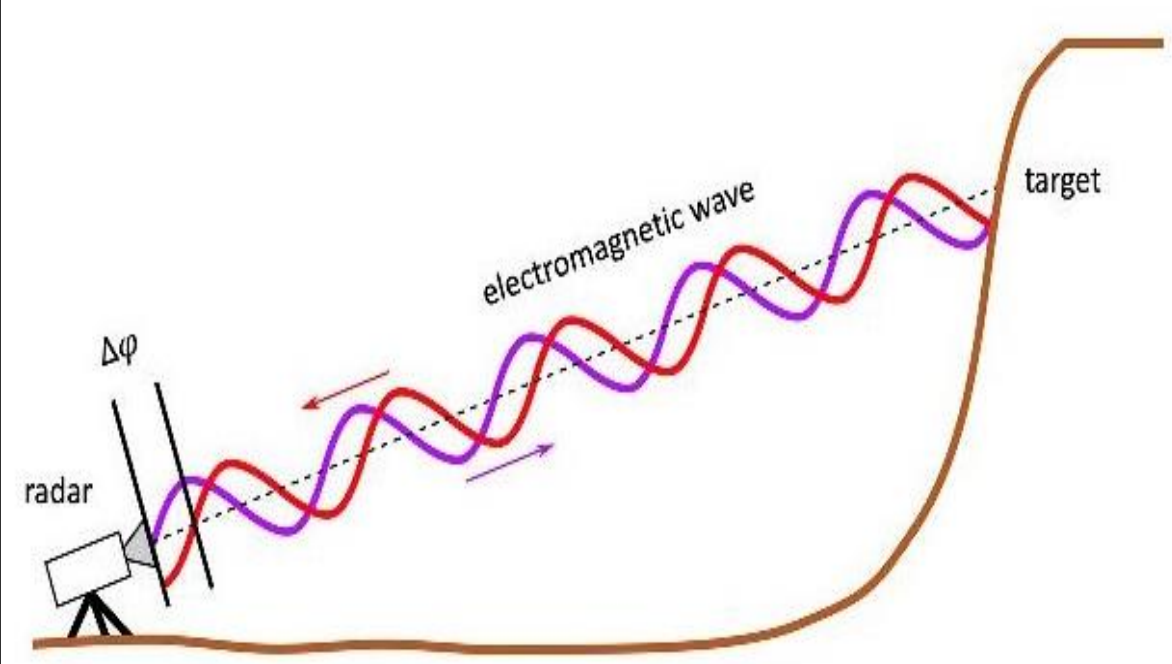

Figure 30: Working Principle of ground transmitter based/ terrestrial radar interferometry [115].

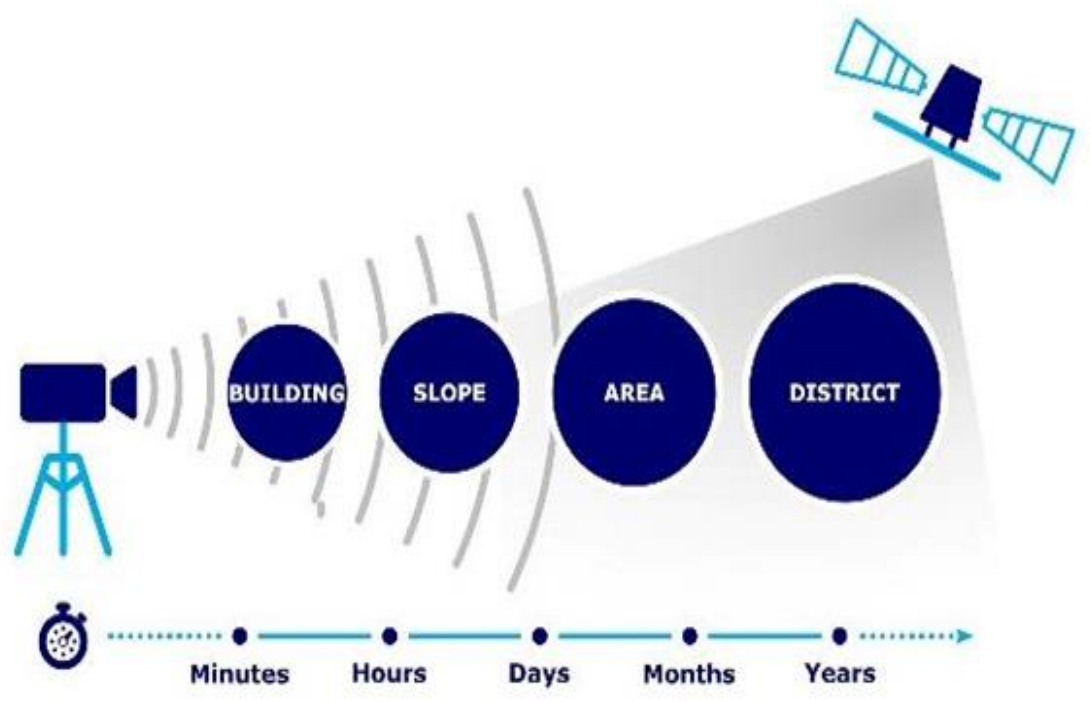

Figure 31: Complementary of GBRI technique with Space Borne InSAR [115]. 
The amount of data provided by these ground based techniques systems is typically much larger than with traditional geodetic techniques, and they potentially represent a real deformations without a need for generalization from displacements of a few carefully selected control points. However, there is no direct point-to-point correspondence between the point clouds obtained at different epochs and thus entirely new algorithms are required in order to analyze deformations.

New concepts for Areal Deformation Monitoring (ADM), namely the Space-Borne InSAR, and GNSS are being developed and investigated including instrumental advances, sensor and process models, and data processing techniques. All of these require thorough validation and assessment before they can be safely applied in critical monitoring applications [116].

One of the (InSAR) techniques developed by an Italian group called PSP-IFSAR may be cited for its versatility and varied applications, Figure 32 [117]. This technique can provide measurements of displacements due to landslides and other slope failures, dam displacement, hydrogeological changes, tunneling, oil/gas or mineral extraction, earthquakes and volcanic phenomena. It is capable for high volume processing and it has been exploited to allow a nationwide (InSAR) survey of Italy. In the context of its application to dams and reservoirs monitoring, several applications exist as explained below.

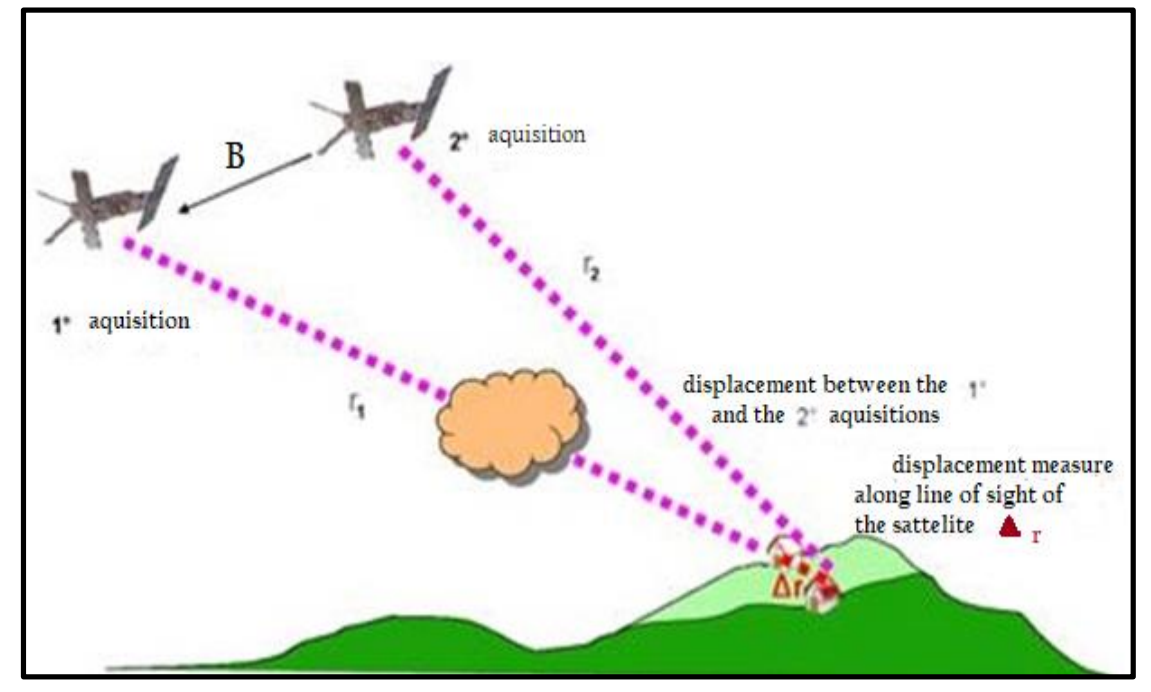

Figure 32: Principle of InSAR technology [117].

1. Monitoring of the reservoirs surroundings for landslide and other ground displacements; this is particularly effective in exploiting the unique benefits of (InSAR) as it can provide a detailed survey of motion in areas which are often not surveyed at all, or can only be very sparsely surveyed with other methods due to the large surface area. The example presented in Figure 33 of landslide motion on the slopes of Mont Cenis Lake, France, shows such an application where a four-year survey of ground motion depicts the extents of two large landslide bodies. The density of measurements made, with no in-situ installation, varied due to vegetation 
cover but the availability of useful displacement measurements was remarkable and gave excellent indication of areas of concern where ongoing monitoring via InSAR or real-time in-situ monitoring systems could be continued.

2. Measurement of displacements on dam structures themselves:

Most dam types lend themselves well to InSAR motion measurement. Although insitu and real time systems are best used for dam safety monitoring, however, InSAR can add significantly to the knowledge since historical archives of applicable SAR satellite data exist from 1992 to present allowing a retro-analysis of past ground motion to be carried out. This allows dam owners to understand past motion on their dams if no preexisting system existed. This is particularly useful in the cases of a mine tailings dams and other dams which may pass from one owner to another, and where the past knowledge of the dam might be scarce.

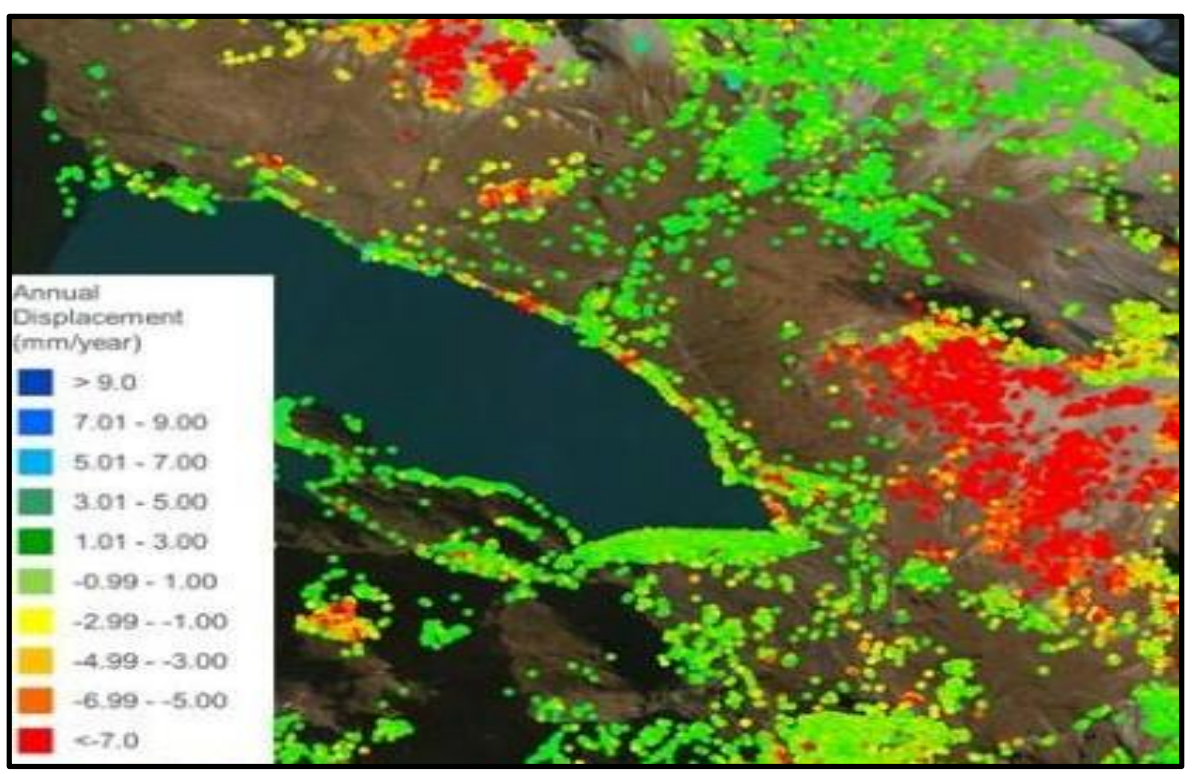

Figure 33: Landslide motion measured by PSP-IFSAR (2011- 2014) on the slopes of Mont Cenis Lake, France [117].

The GNSS systems are similarly used worldwide, whereby they lend themselves to position determination in a wide range of applications. Vehicle navigation to asset tracking, i.e. the American GPS system, is being the most common of them. These systems are not known for their great accuracy (particularly about $3 \mathrm{~m}$ ), but this accuracy limitation can be overcome by using range measurement between the receiver antenna and, at least, four satellites, to compute the position of the receiver on the earth at a point in time, Figure 34. The error sources include accuracy in the satellite orbit determination, delays of the GNSS signal through the atmosphere, satellite and receiver clock and multipath errors. In order to improve the accuracy of the measurements, different techniques can be used. One of them is to use the Differential GPS Technique (DGPS) [118], so centimeter-level accuracy can be 
achieved. To further improve precision, mathematical methods to remove measurement noise can be applied in order to obtain a weighted average between the predicted and the measured position. Of the most common mathematical methods used is Kalman filtering, which is an algorithm that uses a series of measurements observed over time, containing statistical noise and other inaccuracies, and produces estimates of unknown variables that tend to be more accurate than those based on a single measurement alone [119]. It has been demonstrated empirically that for quasi-static points, a millimeter-level precision can be obtained by this way. This level of accuracy is enough for dam motion monitoring in most of the cases.

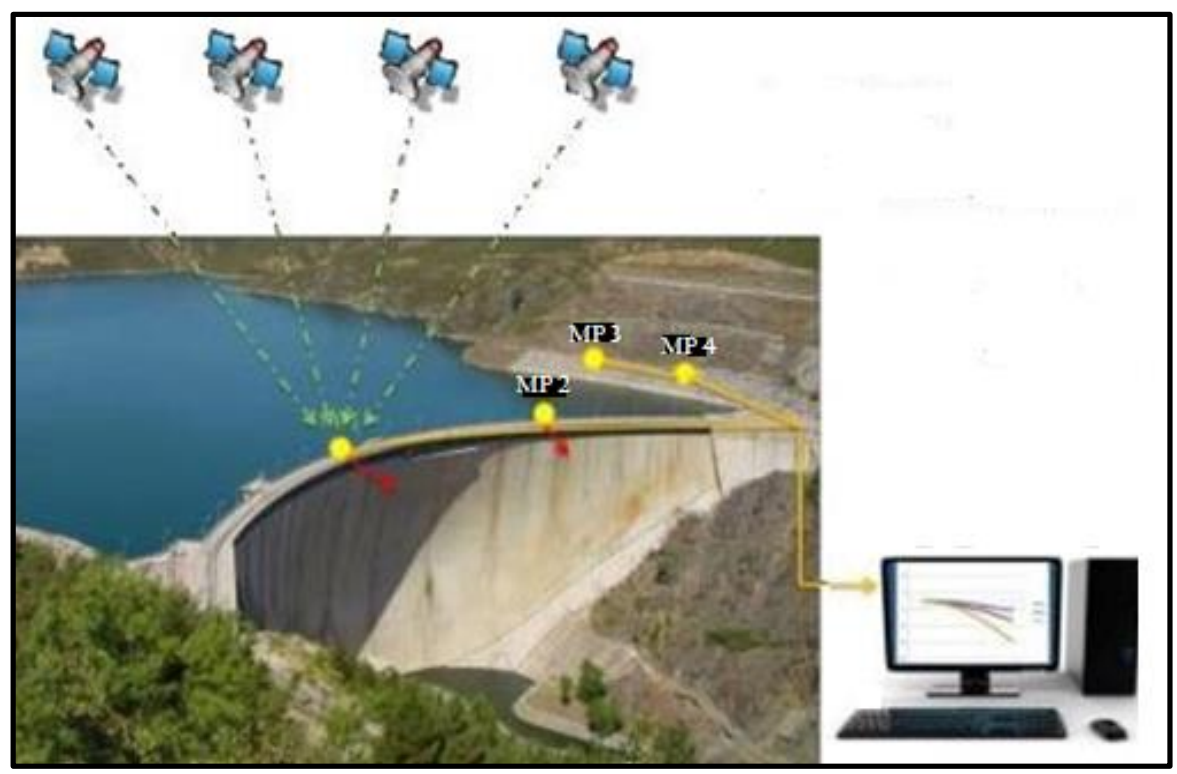

\section{Figure 34: Dam and slope monitoring through Differential GNSS. Typical physical system schematics [118].}

Many dams and reservoirs on which GPS with GNSS were utilized can be mentioned such as; Pacomica Dam (USA) [120, 121, 122], Libby Dam (USA) [123], La Accena Dam (Spain) [117], El Atazar dam (Spain) also [117].

Among the cases where InSAR has been used to monitor dams deformations, some may be cited for illustration of its applicability. The first is the case of Mosul Dam, on the Tigris River, in Iraq. This 113 earthfill dam was observed to be suffering since its completion in 1985 from the dissolution of gypsum karst in its foundation and the deterioration of the deep grout curtain with ongoing deformation which means constant danger of the dam failure, a case which means the drowning of almost of 6.1 people $[124,125,126]$.

A team of researchers from distinguished American and Italian universities, German research center, in addition to NASA and the Italian Space Agency (ASI), carried out a joint research on the ongoing instability of the dam and presented their 
work in a paper published in December 2016 [127].

In this study a multi-sensor cumulative deformation map for the dam was obtained, Figure 35, which was generated from space-based Interferometric SAR measurements from the Italian constellation of satellites (COSMO-SkyMed) [128] and the European sensor Sentinel-1a [129] over the period 2014-2016. These were compared to an older dataset spanning 2004-2010 acquired from the European Envisat satellite [130]. The study revealed that deformation was rapid during 20042010, slowed in 2012-2014 and increased from August 2014 when grouting operations stopped due to the temporary capture of the dam by the self-proclaimed Islamic State (ISIS). The data from these multiple SAR satellites was used to measure the deformation at the dam in great spatial and temporal detail which shed new light on the dynamics of the ongoing destabilization.

Data required for the study was obtained from processing 62 images acquired in an ascending track geometry from the Italian Space Agency (ASI) COSMO-SkyMed (CSK) constellation of four satellites to image ground deformation during 20122015, and 32 images acquired in a descending geometry by the European Space Agency (ESA, Sentinel-1A) sensor starting October 2014 and spanning 18 months. Six Interferograms from ESA's (Envisat) satellite, from both ascending and descending geometries, were computed for monitoring the destabilization process during the period 2004-2010. A multi-temporal Interferometric processing technique was applied to the CSK and Sentinel-1A phase measurements to compute two separate time-series of deformation exploiting point-like scatterers. Time series of the water level at the dam wall using SAR amplitude images was then estimated to measure the horizontal distance between the water and the top of the dam and calibrate the results with satellite altimetry data. Data from the different spacecrafts showed that Mosul dam subsided throughout the observation period at varying rates and revealed a shift in the location of the maximum deformation magnitude.

The obtained deformation pattern and magnitudes in the form of subsidence and horizontal displacements are shown in Figures 35, 36 and 37 for the two mentioned periods. Time series of subsidence at the center of the dam is shown in Figure 38. Comparison of the 2004-2010 and 2014-2015 subsidence-rate profiles indicates a $300 \mathrm{~m}$ eastward shift of the peak subsidence toward the dam's main spillway, Figure 37. The inferred deformation was modeled using a Markov chain Monte Carlo approach to solve for change in volume for simple tensile dislocations. Results from the 2004-2010 and 2012-2014 geodetic datasets suggested that the volume dissolution rate remained constant when the equivalent volume of total grout injected during re-grouting operations was included in the calculations.

The important conclusions of the study may be summarized by:

1. Mosul dam is subsiding at a linear rate of $\sim 15 \mathrm{~mm} /$ year compared to $12.5 \mathrm{~mm} /$ year subsidence rate in 2004-2010. The subsidence restarted at the end of 2013 after regrouting operations stopped. The causes of the observed linear subsidence process can be found in the human activities that have promoted the evaporate subsidence development, primarily in gypsum deposits, and may enable, in case of continuous re-grouting stops, that unsaturated water of flow through or against evaporates 
deposits increases allowing the development of small to large dissolution cavities. Large vertical movements have resulted from the dissolution of extensive gypsum strata previously mapped beneath the Mosul dam. Increased subsidence rate has been due to the absence of re-grouting underlying the dam basement. The subsidence seems to have a linear behavior but, a future acceleration due to the increased dissolution speed cannot excluded.

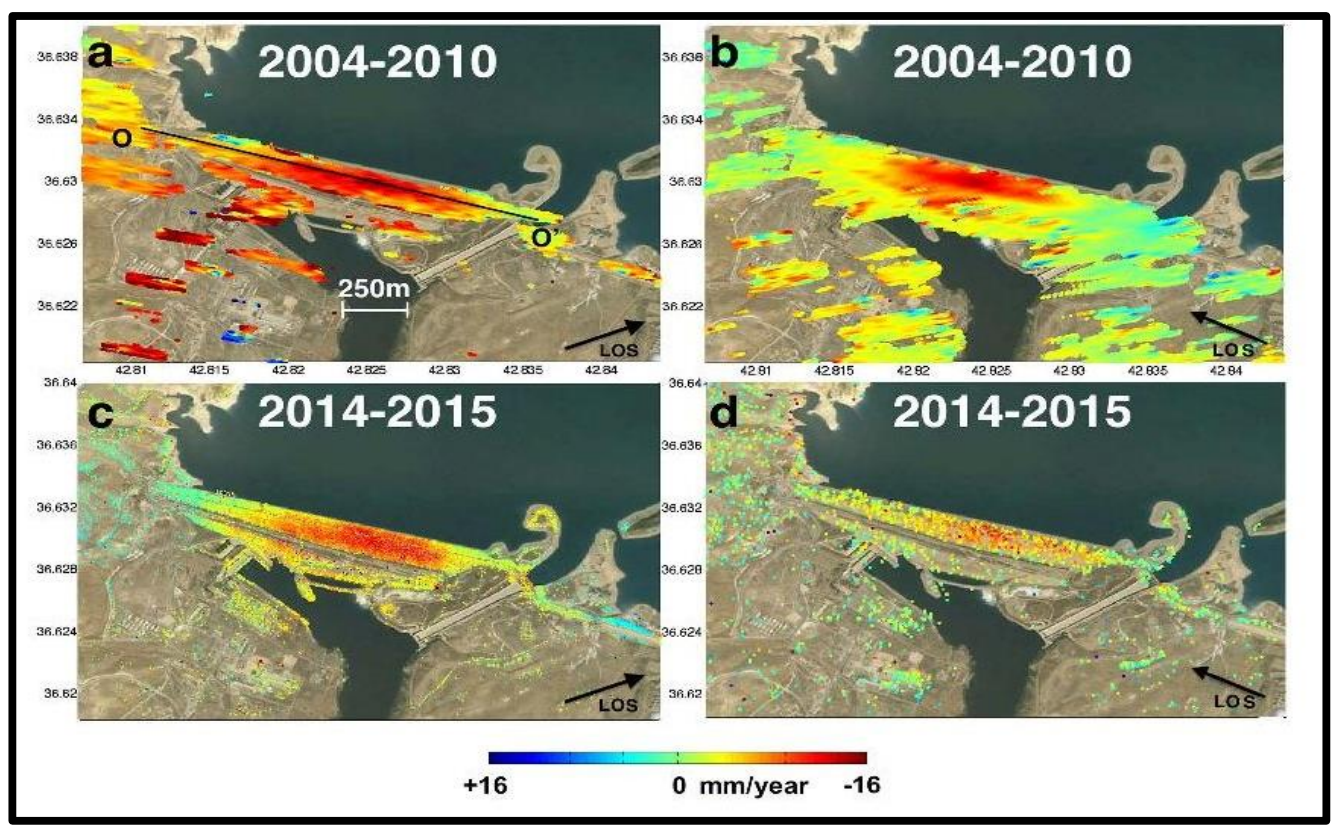

Figure 35: InSAR measured subsidence rates on the Mosul dam, Iraq. Negative values indicate motion away from the satellite, consistent with subsidence. (a) Envisat ascending track DinSAR stacked interfergrams covering May 2004-August 2010. Horizontal/Vertical Profile O-O' is shown in Figure 36. (b) Envisat descending track DinSAR interfergrams spanning May 2004-August 2010. (c) CSK ascending track covering December 2014-July 2015. (d) Sentinel descending track covering December 2014-July 2015. Timeseries analysis generated using SARPOZ Software [127]. 


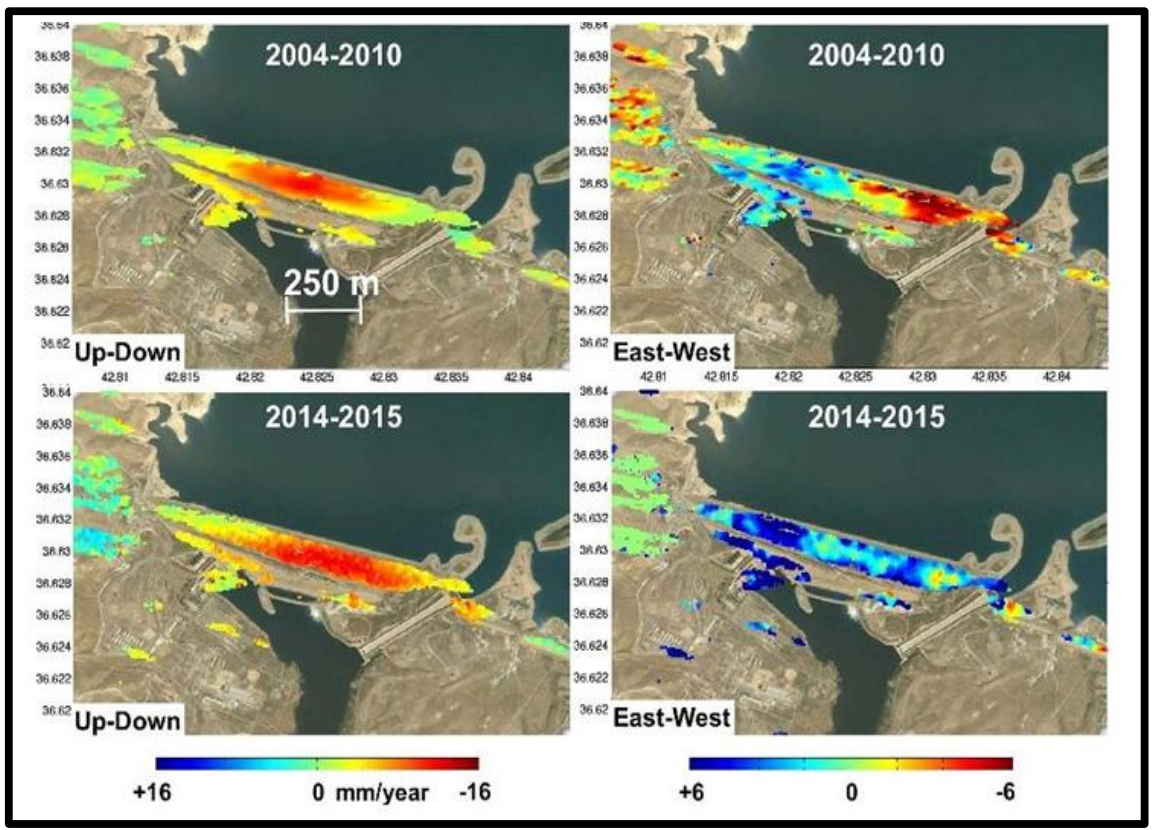

Figure 36: Up-down (left) and east-west (right) displacement at Mosul dam, Iraq. Negative values indicate downward and westward motions, respectively. The data have been resampled on a common grid calculated using the coherence maps from the interfergrams (Envisat) and time-series (CKSSentinel 1-a) [127].

2. The slowdown of the deformation can be interpreted as being due to the reduced water level during the December 2012 to June 2013 dry season, Figure 37b, and consequent low water pressure at the dam basement, which results in reduced dissolution rates of the evaporates underlying the dam foundation. 


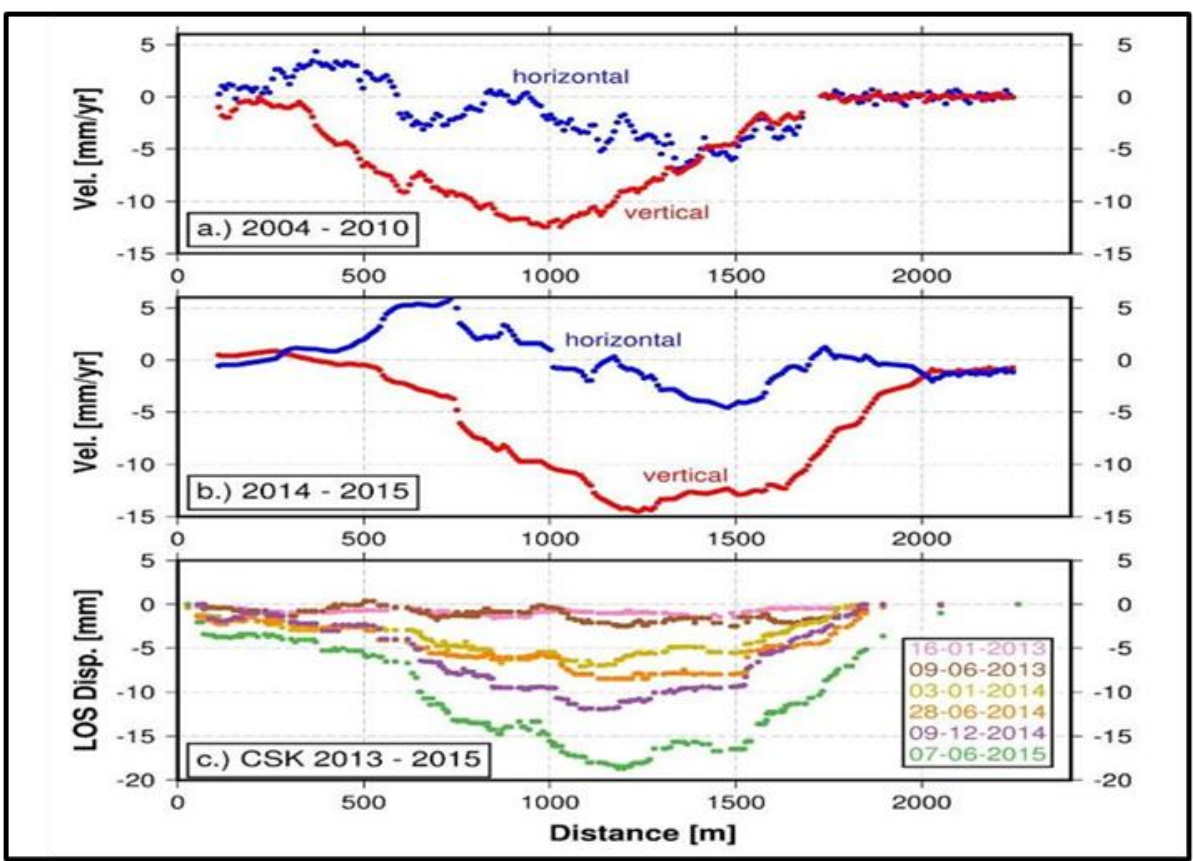

Figure 37: Subsidence profiles. (a) Vertical and east component of surface velocities along the Mosul Dam from Envisat 2004-2010 2D deformation. (b) velocity components from CSK, Sentinel-1a velocity maps obtained using data spanning the same time period (December 2014-July 2015). The results confirm that the vertical velocities greatly exceed the horizontal contribution typical of subsidence patterns. (c) CSK LOS cumulative displacement profiles [127].

3. The inferred lateral propagation of the deformation source seems to be compatible with a hydrogeological model constrained by ground measurements in which the dam substrate is characterized by an increased hydraulic gradient toward the east abutment: promoting fluid pathways connecting the reservoir to the downstream rocks in the subsurface. The model identifies the reservoir-induced pressure as the main cause of an increase in the dissolution rates. Moreover, the abundant presence of readily soluble gypsum below the eastern dam foundation close to the main spillway seems compatible with the observed subsidence shift and the eastward deepening of the dissolution front. These observations agree with the previously mapped geometry of the sedimentary strata, characterized by eastward dipping gypsum beds. SAR data analysis together with the inferred lateral propagation from knowledge of the geology and hydraulic connectivity suggest that the locus of foundation dissolution has shifted eastward toward the dam's principal spillway.

4. Model Inversions for the locus of volume loss in 2004-2010 infer a depth of 70 meters below the surface and a deepening in 2014-2015 of 160 meters below the surface. The annual increase of water levels in the future, especially during the summer months, could lead to an increase of water pressure in the dam foundation, 
which combined with the absence of re-grouting could speed up the dissolution of the dam substrate and promote its destabilization, Figures 35d and 38a, extending the observations until March 2016.

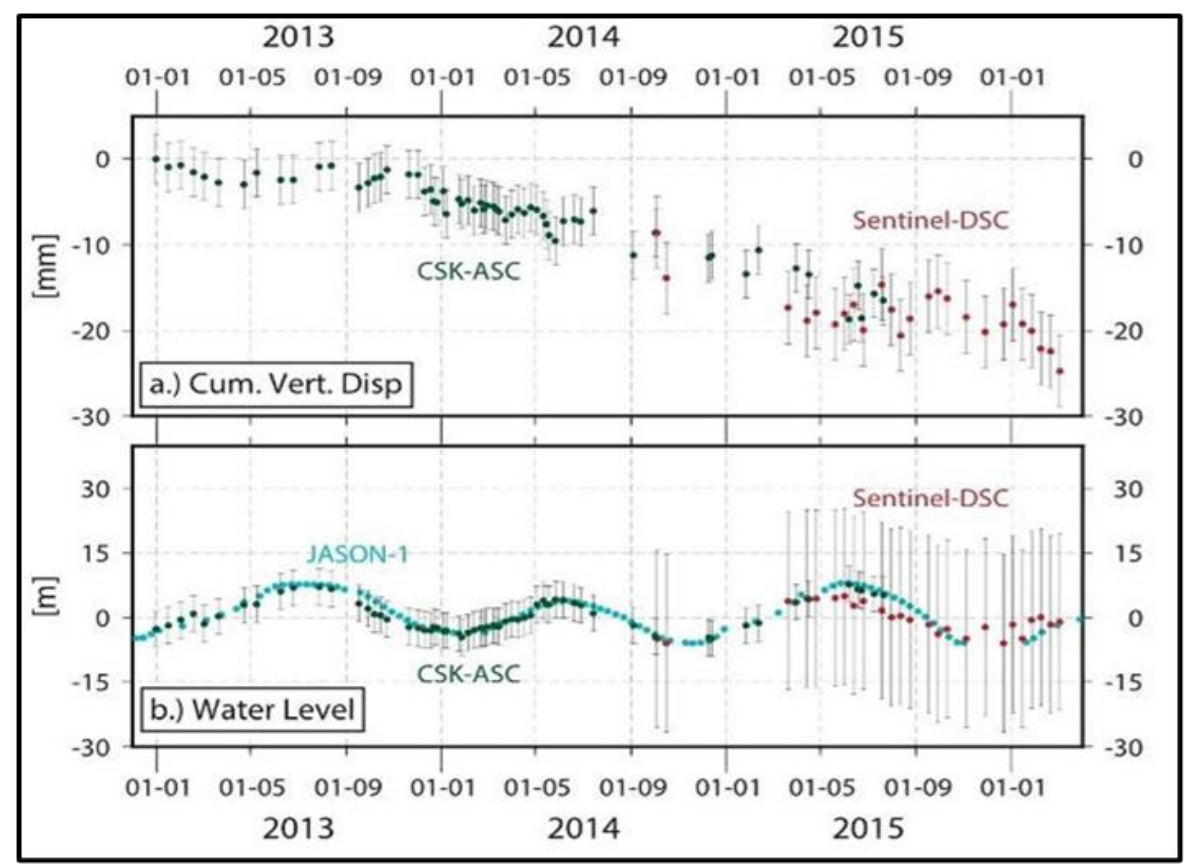

Figure 38: (a) CSK/Sentinel-1a Time series of subsidence at the center of the dam assuming negligible North- South motion. (b) CSK/Sentinel-1a amplitude derived shoreline location on the dam face calculated from amplitude measurements calibrated with JASON-1 altimeter data [127].

5. The Markov chain Monte Carlo (MCMC) approach enabled the calculation of the dissolved volume loss rates at different times which were; $34.1 \times 10^{2} \pm 9 \mathrm{~m}^{3} /$ year during 2004-2010; vs., $44.6 \times 10^{2} \pm 9 \mathrm{~m}^{3} /$ year in 2014-2015, indicating a speed up of the dissolution that was likely caused by the lack of maintenance and re-grouting. 6. This study highlights how the availability of new constellations of SAR sensors supported by historical SAR databases are enabling dam deformation monitoring in which InSAR measurements are accurate enough to measure sub-kilometer scale geologic and anthropogenic processes and providing critical information fundamental for mitigating anthropogenic hazards.

7. The adopted observational strategy together with simple elastic models agreed with independent studies confirming both the depth of the past dissolution source and the eastward shift of the dissolution front that occurred after the re-grouting stopped, [127].

One lecture delivered in the Mosul Dam World Workshop held on 24- 24 May, 2016 in Stockholm gave lesser values for surface settlements and average deformation velocity. The study, however, used only limited number of InSAR 
Sentinel 1a images for the period from 04 October 2014 to 08 February 2016. Compared to the previous study cited above these values may be considered rough and only indicative due to limited data used [131].

In a study published in 2019 [132] the destabilization of Mosul dam was shown to be continuing. This was followed by utilizing again Synthetic Aperture Radar (SAR) as (PS-InSAR) [133] scenes from Sentinel-1A for characterizing deformations. Seventy-eight Single Look Complex (SLC) scenes in ascending geometry from the Sentinel-1A scenes acquired from third October 2014 to twenty seventh June 2019 were used. A lot of 96 points within the dam structure, were selected to determine the deformation rate using persistent Scatterer interferometry (PSI). Maximum deformation velocity found from the study was about $7.4 \mathrm{~mm} \mathrm{x} \mathrm{yr}^{-1}$ at a longitudinal subsidence area extending over a length of $222 \mathrm{~m}$ along the dam axis. The mean subsidence velocity in this area was about $6.27 \mathrm{~mm} \mathrm{x} \mathrm{yr}^{-1}$ and located in the center of the dam. Subsidence rate showed an inverse relationship with the reservoir water level. It also showed a strong correlation with grouting episodes. Variations in the deformation rate within the same year were most probably due to increased hydrostatic stress which was caused by increased water storage in the dam that resulted in an increase in solubility of gypsum beds, creating voids and localized collapses underneath the dam. PSI information derived from Sentinel-1A proved to be a good tool for monitoring dam deformation with good accuracy, yielding results that can be used in engineering applications and also risk management. The study demonstrated the following:

i. It demonstrated the successful application of the Persistent Scatterer Interferometry (PSI) approach for mapping unstable areas and determining geo-hazard risks at Mosul Dam.

ii. The area facing the powerhouse, designated subsidence area $\mathrm{A}$, including PSI-1 to PSI-6, had a mean subsidence velocity of about $-6.27 \mathrm{~mm} \mathrm{x}$ $\mathrm{yr}^{-1}$. Area A includes thick gypsum layers, where solutioning activities have created larger voids due to the presence of the Sinjar-DuhokAmadiya-Fault under the dam foundation. This area also accounts for the maximum hydrostatic pressure due to its lowest topographic elevation in the Mosul Reservoir, causing greater subsidence than elsewhere in the dam.

iii. Subsidence at the old course of the Tigris River i.e., deepest section of the dam, had significantly increased after 2014 due to termination of grouting activities by ISIS, leading to increased dissolution beneath the dam.

iv. In order to maintain safety, the study strongly recommended maintaining the water level at $319 \mathrm{~m}$ (a.s.1.) in the Mosul Reservoir. Increasing the water level beyond $319 \mathrm{~m}$ will speed up failure of the Mosul Dam. The influence of higher water levels on increase in subsidence was clearly seen during the winter of 2014-2015 and 2016-2017, fall 2015 and 2016, and spring 2016 and 2017. 
v. In general, maintaining stability and safe operation of Mosul Dam calls for continuous grouting and a controlled rise of water level in the Mosul Reservoir.

vi. Relevant institutions should explore other ways to store water of the Tigris River to meet various needs. Use of other SAR frequencies such as $\mathrm{X}$-band are also encouraged for further studies [132].

The most recent follow up of the destabilization question of Mosul Dam was given in a study published in July 2020 [134] covering two cases; the first was analysis of the stability of the access bridge on the Tigris River leading to the dam site and, the second which was a more exhaustive analysis which deals with the dam itself, which is more of concern to us. Both cases used Modal and PS-InSAR techniques.

The specific goal of the second analysis was to identify potential cracks existing on Mosul Dam which could have formed from dams displacements. The method used was based on Modal Analysis of the extended and elastic bodies typical of large infrastructures. Results were also compared with those obtained by (PS-InSAR) techniques applied on data obtained from (COSMO-SkyMed) satellite which belong to the Italian Space Agency [135].

The procedure used can be seen as an in-depth Modal assessment based on the micro-motion estimation, through a Doppler sub-apertures tracking and a MultiChromatic Analysis (MCA); the method is based initially on the Persistent Scatterers Interferometry (PSI). The modal analysis detected the presence of several areas of resonance that could mean the presence of cracks, and the results showed that even in 2020 the dam was still in a strong destabilization conditions. Moreover, the dam appeared to be divided into two parts: the northern part was accelerating rapidly while the southern part was decelerating and a main crack in this north-south junction was found.

This study confirmed the results of the previous study of 2019 mentioned above and, the estimated velocities through the PS-InSAR technique showed a good agreement with the GNSS in-situ measurements, resulting in a very high correlation coefficient indicating that the procedure works efficiently.

Mosul Dam studies a/m were follow up and in line with research on the use of SAR in investigation of dam stability.

In 2016 such work was applied on the Pertusillo arch dam, Basilicata, Italy [136]. The reader may also refer to other papers on the same type of work from referenced such as [138] and [139].

The remote sensing application of other advanced techniques such as the (GNSS) on the deformation and instability monitoring of dams can provide also very good tool in this field. GNSS was applied in large number of studies of which we cite few examples documented in number of references such as; 2015 [139], 2016 [138], 2018 [141, 142, 143, 144, 145, 146], 2019 [147], 2020 [148]. 


\section{Summary Notes and Concluding Remarks}

Satellite remote sensing is relatively young technology born at the late fifties of the last century, but one which has found its applications in great many fields. Apart from the obvious military uses it has been applied in fields of water resources. In hydrology remote sensing applications were used to estimating hydrometeorological parameters, such as; land surface temperature, near-surface soil moisture, snow cover, water quality, surface water or sediment accumulations, surface roughness, and land use cover. Moreover, it has been applied to assess fluxes such as evapotranspiration, evaporation from water bodies such as lakes and reservoir, in addition to delineating physiographic variables that can influence hydrologic processes. In geology remotely sensed data are used to derive fine details of geologic features such as landslides, fault lines and anomalies, mineral explorations and similar fields, and in water resources management it has been used in water resources mapping such as in rainfall- runoff studies, drought monitoring, flood forecasting, irrigation management, rainfall water harvesting, watershed planning and management, groundwater studies and dams and reservoir monitoring and studies. Major questions touched upon in this review are related to dams and reservoirs sites selection, dams and reservoirs management, reservoirs surface area and volume changes, bathymetric surveys and sedimentation assessment in relation with catchment erosion, reservoir water quality follow up, and last but not the least monitoring the behavior of dams and their integrity with the added capacity of looking into this in retrospect.

Remote sensing advances in the last fifty years owes its successes to the great technical innovation in producing sensors that use energy fields, whether in passive or active modes to detect even minute variations on the earth surface and record them in imagery formats. These successes, however, were only possible by using satellites as platforms and development of means to process these images, and algorithms and software to refine the results. Space programs carried out by countries and space agencies around the world have provided multitude of scientific satellites for carrying out this work enhanced by development of specialized satellite-born sensors. Today there is a horde of live satellites and sensor roaming in their selected orbits around the earth, while many others have gone dead after expiring their lives, and there are many more refined ones planned for the future. The satellites used so far or in use today have varied according to the specific objectives they were designed for. To mention only few the SEASAT, GEOSAT, Topex/Poseidon or T/P, ERS-1, ERS-2, GFO, ENVISAT, JASON-1 and JASON-2 are examples of those out of service now which are replaced by other more modern ones such as the American LANDSATs, the Japanese (JERS-1 and ALOS 2), the Canadian (RADASATs), the French (Jason-3), the Chinese (BeiDou) satellites in addition to many Italian, Indian and EU satellites.

Development of sensors technologies has produced some powerful ones such as the Moderate Resolution Imaging Spectroradiometer (MODIS), as well as Synthetic Aperture Radar (SAR), and these sensors have the refined capability of estimating 
water storage and storage changes in lakes and reservoirs, in addition to measurements of both surface water area and bathymetry and many more variations in the water management fields. In comparison with other satellites, the primary advantage of LANDSAT is the high resolution of its sensors but it has low repeat frequency of 16 days and is susceptible to cloud cover contamination. The instruments on the Landsat satellites have acquired millions of images which are archived in the United States and at Landsat receiving stations around the world presenting unique resource for global change research and applications in agriculture, cartography, geology, forestry, regional planning, surveillance and education, and can be viewed through the U.S. Geological Survey (USGS) "Earth Explorer" website. The latest (Landsat 8) satellite launched on February 11, 2013, has payload consisting of two science instruments; the Landsat8 (OLI) with two bands of Thermal Infrared Sensor (TIRS, Band $10 \&$ Band 11). These two sensors provide seasonal coverage of the global landmass at a spatial resolution of 30 meters (Visible, Near InfraRed, Short-Wave InfraRed;100 meters (thermal); and 15 meters (panchromatic)[149].

In this review MODIS application is exemplified in a comprehensive study on the derivation of water level and volume variations time series of five of the largest reservoirs in USA, in addition to those of 34 more large dam reservoirs in the world, and derivation of the water surface elevation vs. surface area equations for these reservoirs. Such outputs can still be used in further studies, whether on evaporation losses estimates or bathymetric studies or other operational issues. MODIS data were used to fill in gaps in recorded historical data of these variables and proved to be a powerful tool in providing the full history of this variation.

In other situations, Landsat utilizing the Enhanced Thermal Mapper sensor (ETM) borne by Landsat 7 was used to collect baseline data of small reservoirs surface areas for adopting water conserving policies for such reservoirs scattered over large rural areas located in semi-arid regions where water resources are precious and where collection of such data can be very time consuming and costly. These benefits were further clarified in this review by presenting the results of a study carried out on monitoring three small reservoirs in Ghana which proved that regional to basin scale inventories of small inland water bodies are readily obtainable by using satellite remote sensing. In one case described in this review data was retrieved from the European Satellite (ENVISAT)using advanced SAR images.

Creating inventories of small dams and farm ponds on a regional scale using different available satellites imagery outputs is highly recommendable as this can help water management authorities for better water resources management in minimizing water waste and detecting all the unlicensed farm ponds. Accumulating such data base may help also in better water tax collection increasing the irrigation authorities revenue. This type of satellite observation was done for identifying about 1,000 small dams and farm ponds in Mzingwane catchment (Zimbabwe).

Such studies with constant follow up can be suggested for countries which suffer from decline of water resources such as Iraq, where there exist thousands of unlicensed fish bonds which encroach on the irrigation projects water shares and 
discharge their affluent into drains already suffering of high water levels caused by wasteful irrigation practices. The development of the use of satellite remote sensing in bathymetric studies is described in the review by presenting two studies which shows that such methods can be used on large and small reservoirs, but with certain limitations. With the contribution of ICESat- 2 the obtained dataset has the potential to be expanded to thousands of reservoirs and lakes in the future.

The value of remote sensing applications is further investigated in the present review by presenting the use of these applications in sedimentation studies that linked reservoir sedimentation with erosion rates assessments in their respective watersheds. Such studies were carried out for assessing required watershed protection measures needed and for prioritization of sub-basins in need for such amelioration works. The presented studies are selected from India, Indonesia and Brazil to show the applicability of such methods to various watersheds in different regions of the world where erosion presents serious problems. More of similar studies were carried out in recent years for the assessment of sedimentation of individual dams reservoirs without reference to conditions prevailing in their watersheds and some examples are given here.

In another direction, remote sensing depended on the changes of optical properties of water caused by the presence of various contaminants to assess water quality parameters in water bodies such as lakes and reservoirs. This is touched upon in this the review and supported by real case studies. Water quality parameters are taken to mean all physical, chemical, thermal and biological characteristics of water e.g., temperature, chlorophyll content, turbidity, clarity, Total Suspended Solids (TSS), nutrients, Colored Dissolved Organic Matter (CDOM), dissolved oxygen, $\mathrm{pH}$, Biological Oxygen Demand (BOD), Chemical Oxygen Demand (COD), total organic carbon, and bacteria content. Most of these parameters are found to be amenable to characterization by using the appropriate sensing devices with the use of the fitting wavelength of the EM radiation.

Moreover, thermal remote sensing methods have been widely used to estimate water surface temperature in lakes and estuaries. The use of Landsat5-TM was introduced in the review as this method was used by the USBR in the late 1980s to monitor water quality in its reservoirs. But since then there has been great developments in these applications coupled by remarkable progress in space technology. Examination of the literature shows that the past 10-15 years have brought about a focal shift within the field, where researchers are using improved computing resources, datasets, and operational remote sensing algorithms to better understand complex inland water systems. Future satellite missions promise to continue these improvements by providing observational continuity with spatial/spectral resolutions ideal for inland waters. This progress is outlined and study cases are presented for eutrophication in some reservoirs in USA with description of the imagery and algorithms used indicating limitations of the method. Another study on reservoir water quality assessment in Turkey is also presented to show how different methods using different sensors, which was in this case the RapidEye satellite could produce very good characterization of water quality. 
Shifting focus from water quality research to the research on water availability questions, this review deals next with water losses from reservoirs due to evaporation. This loss is recognized as one of the major factors that should be taken into consideration in the water management of reservoirs, but one which is not given so far its proper weight, or if this was done then available methods of evaluation are either not fitting or inaccurate. Useful use of remote sensing products derived from MODIS for such evaluation is demonstrated by presenting a study carried out on five reservoirs in the Savanah River basin in USA. The aim was to evaluate the seasonal variation in evaporation of these reservoirs and comparing the evaporation rates obtained from Mass Transfer Methods based on MODIS with the evaporation loss rates calculated from Pan Evaporation measurements. In this way avoiding the use of the cumbersome Conventional Mass Transfer Methods or Pan-Evaporation measurements which tend to be sensitive to local weather and landscape conditions. The study utilized data from two sources; the first source was MODIS for obtaining spatially resolved lake surface temperature by combining measurements from the MODIS sensor on NASA's Terra and Aqua satellites since these data were available from the NASA Earth Observing System Data and Information System from July 2002 to December 2012; and from a second source which was the National Weather Service meteorological stations close to the studied reservoirs, which supplied land temperatures measurements, wind speed, eddy flux and relative humidity. These data could be used to quantify the potential error associated with using generated MODIS remote weather data. Likewise, local measurement of lake surface temperature could be used to assess the quality of the MODIS data and can be also utilized to validate the algorithm employed for filling in missing MODIS data. The researches claim that since this approach requires only an existing satellite resource with global coverage and existing meteorological stations close to the study area and having enough recorded data, so this method can potentially be ported to any lake where there is a nearby meteorology station. Hence, this method could be used by both water resource managers and limnologists alike with the possibility of extending this approach beyond a single basin to encompass an entire geographical region or continent. As we see it, this conclusion, however, has to be verified by other studies on various climatic regions to confirm its absolute validity or discover some limitations.

Another approach is also presented in one more study which proposes remote sensing framework to estimate reservoir evaporative loss at the regional scale. This framework uses a multispectral water index to extract reservoir area from Landsat imagery and estimate monthly evaporation volume based on Pan-derived evaporative rates. The optimal index threshold is determined based on local observations to be extended to unobserved locations and periods. Built on the cloud computing capacity of the Google Earth Engine (GEE) this framework can analyze satellite images at large spatiotemporal scales, where such analysis is infeasible with a single computer. The study involved 200 major reservoirs in Texas, captured in 17,811 (Landsat) images over a 32-year period. Results of this study indicate that the magnitude of water loss through evaporation is comparable to water use of major 
economic sectors and ecosystem water requirements. It can be significant enough to counterbalance the positive effects of impounding water and offset the contribution of water conservation and reuse practices. Neglecting the critical impact of reservoir evaporation could result in serious overestimation of water availability and therefore underestimation of the required storage capacity to support the desired water releases. All these findings emphasize the need for more studies on basin or regional scale, and even on individual large reservoirs, to obtain more refined assessments and predictions of these losses. It is important to note that this method is not developed to estimate evaporation in an area where all reservoirs are totally ungauged. However, this method is capable of generating a satellitebased direct quantification of reservoir area dynamics, completing or extending the current area estimates, expanding the estimates to ungauged reservoirs that are close to gauged reservoirs.

The final part of the present review concentrates on one of the most important applications of remote sensing techniques in the field of water management; which is monitoring dam's structures to follow any developing problems threating their stability and their integrity. Most dam types lend themselves well to Interferometric Synthetic Aperture Radar (InSAR) motion measurement. Although in-situ and real time monitoring and observation systems are best used for dam safety monitoring, InSAR, however, can add significantly to the knowledge since historical archives of applicable SAR satellite data exist from 1992 to present allowing a retro-analysis of past ground motion to be carried out.

Similarly, the Global Navigation Satellite System (GNSS) which refers to a constellation of satellites providing signals from space that transmit positioning and timing data to GNSS receivers can also be used to position determination allowing deformation measurements. Accuracy of the results obtained by GNSS can be much improved by different techniques, one of them is to use the DGPS Technique, so centimeter-level accuracy can be achieved. To further improve precision, mathematical methods may be applied to refine the accuracy such as Kalman filtering algorithm which removes statistical noise and other inaccuracies, and therefore produces a millimeter-level precision which is enough for dam motion monitoring in most of the cases. As a demonstration of the applicability of these techniques in dam deformation studies the chronic case of Mosul Dam is presented in this review by citing series of studies and one international workshop presentation in which SAR imagery was used during 2016- 2020.

Mosul Dam is considered at the moment as the most dangerous dam in the world where the persistent dissolution of gypsum in its foundation is challenging the continuous grouting works that are carried out in a non-stop mode and putting the dam on the verge of failure. This condition has merited the importance attached to it and the attention devoted to its stability leading therefore to the use of the most up to date satellite remote sensing for the observation of its integrity.

The deteriorating conditions have been showing in; three dimensional displacements on the dam body, migration of the dissolution zone in deeper formations, increased dissolved volume rates when grouting stopped during 2014- 
2015 indicating the absolute necessity of continuous maintenance grouting, increased subsidence when maintaining high water levels in the reservoir beyond elevation 319 (a.s.1) which occurred during the winters of 2014-2015 and 20162017, fall 2015 and 2016, and spring 2016 and 2017.

The latest study carried out in 2020 showed that the dam was still in a strong destabilization conditions and it appeared to be divided into two parts: the northern part was accelerating rapidly while the southern part was decelerating and a main crack in this north-south junction was found. Moreover, this study confirmed the results of the previous studies. Clearly, the results of all these studies should be translated in to management procedures to which the dam management and owner must adhere to. These shall be:

- First, grouting works must be continued until permanent economical and technical feasible solution is found.

- Second, strong vigilance over the dam stability conditions must be kept all the time by following the enhanced monitoring and observation systems installed in 2016 in accordance with the time schedules and frequencies prescribed.

- Third, frequent satellite remote sensing studies must be performed to extend the information gathered by the conventional monitoring systems to discover any missed anomalies and have an overall view of the damfoundation interaction and dam reactions.

Other cases of using (SAR) techniques are mentioned in this review to show their universal application; such as the Pertusillo arch dam in Basilicata, Italy and references to more cases are given to other similar cases.

The remote sensing application of GNSS as one more advanced technique used for the deformation and instability monitoring of dams is touched upon lightly in the review, but the reader is referred to ten cases as supplemental reading and a list is given of the references.

Generally speaking, it may be concluded that in spite of the large volume of research done on this subject so far, of which this review cites some, the expected future developments in remote sensing technology coupled with advances in algorithms and models used in refining satellite imagery and validate the results, will bring more accurate result and less laborious treatment work. 


\section{References}

[1] Planteck-Italia (2020). On- Line Course of Remote Sensing. Accessed on $27^{\text {th }}$ July 2020.

https://www.planetek.it/eng/training_courses/online_manuals/on_line_course of remote_sensing/1_course introduction

[2] Casagli, N., Tofani, V., Ciampalini, A., Raspini, F., Lu, P. and Morelli, S. (2018). XT-tool 2.039-3.1: Satellite Remote Sensing Techniques for Landslides Detection and Mapping. $\mathrm{n}$ book: Landslide Dynamics: ISDR-ICL Landslide Interactive Teaching Tools. January. https://www.researchgate.net/publication/322102246_TXT-tool_203931_Satellite_Remote_Sensing_Techniques_for_Landslides_Detection_and_ Mapping

[3] Barzaghi, R., Cazzaniga, N. E., De Gaetani, C., di Milano, P., Pinto, L. and Tornatore, V. (2018). Estimating and Comparing Dam Deformation Using Classical and GNSS Techniques. MDPI, Sensors Vol. 18, Issue 3, March. https://www.mdpi.com/1424-8220/18/3/756/htm

[4] Wikipedia (2020). Glonass. Accessed on 27th July. https://en.wikipedia.org/wiki/GLONASS

[5] Military Leak blog (2020). Final Satellite Completes China's BeiDou Global Navigation Network. Accessed on 27th July.

https://militaryleak.com/2020/06/24/final-satellite-completes-chinas-beidouglobal-navigation-network/

[6] Cholan, R. R. (2018). IAS Preparation on line. "IRNSS (Indian Regional Navigational Satellite System). August 6. Accessed on 27th July 2020. https://www.iaspreparationonline.com/irnss-indian-regional-navigationalsatellite-system/

[7] QZSS Site. (2020). What is the Quasi-Zenith Satellite System (QZSS)?. Accessed on 27th July.

https://qzss.go.jp/en/overview/services/sv02_why.html

[8] UN (2012). Global Navigation Satellite Systems. Education Curriculum. Office for Outer Space Affairs, Vienna. https://gssc.esa.int/navipedia/bookshelf/books/5.pdf

[9] Wikipedia (2020). Interferometric synthetic-aperture radar. Accessed on 27 th July.

https://en.wikipedia.org/wiki/Interferometric_synthetic-aperture_radar

[10] Cifres, R. G. and Cooksley, G. (2016). Satellite Technologies for Dam Motion Monitoring. Proceedings of 3rd Joint International Symposium on Deformation Monitoring (JISDM) $30^{\text {th }}$ March-1st April, Vienna, Austria. https://pdfs.semanticscholar.org/25ff/c8488047091cb3d7d56c4feb95b470569 183.pdf?_ga=2.13023543.1878940196.1595780031$1325417008.1592236244 \mathrm{f}$ 
[11] Planteck- Italia. (2020). The history of remote sensing. Accessed on 28th July. https://www.planetek.it/eng/training_courses/online_manuals/on_line_course _of_remote_sensing/2_the_history_of_remote_sensing.

[12] Humboldt State University (2020). History of Remote Sensing. Accessed on 28th July. http://gis.humboldt.edu/OLM/Courses/GSP_216_Online/lesson11/history.html.

[13] Smithsonian National Air and Space Museum (2020). Looking at Earth-The sky Spies. Accessed on 28th July. https://airandspace.si.edu/exhibitions/looking-at-earth/online/the-sky-spies/

[14] Wikipedia (2020). Seasat. Accessed on 28th July. https://en.wikipedia.org/wiki/Seasat\#cite_note-5

[15] Buis, A. (2013). Trailblazer Sea Satellite Marks its Coral Anniversary. Jet Propulsion Laboratory, June 27. https://www.jpl.nasa.gov/news/news.php?release=2013-208

[16] Bagchi, D. R. and Bussa, R. (2010). Application of Remote Sensing in Water "Quality and Water Resources Management - An Overview". Bhujal News Quartet Journal, July-Dec. and Jan-Dec, 2011. Submitted by Hindi on Mon, 05/09/2016 https://hindi.indiawaterportal.org/content/application-remotesensing-water-quality-and-water-resources-management-overview/contenttype-page/53244

[17] Nagesh, D., Kumar, D. N. and Reshmidevi, T. V. (2019). Remote Sensing Applications in Water. Journal of the Indian Institute of Science, A Multidisciplinary Reviews Journal. Indian Institute of Science Resources. January https://www.researchgate.net/publication/330396782_Reviews_Remote_Sens ing_Applications_in_Water_Resources

[18] Rango, A. (1994). Application of remote sensing methods to hydrology and water resources. Hydrological Sciences Journal, Vol.39, No.4, pp.309-320, August 1994. Published online: 29 Dec 2009

https://www.tandfonline.com/doi/pdf/10.1080/02626669409492752?needAcc ess $=$ true

[19] Global Water Security and Sanitation Partnership (2009). New Avenues for Remote Sensing Applications for Water Management. Water Global practice, pp.43-45, June.

http://documents1.worldbank.org/curated/en/810581561961939655/pdf/NewAvenues-for-Remote-Sensing-Applications-for-Water-Management-ARange-of-Applications-and-the-Lessons-Learned-from-Implementation.pdf

[20] NASA (2020). Global Precipitation Measurement-TRMM Microwave Imager (TMI). Accessed on 29th July. https://gpm.nasa.gov/missions/TRMM/satellite/TMI

[21] Collins Aero Space (2020). Laser Radar/LIDAR/LADAR including Eye-safe Lasers. Accessed on 29th July.

http://www.sensorsinc.com/applications/military/ladar 
[22] Wikipedia. (2020). Lidar. Accessed on 29th July. https://en.wikipedia.org/wiki/Lidar

[23] Alonzo, M. (2013). Did you say LiDAR or LADAR?. Harris Geospatial Solutions, February 14. https://www.harrisgeospatial.com/Learn/Blogs/BlogDetails/ArtMID/10198/ArticleID/16391/Did-you-say-LiDAR-or-LADAR

[24] Wikimedia (2013). Remote Sensing Illustration.jpg. November $20^{\text {th }}$. Accessed on 29th July 2020 https://commons.wikimedia.org/wiki/File:Remote_Sensing_Illustration.jpg

[25] Mårtensson, U. (2011). Introduction to Remote Sensing and Geographical Information. Department of Physical Geography and Ecosystems Sciences Lund University. Lund, December 2011. https://www.nateko.lu.se/sites/nateko.lu.se.sv/files/remote_sensing_and_gis_ 20111212.pdf

[26] NASA (2015). Climate Variability, Hydrology, and Flooding-Fundamentals of Remote Sensing. Latin American and Caribbean Water Cycle Capacity Building Workshop Cartagena, Colombia, May 19-22. https://arset.gsfc.nasa.gov/sites/default/files/users/S1_P4_RSbasics_final.pdf

[27] Canada Centre for Remote Sensing (Undated). Fundamentals of Remote Sensing. Remote Sensing Tutorial.

https://www.nrcan.gc.ca/sites/www.nrcan.gc.ca/files/earthsciences/pdf/resour ce/tutor/fundam/pdf/fundamentals_e.pdf

[28] Eurocode Standards (2020). The use of remote sensing in civil engineering. Theory of Structures, Last Updated on 24 Jul 2019. Accessed on 30th July 2020.https://www.eurocode.us/theory-of-structures/the-use-of-remotesensing-in-civil-engineering.html

[29] Qureshi, M. A. (2010). Dam/reservoir sites selection using remote sensing and GIS techniques. Conference: Bridging the Gap through Satellite Technology: 18-21 October. Cairo, Egypt. https://www.researchgate.net/publication/271531649_DAM_RESERVOIR_S ITES_SELECTION_USING_REMOTE_SENSING_GIS_TECHNIQUES

[30] The Swedish Royal Institute of Technology (KTH) (2020). ArcGIS, the platform for designing and managing solutions through the application of geographic knowledge. Accessed on 31st July. https://www.kth.se/student/kth-it-support/software/download/arcgis

[31] Wikipedia (2020). SPOT-Satellite. Accessed on 31st July. https://en.wikipedia.org/wiki/SPOT_(satellite)

[32] Wikipedia (2020). Shuttle Radar Topography Mission. Accessed on 31st July. https://en.wikipedia.org/wiki/Shuttle_Radar_Topography_Mission 
[33] Rapley, C., Guzkawska, A. J., Cudlip, W. and Mason, I. (1987). An Exploratory Study of Inland Water Altimetry Using Seasat Data. European Space Agency. Final Report, Contract No: 6483/85/NL/B1, Chapter 5, pp.89 , February. https://www.researchgate.net/publication/269518719_An_Exploratory_Study _of_Inland_Water_and_Land_Altimetry_Using_Seasat_Data

[34] Cazenave, A., Bonnefond, P., Dominh, K. and Schaeffer, P. (1997). Caspian sea level from Topex-Poseidon altimetry' Level now falling. Geophysical Research Letters Vol. 24, No.8, pp.881-884, April 15. https://agupubs.onlinelibrary.wiley.com/doi/pdf/10.1029/97GL00809

[35] Gao, H., Birkett, C. and Lettenmaier, D. P. (2012). Global monitoring of large reservoir storage from satellite remote sensing. Water Resources Research, Vol. 48, W09504. Received 29 February 2012; revised 5 July 2012; accepted 9 July 2012; published 5 September. https://agupubs.onlinelibrary.wiley.com/doi/pdf/10.1029/2012WR012063

[36] Global Dam Watch (2020). Global Reservoir and Dam Database (GRanD). Accessed on 31st July 2020. http://globaldamwatch.org/grand/.

[37] European Space Agency (2020). Landsat TM/ETM. eesa online. Accessed on 1st August. https://earth.esa.int/web/guest/missions/3rd-partymissions/historical-missions/landsat-tmetm

[38] Liebe, J. R., de Giesen, N., Andreini, M. S., Steenhuis, T. S. and Walter, M. T. (2009). Suitability and Limitations of ENVISAT ASAR for Monitoring Small Reservoirs in a Semiarid Area. IEEE Transactions on Geoscience and Remote Sensing, Vol.47, No.5, May. https://www.researchgate.net/publication/224358121_Suitability_and_limitat ions_of_ENVISAT_ASAR_for_monitoring_small_reservoirs_in_a_semiarid area

[39] Wikipedia (2020). Envisat. Accessed on 2nd August. https://en.wikipedia.org/wiki/Envisat

[40] European Space Agency (2020). Envisat. Accessed on 2nd August. https://earth.esa.int/web/sppa/mission-performance/esa-missions/envisat

[41] European Space Agency (2020). ASAR. Accessed on 2nd August. https://earth.esa.int/web/sppa/mission-performance/esamissions/envisat/asar/sensor-modes

[42] Sawunyama, T., Senzanjeb, A. and Mhizha, A. (2006). Estimation of small reservoir storage capacities in Limpopo River Basin using geographical information systems (GIS) and remotely sensed surface areas: Case of Mzingwane catchment. Journal of Physics and Chemistry of the Earth, Volume 31, Issues 15-16. https://core.ac.uk/reader/145046238 
[43] Love, D., Taigbenu, A. E. and Jonker, L. (2005). An overview of the Mzingwane Catchment, Zimbabwe. International Agricultural Research (CGIAR). A contribution to the Water Net Challenge Program Project 17. Water Net Working Paper 1 February. https://assets.publishing.service.gov.uk/media/57a08ca1e5274a27b2001305/ WP1-Mzingwane.pdf

[44] Jenness, J. (2008). Surface tools for points, lines, and polygons v. 1.6b. Jenness Enterprises. http://www.jennessent.com/downloads/Surface_Tools_Online.pdf

[45] Wyrick, D. (2003). Software validation test for ArcView, Version 3,2, 3.2a. U.S. Nuclear Regulatory Commission Contract NRC-02-02-012 Report. June. https://www.nrc.gov/docs/ML0527/ML052770258.pdf

[46] Sawunyama, T. (2005). Master's degree dissertation on the Integrated Water Resources Management in Limpopo River basin using GIS and remotely sensed surface areas. Department of Civil Engineering, Faculty of Engineering, University of Zimbabwe, June. https://core.ac.uk/download/pdf/132641263.pdf

[47] Golden Software (2020). Surfer, Explore the depth of your data. Accessed on 2nd August.

https://www.goldensoftware.com/products/surfer

[48] Rodrigues, L. N., Sano, E. E., Steenhuis, T. S. and Passo, D. P. (2012).

Estimation of Small Reservoir Storage Capacities with Remote Sensing in the Brazilian Savannah Region. Journal of Water Resources Management, Volume 26, Issue 4, pp.873-882, March. https://www.researchgate.net/profile/Lineu_Rodrigues/publication/25767295 1_Estimation_of_Small_Reservoir_Storage_Capacities_with_Remote_Sensin g_in_the_Brazilian_Savannah_Region/links/004635303c87b0ae6c000000.pd f

[49] Rango, A. (2009). Application of remote sensing methods to hydrology and water resources. Hydrological Sciences Journal, Received 17 Nov 1993, Accepted 08 Mar 1994, Published online: 29 Dec 2009 39:4, 309-320. https://www.tandfonline.com/doi/pdf/10.1080/02626669409492752

[50] Frappart, F. and Bourrel, L. (2018). The Use of Remote Sensing in Hydrology. The Journal Water Special Issue May. https://www.mdpi.com/books/pdfview/book/642

[51] Gao, J. (2009). Bathymetric mapping by means of remote sensing: methods, accuracy and limitations. Progress in Physical Geography 33(1) pp.103-116. https://pdfs.semanticscholar.org/627a/27ce12e9aa4135f8e352059b9c06f56dd fc4.pdf

[52] Wikipedia (2020). Lidar. Accessed on 4th July. https://en.wikipedia.org/wiki/Lidar

[53] National Oceanic and Atmosphere Administration (NOAA). (2020). What is VDatum Software?. Accessed on 4th July. https://oceanservice.noaa.gov/facts/vdatum.html 
[54] Tronvig, A. K. (2008). Geospatial Products and Ecological-Near-shore Bathymetry. Hydro International Magazine. 1st January.

https://www.hydro-international.com/content/article/near-shorebathymetry?output=pdf

[55] Saylam, K., Brown, R. A. and Hupp, J. R. (2017). Assessment of depth and turbidity with airborne Lidar bathymetry and multiband satellite imagery in shallow water bodies of the Alaskan North Slope. International Journal of Applied Earth Observation and Geoinformation, Vol.58, June, pp.191-200. https://www.sciencedirect.com/science/article/abs/pii/S0303243417300387?v ia\%3Dihub

[56] Getirana, A., Jung, H. C. and Tseng, K. H. (2018). Deriving three dimensional reservoir bathymetry from multi-satellite datasets. NASA Technical Reports Server. doi:10.1016/j.rse.2018.08.030, August. https://ntrs.nasa.gov/archive/nasa/casi.ntrs.nasa.gov/20180006586.pdf

[57] NASA (2020). ICESat and ICESat-2. Accessed on 4th August. https://icesat.gsfc.nasa.gov/.

[58] Li, Y., Gao, H., Michael, F., Zhang, S., and Stoll, J. D. (2019). Deriving High-Resolution Reservoir Bathymetry From ICESat-2 Prototype PhotonCounting Lidar and Landsat Imagery. EEE transactions on Geoscience and Remote Sensing, Vol.57, No.10, pp.7883-7893, October. https://www.researchgate.net/publication/333856800_Deriving_HighResolution_Reservoir_Bathymetry_From_ICESat-2_Prototype_PhotonCounting_Lidar_and_Landsat_Imagery

[59] Li, Y., Gao, H., Zhao, G. and Tseng. K. (2020). A high resolution bathymetry dataset for global reservoirs using multi-source satellite imagery and altimetry. Remote Sensing of Environment Journal, Vol.244, July. (111831) https://www.sciencedirect.com/science/article/abs/pii/S0034425720302017

[60] EU Joint Research Centre (2020). Global Surface Water - Data Access. Accessed on 5th August 2020. https://global-surfacewater.appspot.com/download

[61] Jagalingam, P., Akshaya, B. J. and Hegde, A. V. (2015). Bathymetric Mapping Using Landsat8 Scattered Imagery. Procedia Engineering, Volume 116, pp.560-566. https://www.sciencedirect.com/science/article/pii/S1877705815019815

[62] Elsahabi, M. A., Makboul, O. and Negm. A. M. (2018). Lake Nubia Bathymetry Detection by Satellite Remote Sensing. International Water Technology Journal, IWTJ, Vol.8, No.1, March. https://www.researchgate.net/publication/324862074_LAKE_NUBIA_BAT HYMETRY_DETECTION_BY_SATELLITE_REMOTE_SENSING 
[63] Zhu, S., Liu, B., Wan, W., Xie, H., Fang, Y., Chen, X., Huan, Li. H., Fang, W., Zhang, G., Tao, M. and Hong, Y. (2019). A New Digital Lake Bathymetry Model Using the Step-Wise Water Recession Method to Generate 3D Lake Bathymetric Maps Based on DEMs. Water Journal 2019, Vol.11, No.11, 2419 Published: published on 19 November. https://www.mdpi.com/20734441/11/11/2419

[64] Vishwakarma, Y., Tiwari, H. L. and Jaiswal. R. K. (2015). Assessment of Reservoir Sedimentation Using Remote Sensing Technique with GIS ModelA Review. International Journal of Engineering and Management Research Vol.5, No.3, pp.411- 417, June.

https://www.ijemr.net/DOC/AssessmentOfReservoirSedimentationUsingRem oteSensingTechniqueWithGISModelAReview(411-417).pdf

[65] Jain, Sanjay, K., Jain, Shardad, K. and Sharma, K. D. (2005). Estimation of soil erosion and sedimentation in Ramganga Reservoir (India) using remote sensing and GIS. Sediment Budgets 1\&2, Proceedings of symposium held during the Seventh IAHS Scientific Assembly at Foz do Iguaçu, Brazil, April 2005. IAHS Publication Number 292, 2005. ISBN Number: 978-1-901-50292-3 https://iahs.info/uploads/dms/13082.45\%20315-323\%20Foz\%20S1210\%20Jain.pdf

[66] Tour My India (2020). Ramganga River Uttarakhand. Accessed on 7th August. https://www.tourmyindia.com/states/uttarakhand/ramganga-river.html

[67] ITC Satellites and Sensor Data Base (2020). LISS-3 RESOURCESAT. University of Twente, Netherlands. Accessed on 7th August. https://webapps.itc.utwente.nl/sensor/getsen.aspx?name=LISS3\%20(RESOURCESAT)

[68] Wikipedia (2020). Indian Remote Sensing Programme. Accessed on 7th August. https://en.wikipedia.org/wiki/Indian_Remote_Sensing_Programme\#IRS_Syst em

[69] Desai, V. R., Mishra, A. and Kumar, A. Lesson 10 Prioritization of Watersheds. Watershed Planning and Management, undergraduate Courses in the stream of Agricultural Engineering, Anand Agricultural University, Anand (Gujarat) as Lead Center. http://ecoursesonline.iasri.res.in/mod/page/view.php?id=414

[70] Horvath, E. (2011). Using GIS for Prioritization in Sub-watershed Restoration. Pennsylvania State University Master Project in Geographic Information Systems, November 28. https://gis.eeducation.psu.edu/sites/default/files/capstone/HorvathE_FinalReport_201111 10.pdf

[71] Remote Sensing and GIS software (2020). Remote Sensing and GIS software-Integrated Land and Water Information System (ILWIS). University of Twente, Netherlands. Accessed on 7th August 2020 https://www.itc.nl/ilwis/ 
[72] Wikipedia (2020). Tasseled cap transformation. Accessed on 6th August. https://en.wikipedia.org/wiki/Tasseled_cap_transformation

[73] Hexagon's Geospatial Division (2020). ERDAS IMAGINE: World-Class Remote Sensing Software. Accessed on 7th August. https://www.hexagongeospatial.com/products/power-portfolio/erdasimagine/erdas-imagine-remote-sensing-software-package

[74] Sharad. K. and Sanjay, K. J. (2009). Assessment of reservoir sedimentation using remote sensing. Sedimentation Problems and Sediment management in Asian River Basins. Proceedings of the workshop held at Hyderabad, India, September, pp.163- 169. https://iahs.info/uploads/dms/16303.21-163-170349-16-Res-Sed-Hyderabad-Jain.pdf

[75] Apip, Takara, K. and Yamashki, Y. (2009). Spatially-distributed assessment of sediment yield and shallow landslide potential area in the upper Citarum River basin, Indonesia. Sediment Problems and Sediment Management in Asian River Basins, Proceedings of the Workshop held at Hyderabad, India, pp.130- 140 September. IAHS Publ. 349, 2011 https://www.researchgate.net/publication/287028770_Spatiallydistributed_assessment_of_sediment_yield_and_shallow_landslide_potential _area_in_the_upper_Citarum_River_basin_Indonesia

[76] Satellite Imaging Corporation (2020). LANDSAT 7 ETM+ Satellite Sensor. Accessed on 8th August. https://www.satimagingcorp.com/satellitesensors/other-satellite-sensors/landsat/

[77] DATA. GOV. (2019). HydroSHEDS: The Hydrological data and maps based on Shuttle Elevation Derivatives at multiple Scales. Updated on August 15. https://catalog.data.gov/dataset/hydrosheds-the-hydrological-data-and-mapsbased-on-shuttle-elevation-derivatives-at-multiple-sc

[78] Indirect Assessment of Sedimentation in Hydropower Dams Using MODIS Remote Sensing Images https://horizon.documentation.ird.fr/exldoc/pleins_textes/divers19-03/010075282.pdf

[79] Schellenberg, G., Donnelly, R. C., Holder, C. and Ahsan, R. (2017). Dealing with Sediment: Effects on Dams and Hydropower Generation. HydroReview, Issue 1 and Vol.25, 22nd February. https://www.hydroreview.com/2017/02/22/dealing-with-sediment-effects-ondams-and-hydropower-generation/

[80] Khadatare, M. Y. and Jedhe, S. H. (2017). Sediment Assessment of UJJANI Reservoir in Maharashtra by using Remote Sensing Technique. International Research Journal of Engineering and Technology (IRJET), Vol.4, No.8, pp.1255-1258, Aug. https://www.irjet.net/archives/V4/i8/IRJET-V4I8223.pdf

[81] Wikipedia (2020). Landsat 7. Accessed on 9th August. https://en.wikipedia.org/wiki/Landsat_7 
[82] Dadoria, D. and Tiwari, H. L. (2017). Assessment of Reservoir Sedimentation in Chhattisgarh State Using Remote Sensing and GIS. International Journal of Civil Engineering and Technology (IJCIET). Vol. 8, No.4, pp.526-534, April. http://www.iaeme.com/IJCIET/issues.asp?JType=IJCIET\&VType=8\&IType $=4$ ISSN Print: 0976-6308 and ISSN Online: 0976-6316 https://www.researchgate.net/publication/317217526_Assessment_of_reserv oir_sedimentation_in_Chhattisgarh_state_using_remote_sensing_and_GIS

[83] Pandey, A., Chaube, U. C., Mishra, S. K. and Kumar, D. (2016). Assessment of reservoir sedimentation using remote sensing and recommendations for desilting Patratu Reservoir, India. Hydrological Science Journal, Vol. 61, No. 4, pp.711-718. https://www.tandfonline.com/doi/pdf/10.1080/02626667.2014.993988

[84] Gitelson, A. A., Schalles, J. F. and Hladik, C. M. (2007). Remote chlorophylla retrieval in turbid, productive estuaries: Chesapeake Bay case study. Journal of Remote Sensing of Environment 109. $464-472$. https://www.researchgate.net/publication/222699458_Remote_chlorophylla_retrieval_in_turbid_productive_estuaries_Chesapeake_Bay_case_study

[85] Kumar, D. N. and Reshmidevi, T. V. (2013). Remote Sensing Applications in Water Resources. Journal of the Indian Institute of Science, Vol.93, No.2, pp.163-187, Apr.-Jun. http://citeseerx.ist.psu.edu/viewdoc/download;jsessionid=DE93D01E8E3AC B3C9FDBDECE01FD92E2?doi=10.1.1.399.2910\&rep=rep1\&type=pdf

[86] Wikipedia (2020). SeaWiFS. Accessed on 9th August. https://en.wikipedia.org/wiki/SeaWiFS

[87] USBR (2005). Remote Sensing Technology: Guidelines and Applications within the Bureau of Reclamation. Series Report Number D-8260-05-05, pp.52-62, September. https://www.usbr.gov/tsc/techreferences/mands/mands-pdfs/RemtSens.pdf

[88] Wikipedia (2020). Landsat 5. Accessed on 10th August. https://en.wikipedia.org/wiki/Landsat_5

[89] USGE (2020). Landsat 4. Landsat Missions. Accessed on 10th August. https://www.usgs.gov/land-resources/nli/landsat/landsat-4?qtscience_support_page_related_con $=0 \# q t-$ science support_page related_conAccessed on 10th August 2020

[90] Topp, S. N., Pavelsky, T. M., Jensen, D., Simard, M. and Ross, M. R. V. (2020). Research Trends in the Use of Remote Sensing for Inland Water Quality Science: Moving Towards Multidisciplinary Applications. MDPI Journals, Water, Vol.12, Issue Published on 7 January. https://www.mdpi.com/2073-4441/12/1/169/htm 
[91] Atique, U. and Kwang-Guk, A. (2019). Reservoir Water Quality Assessment Based on Chemical Parameters and the Chlorophyll Dynamics in Relation to Nutrient Regime. Polish Journal of Environmental Studies, Vol.28, No.3, pp.1043-1061. http://www.pjoes.com/Reservoir-Water-Quality-AssessmentBased-non-Chemical-Parameters-and-the-Chlorophyll,85675,0,2.html

[92] Hansen, C. H., Williams, G. P., Adjei, Z., Barlow, A. E., Nelson. E. J, and Woodruff Miller A. (2015). Reservoir water quality monitoring using remote sensing with seasonal models: case study of five central-Utah reservoirs. The North American Lake Management Society. Lake and Reservoir Management Journal, Vol.31, No.3, pp.225-240. Published online: 21 Aug 2015. https://www.tandfonline.com/doi/pdf/10.1080/10402381.2015.1065937?need Access $=$ true

[93] Avdan, Z. Y., Kaplan, G., Goncu, S. and Avdan U. (2019). Monitoring the Water Quality of Small Water Bodies Using High-Resolution Remote Sensing Data. MDPI, ISPRS International Journal of Geo-Information, Vol. 8, No.12. https://www.mdpi.com/2220-9964/8/12/553/pdf

[94] Wikipedia (2020). RapidEye. Accessed on 11th August. https://en.wikipedia.org/wiki/RapidEye

[95] NASA (2020). Landsat 9. Landsat Science. Accessed on 12th August. https://landsat.gsfc.nasa.gov/landsat-9/

[96] Alvarez, V. M., González-Real, M. M., Baille, A., Maestre, A., Valero, J. F. and Elvira, B. G. (2008). Regional assessment of evaporation from agricultural irrigation reservoirs in a semiarid climate. J. Agricultural Water Management, Vol.95, No.9, September, pp.1056-1066.

https://www.sciencedirect.com/science/article/abs/pii/S0378377408000917?v ia\%3

[97] Rost, S., Gerten, D., Bondeau, A, Lucht, W., Rohwer, J. and Schaphoff, S. (2008). Agricultural green and blue water consumption and its influence on the global water system. Water Resources Research, Vol.44, No.9, September. https://agupubs.onlinelibrary.wiley.com/doi/10.1029/2007WR006331

[98] Zaho, G. and Gao, H. (2019). Estimating reservoir evaporation losses for the United States: Fusing remote sensing and modeling approaches. Journal of Remote Sensing of Environment, Vol.226, No. 1, June, pp.109-124. https://www.researchgate.net/publication/332426877_Estimating_reservoir_e vaporation_losses_for_the_United_States_Fusing_remote_sensing_and_mod eling_approaches

[99] McGloin, R., McGowan, H., McJannet, D., Cook, F., Sogachev, A. and Burn, S. (2014). Quantification of surface energy fluxes from a small water body using scintillometry and eddy covariance. Water Resources Research, Vol.50, No.1, January, pp.494-513. https://agupubs.onlinelibrary.wiley.com/doi/full/10.1002/2013WR013899 
[100] Phillips, R. C., Saylor, J. R., Kaye, N. B. and Gilbert, J. M. (2016). A multi-lake study of seasonal variation in lake surface evaporation using MODIS satellite-derived surface temperature. The Japanese Society of Limnology, 17:273-289 Published 16 April. http://cecas.clemson.edu/ jsaylor/paperPdfs/limnology.v17.2016.pdf

[101] Craig, I. P. (2005). Loss of Storage due to Evaporation. National Centre for Engineering in Agriculture, Toowoomba. https://eprints.usq.edu.au/2660/1/Craig_2005_Evap_Lit_Review.pdf

[102] Mu, Q., Zhao, M., and Running, S. W. (2013). MODIS Global Terrestrial Evapotranspiration (ET) Product (NASA MOD16A2/A3)Algorithm Theoretical Basis Document Collection 5 Collection 5. NASA Headquarters, November 20.

https://www.researchgate.net/publication/315700715_Algorithm_Theoretical _Basis_Document_MODIS_Global_Terrestrial_Evapotranspiration_ET_Prod uct_NASA_MOD16A2A3_Collection_5_NASA_Headquarters

[103] Phillips, R. C., Saylor, J. R., Kaye, N. B. and Gibert, J. M. (2016). A multi-lake study of seasonal variation in lake surface evaporation using MODIS satellite-derived surface temperature. Limnology 17, pp.273-289. http://cecas.clemson.edu/ jsaylor/paperPdfs/limnology.v17.2016.pdf https://ladsweb.modaps.eosdis.nasa.gov/missions-andmeasurements/products/MOD11A1/

[104] Espinoza, G. E. (2020). Harmonic Analysis of Time Series (HANTS). Integrated Water Systems and Governance, IHE Delft Institute for Water Education. Accessed on 14th August. https://github.com/gespinoza/hants

[105] Hua, Z., Gorelick, S. M., Zimba, P. V. and Zhang, X. (2017). A remote sensing method for estimating regional reservoir area and evaporative loss. Journal of Hydrology,Vol.555, December,pp.214-227 https://www.sciencedirect.com/science/article/abs/pii/S0022169417306716?v ia\%3Dihub or https://www.osti.gov/pages/servlets/purl/1415402

[106] Landsat Science (2020). The Worldwide Reference System. Accessed on 14th August. https://landsat.gsfc.nasa.gov/the-worldwide-reference-system/

[107] ESIR-ArcGIS Pro. (2020). Indices gallery. Accessed on 14th August. https://pro.arcgis.com/en/pro-app/help/data/imagery/indices-gallery.htm

[108] Liebe, J. R., van de Giesen, N., Andreini, M. S., Walter, M. T. and Steenhuis, T. S. (2009). An eye on small reservoirs: remote sensing of storage volumes, their use as remotely sensed runoff gauges, and evaporation losses. Geophysical Research Abstracts, Vol. 11, European Geosciences Union General Assembly 2009. Vienna, Austria, 19-24 April.

https://www.researchgate.net/publication/253422220_An_eye_on_small_rese rvoirs_remote_sensing_of_storage_volumes_their_use_as_remotely_sensed_ runoff_gauges_and_evaporation_losses 
[109] Hassan, M. (1013). Evaporation estimation for Lake Nasser based on remote sensing technology. Ain Shams University, Ain Shams Engineering Journal, Vol. 4, No.4, December, pp.593-604 https://paradigmaps.geo.unihalle.de/klimawandel/sites/default/files/Evaporation\%20estimation\%20for\% 20Lake\%20Nasser\%20based\%20on\%20remote\%20sensing\%20technology.p df

[110] Evaluating evaporation rate from high Aswan Dam Reservoir using RS and GIS techniques (2018). The Egyptian Journal of Remote Sensing and Space Science, Vol. 21, No.3, December, pp.285-293 https://reader.elsevier.com/reader/sd/pii/S1110982317300340?token=A4F5F 5BFA04678FE7C500261BA824E310B77B287DA83CF205CC8BE6780C74 1459529EA73A43866FF9C4C43811A8D92D5

[111] Friedrich, K., Grossman, R. L., Huntington, J., Blanken, P. D, Lenters, J., Holman, K. D., Gochis, D., Livneh, B., Prairie, J., Skeie, E., Healey, N. C., Dahm, K., Pearson, C., Finnessey, T., Hook, S. J. and Kowalski, T. (2018). Reservoir Evaporation in the Western United States: Current Science, Challenges, and Future Needs. Bulletin of the American Meteorological Society, Vol.99, No.1, January. https://journals.ametsoc.org/bams/article/99/1/167/216151/ReservoirEvaporation-in-the-Western-United-States

[112] Wikipedia (2020). Interferometric synthetic-aperture radar. Accessed on $16^{\text {th }}$ August.

https://en.wikipedia.org/wiki/Interferometric_synthetic-aperture_radar

[113] Scaioni, M. and Wang, J. (2016). Technologies for Dam Deformation Measurement: Recent Trends and Future Challenges. Proceedings of the 3rd Joint International Symposium on Deformation Monitoring, 30 March-1 April, 2016. Vienna University of Technology, Vienna, Austria. http://www.fig.net/resources/proceedings/2016/2016_03_jisdm_pdf/nonrevie wed/JISDM_2016_submission_79.pdf

[114] Oguchi, T., Hayakawa, Y., and Wasklewicz (2011). Chapter 7-Data Sources. Geomorphological Mapping,Vol.15, pp.189-224 https://www.sciencedirect.com/science/article/pii/B9780444534460000070. or, from: "Terrestrial Laser Scanning-Geomorphological Mapping" https://www.sciencedirect.com/topics/earth-and-planetarysciences/terrestrial-laser-scanning

[115] Pieraccini, M. and Miccinesi, L. (2019). Ground-Based Radar Interferometry: A Bibliographic Review. MDPI, Remote Sensing, Vol.11, No.9, 30 April. https://www.mdpi.com/2072-4292/11/9/1029/htm

[116] Capra, A., Scaioni, M. and Wieser, A. (2015). Editorial-Special issue: terrestrial remote sensing for areal deformation monitoring. Applied Geomatics Vol.7, pp.61-63. https://link.springer.com/content/pdf/10.1007\%2Fs12518-015-0159-y.pdf 
[117] Cifres, R. and Cooksley, G. (2016). Satellite Technologies for Dam Motion Monitoring. Proceeding of the 3rd Joint International Symposium on Deformation Monitoring, from 30 March to 01 April 2016, Vienna University of Technology, Vienna, Austria. https://www.fig.net/resources/proceedings/2016/2016_03_jisdm_pdf/nonrevi ewed/JISDM_2016_submission_23.pdf

[118] DePriest, D. (2020). Differential GPS. Last revision on 06/03/2015. Accessed on 16th August. http://www.gpsinformation.org/dale/dgps.htm

[119] Wikipedia (2020). Kalman filter. Accessed on 16th August. https://en.wikipedia.org/wiki/Kalman_filter

[120] Hudnut, K. W. and Behr, J. A (1998). Continuous GPS Monitoring of Structural Deformation at Pacoima Dam, California.

https://pubs.geoscienceworld.org/ssa/srl/articleabstract/69/4/299/142324/Continuous-GPS-Monitoring-of-Structural

[121] Behr, J., Hudnut, K. W., and King, N. E. (2017). Monitoring Structural Deformation at Pacoima Dam, California Using Continuous GPS. Seismological Research Letters,1998,Vol.69,No. 4,pp.299-309, first online March.

https://www.researchgate.net/publication/252210598_Monitoring_Structural _Deformation_at_Pacoima_Dam_California_Using_Continuous_GPS

[122] Stewart, M. and Tsakri, M. The Application of GPS to Dam Surface Monitoring. Journal of Geospatial Engineering, Vol.3, No.1, pp.45-57.

January 2001, uploaded on 26 September 2014.

https://www.researchgate.net/publication/253756970_The_Application_of_G PS_To_Dam_Surface_Monitoring

[123] Hillman, B. A., Rutledge, D. R., Meyerholtz, S. Z., Cory, S. and Baldwin, C. S. (2003). Using Global Positioning Systems to Monitor Movement in Dams. Hydro Review 4.7.16. Originally published in the September 2003 issue of Hydro Review. https://www.hydroreview.com/2016/04/07/using-global-positioning-systemsto-monitor-movement-in-dams/

[124] Adamo, N., Al- Ansari, N. (2016). Mosul Dam the Full Story: Engineering Problems. Journal of Earth Sciences and Geotechnical Engineering, Vol.6, No.3, pp.213-244, ISSN: 1792-9040 (print version), 1792-9660 (online).

https://www.diva portal.org/smash/get/diva2:984931/FULLTEXT01.pdf

[125] Adamo, N. and Al- Ansari, N. (2016). Mosul Dam Full Story: Safety Evaluations of Mosul Dam. Journal of Earth Sciences and Geotechnical Engineering, Vol.6, No. 3, 2016, pp.185-212 ISSN: 1792-9040 (print version), 1792-9660 (online). http://www.diva-portal.org/smash/get/diva2:988308/FULLTEXT01.pdf 
[126] Adamo, N. and Al- Ansari, N. (2016). Mosul Dam Full Story: What If The Dam Fails?. Journal of Earth Sciences and Geotechnical Engineering, Vol.6, No. 3, 2016, pp.245-269, ISSN: 1792-9040 (print version), 1792-9660 (online).

http://www.diva-portal.org/smash/get/diva2:982079/FULLTEXT01.pdf

[127] Milillo, P., Bürgmann, R., Lundgren, P., Salzer, J., Perissin, D.,

Fielding, E., Biondi, F. and Milillo, G. (2016). Space geodetic monitoring of engineered structures: The ongoing destabilization of the Mosul dam, Iraq.

Nature Research Journal- Scientific Reports. Received: 05 July 2016 accepted: 28 October 2016 Published: 06 December.

https://www.nature.com/articles/srep37408.pdf

[128] Wikipedia (2020). COSMO-SkyMed. Accessed on 17th August. https://en.wikipedia.org/wiki/COSMO-SkyMed

[129] Earth Observation system (2020). About SENTINEL 1. Accessed on 17th August. https://eos.com/sentinel-1/

European Space Agency. "What is Envisat?". Accessed on 17th August 2020. https://earth.esa.int/web/guest/missions/esa-operational-eo-missions/envisat

[130] Cetinic, F. (2016). Satellite Based Information to Support Health Analysis of Mosul Dam. Mosul dam workshop 24-25 May. Stockholm https://ia601409.us.archive.org/30/items/workshop-on-mosul-dam-24-25may-2016-sthlm-reano-centic-24-052016/Workshop\%20on\%20Mosul\%20dam\%202425\%20May\%202016\%20STHLM\%20Reano\%20Centic\%20\%2024\%2005\% 202016.pdf

[131] Othman, A. A., Al- Maamar, A. F., Al-Manmi, D. M., Liesenberg, V. Hasan, S. E., Al-Saady, Y. I., Shihab, A. T. and Khwedim, K. (2019). Application of Din SAR-PSI Technology for Deformation Monitoring of the Mosul Dam, Iraq. MDPI, Journal Remote Sensing. Received: 28 August 2019; Accepted: 8 November 2019; Published: 11 November 2019 https://www.mdpi.com/2072-4292/11/22/2632/htm

[132] Berkley Seismological Laboratory (2020). PS-InSAR. Annual reports. Accessed on 18th August. https://seismo.berkeley.edu/annual_report/ar05_06/node136.html

[133] Biondi, F., Addabbo, P., Clemente, C., Ullo, S. L. and Orlando, D. (2020). Monitoring of Critical Infrastructures by Micro-Motion Estimation: The Mosul Dam Destabilization. IEE Journal of Selected Topics on Geoscience and Remote Sensing, 10 Jul. https://arxiv.org/pdf/2007.05326.pdf

[134] Open EI (2020). Exploration Technique: PSInSAR. Accessed on 19th August. https://openei.org/wiki/PSInSAR

[135] Wikipedia (2020). COSMO-SkyMed. Accesses on 19th August. https://en.wikipedia.org/wiki/COSMO-SkyMed 
[136] Mililloa, P., Perissind, D., Salzere, J. T., Lundgrenc, P., Lacavaa, G., Milillof, G. and Serio, C. (2016). Monitoring dam structural health from space: Insights from novel InSAR techniques and multi-parametric modeling applied to the Pertusillo dam Basilicata, Italy. International Journal of Applied Earth Observation and Geoinformation, 52, pp.221-229.

https://www.researchgate.net/publication/304676202_Monitoring_dam_struc tural_health_from_space_Insights_from_novel_InSAR_techniques_and_mult i-parametric_modeling_applied_to_the_Pertusillo_dam_Basilicata_Italy

[137] Talich, M., Glöckner, M., Böhm, O., Antoš, F., Soukup, L., Havrlant, J. and Šolc, J. (2014). The Application of the Ground-based InSAR Technique for the Deformation Monitoring of Concrete Hydropower Dam Orlík on Vltava River. INGEO 2014, 6th International Conference on Engineering Surveying Prague, Czech republic, April 3-4. https://www.fig.net/resources/proceedings/2014/2014_ingeo/TS602_Talich.pdf.pdf

[138] Pipitone, C., Cigna, F., Dardanelli, G., La Loggia, G. A. and Muller, J. P. (2018). Reservoir Monitoring Using Satellite SAR and GNSS: a Case Study in Southern Italy. HIC 2018, 13th International Conference on Hydroinformatics, Vol.3, pp.1682-1691.

https://easychair.org/publications/paper/C12g

[139] Bouziani, M. and Hassan, I. (2015). Example of Use of GNSS and Laser scanning for Dams monitoring. United Nations/Russian Federation Workshop on GNSS. 18-22 May.

https://www.unoosa.org/documents/pdf/psa/activities/2015/RussiaGNSS/Pres entations/39.pdf

[140] Scaioni, M. and Wang, J. (2016). Technologies for Dam Deformation Measurement: Recent Trends and Future Challenges. Proceedings of the 3rd Joint International Symposium on Deformation Monitoring (JISDM), 30 March - 1 April, Vienna, Austria. https://www.fig.net/resources/proceedings/2016/2016_03_jisdm_pdf/nonrevi ewed/JISDM_2016_submission_79.pdf

[141] Barzaghi, R., Cazzaniga, N. E., De Gaetani, C., Livio, P. and Tornatore, V. (2018). Using Classical and GNSS Techniques. MDPI Journal, Sensors, Vol.18, No.3. Received 22 January 2018;Revised: 20 February 2018;Accepted: 23 February 2018;Published: 2 March 2018. https://www.mdpi.com/1424-8220/18/3/756

[142] Acosta, L. E., M. de Lacy, C., Ramos, M. I., Cano, J. P., Herrera, A. M., Avilés, M. and Gil, A. J. (2018). Displacements Study of an Earth Fill Dam Based on High Precision Geodetic Monitoring and Numerical Modeling. MDPI Journal, Sensors. Received: 8 February 2018; Accepted: 19 April 2018; Published: 27 April 2018. https://pubmed.ncbi.nlm.nih.gov/29702627/ 
[143] Zhang, Y., Yang, S., Liu, J., Qiu, D., Luo, X. and Fang, J. (2018). Evaluation and Analysis of Dam Operating Status Using One ClockSynchronized Dual-Antenna Receiver. Special Issue, Hindawi Journal of Sensors Systems and Sensors in Geoscience Applications. Received 18 September 2017; Revised 26 January 2018; Accepted 04 March 2018; Published 22 Apr 2018.

https://www.hindawi.com/journals/js/2018/9135630/

[144] Pipitone, C., Cigna, F., Dardanelli, G., Loggia, G. L., Antonino, M. and Muller, J. P. (2018). Reservoir monitoring using satellite SAR and GNSS: a case study in southern Italy. HIC 2018, EPiC Series in Engineering, Vol. 3, pp.1682-1691. https://easychair.org/publications/paper/C12g

[145] Marcella, M. and Scaioni, M. (2018). Sensors for Deformation Monitoring of Large Civil Infrastructures. MDPI Journal, Sensors, Received: 5 November 2018, Accepted: 9 November 2018; Published: 14 November 2018.https://www.researchgate.net/publication/328944815_Sensors_for_Def ormation_Monitoring_of_Large_Civil_Infrastructures.

[146] Scaioni, M., Marsella, M., Crosetto, M., Tornatore, V. and Wang, J. (2018). Geodetic and Remote-Sensing Sensors for Dam Deformation Monitoring. MDPI Journal, Sensors, 2018, 18, 11. Received: 5 September 2018; Revised 22 October 2018; Accepted 25 October 2018; Published: 29 October. 2018 https://www.researchgate.net/publication/328636245_Geodetic_and_Remote -Sensing_Sensors_for_Dam_Deformation_Monitoring

[147] Xia, R., Shi, H., He, X., Li, Z., Jia, D. and Yang, Z. (2019). Deformation Monitoring of Reservoir Dams using GNSS: An Application to South-toNorth Water Diversion Project, China. IEEE Access, Vol.7, p.99. Date of Publication: 22 April.

https://www.researchgate.net/publication/332659747_Deformation_Monitori ng_of_Reservoir_Dams_using_GNSS_An_Application_to_South-toNorth_Water_Diversion_Project_China

[148] Konakoglu, B., Cakir, L. and Yilmaz, V. (2020). Monitoring the deformation of a concrete dam: a case study on the Deriner Dam, Artvin, Turkey. Journal of Geomatics, Natural Hazards and Risks, Vol.11, No. 1, pp.160-177, January 2020. https://www.tandfonline.com/doi/full/10.1080/19475705.2020.1714755

[149] Landsat Science. (2020). Landsat 8. Accessed on 22nd August. https://landsat.gsfc.nasa.gov/landsat-data-continuity-mission/ 